University of Louisville

ThinkIR: The University of Louisville's Institutional Repository

Electronic Theses and Dissertations

$12-2007$

\title{
Optimization modeling for the operation of closed-loop supply chains.
}

Aman Gupta 1978-

University of Louisville

Follow this and additional works at: https://ir.library.louisville.edu/etd

\section{Recommended Citation}

Gupta, Aman 1978-, "Optimization modeling for the operation of closed-loop supply chains." (2007). Electronic Theses and Dissertations. Paper 548.

https://doi.org/10.18297/etd/548

This Doctoral Dissertation is brought to you for free and open access by ThinkIR: The University of Louisville's Institutional Repository. It has been accepted for inclusion in Electronic Theses and Dissertations by an authorized administrator of ThinkIR: The University of Louisville's Institutional Repository. This title appears here courtesy of the author, who has retained all other copyrights. For more information, please contact thinkir@louisville.edu. 


\title{
OPTIMIZATION MODELING FOR THE OPERATION OF CLOSED-LOOP SUPPLY CHAINS
}

\author{
By \\ Aman Gupta \\ B.E., Thapar Institute of Engineering and Technology, 2000 \\ M.S., University at Buffalo, 2003
}

\begin{abstract}
A Dissertation
Submitted to the faculty of the

Graduate School of the University of Louisville

In partial fulfillment of the requirements

For the degree of
\end{abstract}

Doctor of Philosophy

Department of Industrial Engineering

University of Louisville

Louisville, KY

December, 2007 


\title{
OPTIMIZATION MODELING FOR THE OPERATION OF CLOSED-LOOP SUPPLY CHAINS
}

\author{
By \\ Aman Gupta \\ B.E., Thapar Institute of Engineering and Technology, 2000 \\ M.S., University at Buffalo, 2003
}

A Dissertation Approved on

September 19, 2007

by the following Reading Committee:

Gerald W. Evans, Ph.D., Director

John S. Usher, Ph.D., P.E.

Suraj M. Alexander, Ph.D., P.E.

William E. Biles, Ph.D., P.E.

Mahesh C. Gupta, Ph.D. 


\section{ACKNOWLEDGEMENTS}

I am deeply appreciative of the efforts of my Dissertation Committee members (Dr. Gerald W. Evans, Dr. Suraj M. Alexander, Dr. John S. Usher, Dr. William E. Biles, and Dr. Mahesh C. Gupta), each of whom provided invaluable guidance and support throughout my experience in the Ph. D. program. I am especially indebted to my advisor and committee chair Dr. Gerald W. Evans, for his tireless efforts to mentor me as I developed this work. Throughout this program he has been very inspirational to me and has been a great friend and equally great mentor. I will always remember the moments when Dr. Evans boosted my morale in times when my research used to drive me crazy and thought of running away from it. He always supported and encouraged me to present my work at various industrial engineering conferences. I would also like to thank the Department of Industrial Engineering and Logistics and Distribution Institute (LODI) at University of Louisville for providing me financial support during my $\mathrm{Ph}$. D. program.

A very special thanks to my wife, Meenakshi Bansal for her continuous support during different phases of the program. She is a backbone of my life and was always there when I needed her. I am greatly appreciative of my parents, Sham L. Gupta and Veena Gupta, and my brother Gagan Gupta for their infinite love and support. I am also thankful to rest of my family and to my wife's family. I am thankful to Mr. Doug Jones for giving me the opportunity to work for TMSi Logistics, a leading $3^{\text {rd }}$ party logistics

company. Lastly, I am thankful to Mr. Michael W. Golway for giving me the opportunity 
to work as an Industrial Engineering consultant for IDS Engineering where I am presently employed. 


\section{ABSTRACT \\ OPTIMIZATION MODELING FOR THE OPERATION OF CLOSED-LOOP SUPPLY CHAINS}

\section{Aman Gupta}

\section{September 19, 2007}

Environmentally conscious manufacturing and remanufacturing/recycling of endof-life products are steadily growing in importance. The problem of managing the waste generated due to the disposal of many types of products has many aspects. The main driving forces for solving this growing problem are the rapid diminishment of raw material resources, decreasing space in landfills and increasing levels of pollution. The drivers associated with these forces are governmental regulations which require that the manufacturers take back the end-of-life products and customer perspectives on environmental issues.

This research considers the problem of increasing levels of electronic and electrical equipments waste. The implementation of closed-loop supply chains can be beneficial both economically and ecologically for these problems. Relevant literature to understand various issues involved in the operation of reverse logistics systems and closed-loop supply chains is reviewed.

Upon reviewing the issues involved in closed-loop supply chains, the problem is considered as an ill-structured problem. A problem structuring technique called Why- 
What's Stopping Analysis is used to analyze the problem from various perspectives. Also, since a closed-loop supply chain involves multiple objectives, two techniques for categorizing the objectives into fundamental and means objectives are presented: Fundamental Objective Hierarchy and Means Objective Network techniques, respectively.

A Goal Program (GP) modeling approach is used to handle many of the objectives identified by the previously mentioned techniques. In this research a consolidated objective function is defined which includes all of the deviational variables considered in various goals defined in the model. The consolidated goal is to minimize the weighted sum of all deviational variables. A non preemptive goal programming approach has been used with goals being assigned different weights according to their priorities. The values of the deviational variables help the decision maker to see which of the different goals are satisfied with the existing values of parameters and which of the goals aren't.

The goal program has been run with both uniform and variable demand values in all the periods. In the absence of real data, all the parameter values considered for this research have been assumed. The major contributions of the research are as follows: each member of the supply chain has its own individual objective and the related constraints which is a more realistic approach, the model considers multiple products, and the model considers operations at the product, subassembly, part, and material levels. All the above contributions make this research as the first approach of its kind which has never been attempted (based on literature reviewed) and the goal programming methodology used is also a well accepted approach among all the multi-objective programming approaches. 
Results show the effect of varying the priority/weight associated with a goal. Results also show that values of the deviational variables (positive or negative) help a decision maker to analyze the model. The goal programming approach is considered to be the most effective approach in terms of defining the mathematical model, analyzing the output, and modifying the model (if needed). 


\section{TABLE OF CONTENTS}

PAGE

ACKNOWLEDGEMENTS....................................................... iii

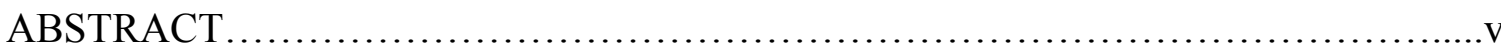

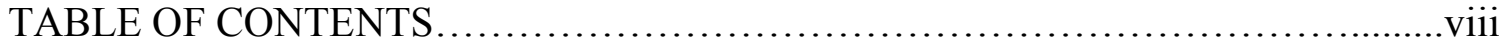

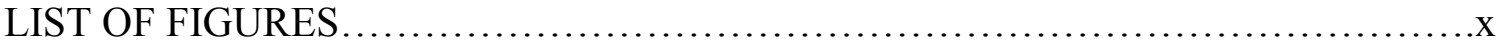

LIST OF TABLES ....................................................................

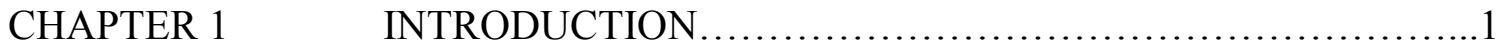

$1.1 \quad$ Reverse Logistics and Closed-Loop Supply Chains.................

1.2 Decision Making in the Integration of a Reverse Supply Chain and

a Forward Supply Chain............................................12

$1.3 \quad$ Problem Definition............................................14

$1.4 \quad$ Organization of the Dissertation................................. 15

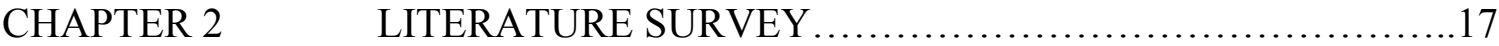

$2.1 \quad$ Literature on Reverse Supply Chains..........................17

$2.2 \quad$ Literature on Closed-Loop Supply Chains....................22

$2.3 \quad$ Literature on Disassembly .........................................

2.4 Literature on Environmental Legislation..........................30

CHAPTER 3 PROBLEM ANALYSIS AND METHODOLOGY ............... 33

$3.1 \quad$ Problem Analysis.............................................

$3.2 \quad$ Importance of the Research.....................................37

$3.3 \quad$ Overview of Goal Programming..................................39

3.4 Variations of Goal programming..............................42

CHAPTER 4 INITIAL MODEL AND FUTURE TASKS TO BE COMPLETED FOR DISSERTATION........................44

$4.1 \quad$ Model Description............................................ 44

4.2 Mathematical Model.........................................46

CHAPTER 5 MODEL RESULTS......................................65

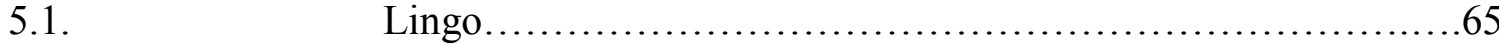

5.2. Applications of the GP Model............................... 71

CHAPTER 6 CONCLUSIONS AND FUTURE RESEARCH..................73

A. Conclusions..................................................73

B. Future Research......................................... 75 
REFERENCES.

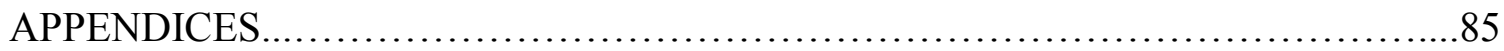

CURRICULUM VITAE .................................................... 157 


\section{LIST OF FIGURES}

FIGURE

PAGE

Figure 1. A Typical Closed-Loop Supply Chain...............................

Figure 2. Why-What's Stopping Analysis for the Integration of Forward and Reverse Supply Chains...............................35

Figure 3. Means-Objectives Network ..................................... 36

Figure 4. Fundamental-Objectives Hierarchy................................. 37

Figure 5. Assembly Structures of Products A, B and C........................60

Figure $6 \&$ 7. Comparison of profits for constant demand with different weight Sets..........................................................68

Figure $8 \&$ 9. Comparison of profits for constant demand with different weight Sets.............................................................. 70 


\section{LIST OF TABLES}

TABLE

Table 1.

Table 2.

Table 3

Table 4.

Table 5.

Table 6.

Table 7.

Table 8.

Table 9.

Table 10.

Table 11.

Table 12.

Table 13.

Table 14.

Table 15.

Table 16.

Table 17.

Table 18.

Table 19.

Table 20.

Table 21.

Table 22.

Table 23.

Table 24.

Table 25.

Table 26.

Table 27.

Table 28.

Table 29.

Table 30.

Table 31.

Table 32.
E-waste Generated per Year in Different Countries of the World...........3

Profit Values by Period for all Members of Supply Chain....................66 Comparison of results with the change in weights of different goals in the model for Constant Demand........................................66

Comparison of results with the change in weights of different goals in the model for Variable Demand......................................6 69

Material Transported and Inventory for Raw Materials Supplier............116

Profit Values by Period for Raw Materials Supplier....................117

Parts Transported and Inventory for Parts Supplier.....................118

Material Inventory for Parts Supplier...............................121

Profit Values by Period for Parts Supplier.............................. 122

Products Transported and Inventory for Manufacturer...................123

Subassembly Inventory for Manufacturer.............................124

Parts Inventory for Manufacturer................................... 125

Profit Values by Period for Manufacturer............................129

Product Transported and Inventory for Distributor...................130

Profit Values by Period for Distributor................................131

Product Transported and Inventory for Retailer.........................132

Profit Values by Period for Retailer.........................................133

Product Transported and Inventory for Collection Facility................134

Profit Values for Collection Facility..................................135

Product Transported and Inventory for Refurbishing Facility...........136

Profit Values for Refurbishing Facility............................... 137

Product Inventory for Disassembly Facility...........................138

Subassembly Transported and Inventory for Disassembly Facility.......139

Product Transported and Inventory for Disassembly Facility........... 140

Profit Values by Period for Disassembly facility....................... 144

Subassembly Transported and Inventory for Testing Facility...............145

Part Transported and Inventory for Testing Facility................... 146

Profit values by period for Testing Facility...........................150

Material inventory for Remanufacturing Facility.....................151

Subassembly inventory for Remanufacturing Facility............... 151

Part inventory for Remanufacturing Facility........................153

Profit Values by Period for Remanufacturing Facility..................156 


\section{CHAPTER 1 - INTRODUCTION}

Traditionally Supply Chain Management (SCM) has dealt mainly with product manufacturing and its movement through the supply chain. This movement normally starts at the suppliers and ends at the customers. According to the Council of Supply Chain Management Professionals (CSCMP), Supply Chain Management is defined as "The process of planning, implementing and controlling the efficient, cost-effective flow of raw materials, in-process inventory, finished goods and related information from the point of origin to the point of consumption for the purpose of conforming to customer requirements." However, the operation of a company's supply chain does not end with a consumer's initial purchase of an item. A company needs to consider the products returned or disposed by customers (both business and domestic). The reverse flow of products may be due to a variety of reasons (Brito, Flapper and Dekker 2002, Dekker and van der Laan 2002):

- Manufacturing returns

- Commercial returns

- Product recalls

- Warranty returns

This research is mainly concerned with the returns and disposal of electronics and electrical equipment.
- Service returns

- End-of-use returns

- End-of-life returns 
With the rapid diminishment of raw material resources, decreasing space in landfills and increasing levels of pollution, efforts are now being put towards the development of closed-loop supply chains. According to an estimate by the U.S. Environment Protection agency (EPA), 29 states in the United States have 10 years or more of landfill capacities remaining, 15 states have between 5 and 10 years of landfill capacity remaining, and 6 states have less than 5 years of landfill capacity remaining (Rogers and Tibben, 1999).

Electronic and electrical devices which include computers, computer accessories, digital cameras, cell phones, televisions, refrigerators, air conditioners and washing machines, have one of the largest rates of disposal in most industrialized nations. One of the biggest reasons for this is rapidly changing technologies, resulting in decreasing life cycles for these products. Considering computers for example, it has been estimated that about 60 million computers enter the market every year in the United States and over 12 million computers are disposed of every year. Only about $10 \%$ of these 12 million computers are remanufactured or recycled (Ravi et al., 2005). It has been estimated that in the United States alone, about 500 million computers will be rendered obsolete by 2007 (Hamilton, 2001). The numbers become even more alarming if we examine the amounts of materials which may be sent to landfills and thereby create enormous amounts of electronics waste: 4 billion pounds of plastic, 1 billion pounds of lead, 1.9 million pounds of cadmium, 1.2 million pounds of chromium, 400,000 lbs of mercury, etc (E-waste guide, website). Table 1 gives the numbers in tons of electronics waste (Ewaste) generated per year in different countries across the world (E-waste guide, website). Table 1 only gives an overview of the quantities of e-waste generated in different countries of the world. 
Table 1: E-waste generated per year in different countries of the world (E-waste guide).

\begin{tabular}{|c|c|c|c|}
\hline Country & $\begin{array}{l}\text { Total E-waste } \\
\text { generated } \\
\text { tons/year }\end{array}$ & Categories of Appliances & Year \\
\hline Switzerland & 66,042 & $\begin{array}{l}\text { Office \& Telecommunications Equipment, Consumer } \\
\text { Entertainment Electronics, Large and Small Domestic } \\
\text { Appliances, Refrigerators, Fractions }\end{array}$ & 2003 \\
\hline Germany & $1,100,000$ & $\begin{array}{l}\text { Office \& Telecommunications Equipment, Consumer } \\
\text { Entertainment Electronics, Large and Small Domestic } \\
\text { Appliances, Refrigerators, Fractions }\end{array}$ & 2005 \\
\hline $\begin{array}{l}\text { United } \\
\text { Kingdom }\end{array}$ & 915,000 & $\begin{array}{l}\text { Office \& Telecommunications Equipment, Consumer } \\
\text { Entertainment Electronics, Large and Small Domestic } \\
\text { Appliances, Refrigerators, Fractions }\end{array}$ & 1998 \\
\hline USA & $2,124,400$ & $\begin{array}{l}\text { Video Products, Audio Products, Computers and } \\
\text { Telecommunications Equipment }\end{array}$ & 2000 \\
\hline Taiwan & 14,036 & $\begin{array}{l}\text { Computers, Home electrical appliances (TVs, Washing } \\
\text { Machines, Air conditioners, Refrigerators) }\end{array}$ & 2003 \\
\hline Thailand & 60,000 & $\begin{array}{l}\text { Refrigerator, Air Conditioners, Televisions, Washing } \\
\text { Machines, Computers }\end{array}$ & 2003 \\
\hline Denmark & 118,000 & Electronic and Electrical Appliances including Refrigerators & 1997 \\
\hline Canada & 67,000 & $\begin{array}{l}\text { Computer Equipment (computers, printers etc) \& Consumer } \\
\text { Electronics (TVs) }\end{array}$ & 2005 \\
\hline
\end{tabular}

It is difficult to make direct country-to-country comparisons regarding E-waste quantities, because each country has different categories of appliances counted in E-waste and different methods of estimation.

E-waste can be defined according to the following quote: 
"It is a term used to describe old, end-of-life electronic appliances. E-waste includes computers, entertainment electronics, mobile phones etc, which have been disposed of by their original users. E-waste generally comprises of relatively expensive and essentially durable products used for data processing, telecommunications or entertainment in private households and businesses" (E-waste guide).

\subsection{Reverse Logistics and Closed-Loop Supply Chains}

Most of the literature in Supply Chain Management (SCM) deals with forward supply chains in which goods are conveyed from suppliers to manufacturers, from manufacturers to distributors, from distributors to retailers and finally to customers. In the early 1990's researchers around the world recognized reverse logistics as a potential field of research. According to the most recent definition by (Rogers and Tibben, 1999) Reverse Logistics can be defined as:

"The process of planning, implementing, and controlling the efficient, cost-effective flow of raw materials, in-process inventory, finished goods, and related information from the point of consumption to the point of origin for the purpose of recapturing value or proper disposal."

Recently there has been a growing interest among manufacturers in managing the flow of returns from consumers as an additional and more economical source of spare parts and complete products. The other two main driving forces are governmental regulations and customer perspectives on environmental issues. These government regulations include take-back legislation imposed on the companies in most industrialized 
nations. According to this type of legislation, companies need to take their products back and treat them accordingly. Companies need to remove the hazardous elements like lead, mercury, cadmium etc. out of the electronics before disposing them.

In many Western European countries like Germany and The Netherlands, legislation will soon be implemented to ban landfills, and incineration will be permitted only under special conditions; this implies the need for recovering end of life products (Lambert, 2003). In Europe, the Waste Electrical and Electronics Equipment regulation (WEEE) and the Restriction of Hazardous Substances (RoHS) directive took effect on July 1, 2006 (Waste Electrical and electronic equipment, European Union, Feb 2003). Japan has already passed take-back legislation for the recycling of household electronic appliances and for the mandated reclamation of lead used by 2001 (Japan File, By Richard Donovan, Dec 2003). In the United States, some states are putting efforts towards the recycling of electronics, but there has not been any federal regulation passed. Due to these reasons and other, reverse logistics has received recognition both as an important area of research as well as an important area of practice.

Development of a closed-loop supply chain can be beneficial both economically and ecologically. One of the biggest challenges in this development is the integration of the forward supply chain with the reverse supply chain. Products are returned to the manufacturers. There are delays in processing of these returns due to the lack of a defined system for putting the returns back into the forward chain. Manufacturers often struggle to integrate the return goods flow into the supply chain. Shortening of the life cycles of products is another motivation for the development of closed-loop supply chains so that maximum value can be recovered out of the returns. In conclusion, manufacturers can 
generate a more economical source of the inbound supply of parts, subassemblies and products in addition to protecting the environment from many hazardous elements, with an efficient closed-loop supply chain.

Figure 1 represents a typical Closed-Loop supply chain. The blocks enclosed in the dotted lines represent a typical organization. As seen in Figure 1, there are number of points in the closed-loop supply chain where there is a need to integrate various issues associated with reverse and forward loop supply chains.

Following are some of the functions associated with a typical reverse supply chain:

- Collection

- Refurbishing/Reuse

- Disassembly

- Testing

- Remanufacturing

- Recycling

- Disposal/Incineration 


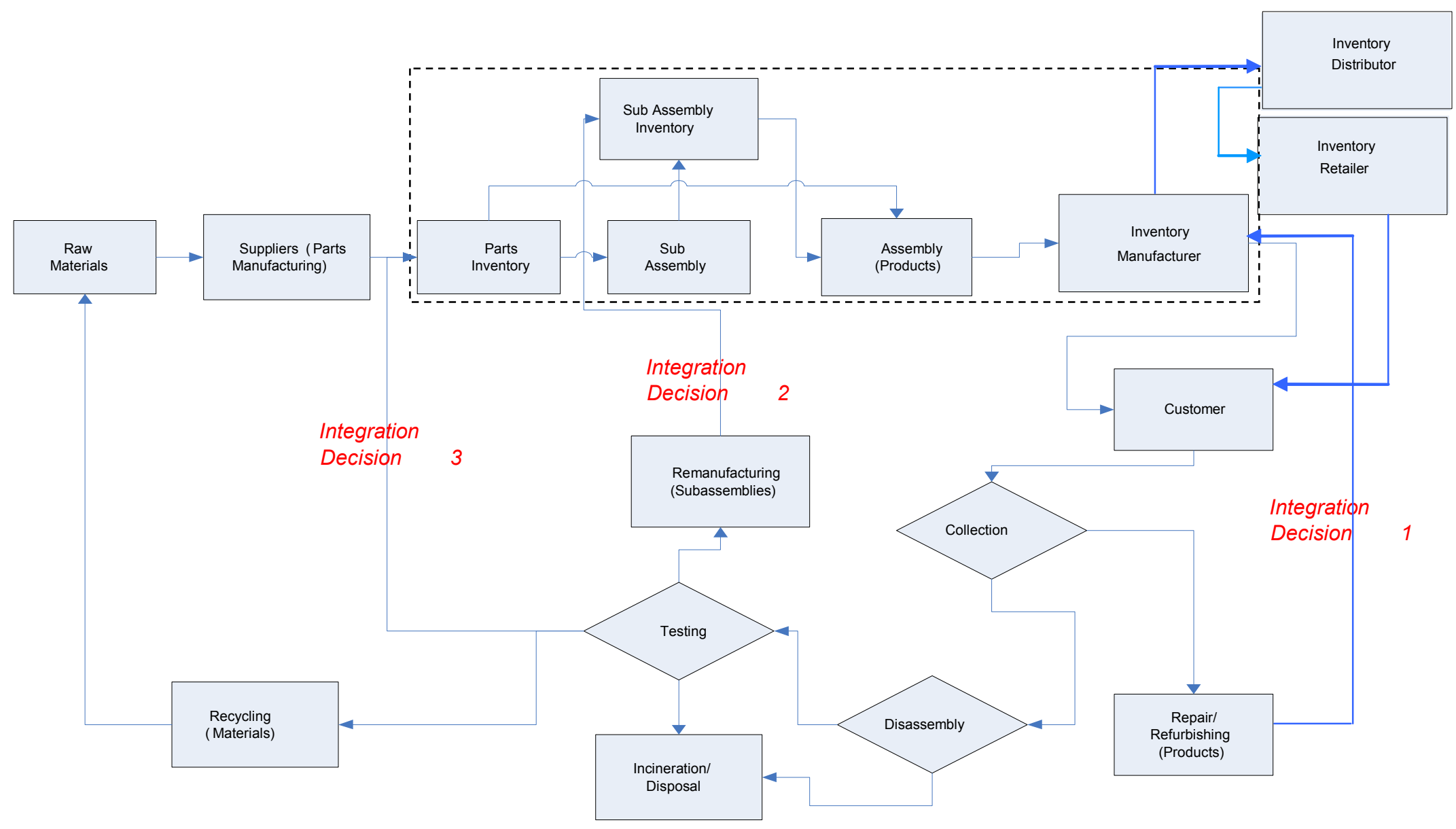

Figure 1: Typical closed-loop supply chain 
The general processes associated with reverse logistics are described as follows (Fleischmann et al., 1997):

- Collection: Collection refers to all activities rendering used products available and physically moving them to some point for further treatment. Collection may include purchasing, transportation, and storage activities.

- Inspection/separation: Inspection/separation denotes all operations which determine whether a given product is in fact reusable and in which way. Thus, inspection and separation result in splitting the flow of used products according to distinct re-use (and disposal) options. Inspection and separation may encompass disassembly, shredding, testing, sorting, and storage steps.

- Re-processing: Re-processing means the actual transformation of a used product into a usable product/component/material again. This transformation may take different forms including recycling, repair, and remanufacturing. In addition, activities such as cleaning, replacement, and reassembly may be involved.

- Disposal: Disposal is required for products that cannot be re-used for technical or cost reasons. This applies, e.g., to products rejected at the separation level due to excessive repair requirements but also to products without satisfactory market potential, e.g., due to obsolescence. Disposal may include transportation, landfilling, and incineration steps.

- Re-distribution: Re-distribution refers to directing re-usable products to a potential market and to physically moving them to future users. This may include sales, transportation, and storage activities. 
Another important issue in the design of a closed-loop supply chain involves the resources required for the integrated supply chain. These resources may be machines, manpower, storage space, trucks etc. If a company is involved only into a forward supply chain and would put efforts towards getting involved into the area of reprocessing, the company has to reexamine the decisions on the allocation of resources. The resources used can be the available resources in-house, outside resources, or a combination of both.

Categorization of alternatives for reverse logistics can be done as follows (Ravi et al., 2005):

- Third party demanufacturing: Some private company(s) takes up end-of-life responsibility for products on behalf of the OEM. In this arrangement, an OEM would pay a fee to that company that would ensure that the manufacturer's product is disposed in a way that is environmentally responsible.

- Symbiotic logistics concept: In the effective implementation of reverse logistics, companies have realized that individual attempts at product reclamation make little sense, both economically as well as environmentally. A logical solution would be to pool resources with other firms in similar situations in order to gain economies.

- Virtual reverse logistics network: This network relies on e-commerce and internet technologies instead of physical transportation and distribution, for remote monitoring and benchmarking. In this configuration a monitoring and benchmarking agent screens the computer that is about to enter the end-of-use stream and registers the data in the system databases. Buyers and sellers come together at one virtual marketplace. 
Based on their situation, a company can make decisions depending upon the resources available and economies. According to (Krikke et al., 2001), it is advisable to assign the repairs and remanufacturing to the original supplier since it will have the most knowledge and dedicated equipment.

Some of the design principles proposed for closed-loop supply chains are given as follows (Krikke et al., 2001):

- Impose sustainability standards on suppliers: Suppliers may co-design the product to enable modularization and design for recycling.

- Accounting systems that account for the full life cycle costing of a product or service, and the environmental impacts it creates: Develop and design recoverable products, which should be technically durable, repeatedly usable, harmlessly recoverable after use and environmentally compatible in disposal. Modularity and standardization also improve opportunities for repair and reuse of components and materials.

- Use of management tools, such as ISO 9000-14000, life cycle analysis, and environmental accounting methods: These tools help businesses to identify and select opportunities for improvement. For example, using less energy is obviously good for the environment. It is also self-evidently good for business because it cuts companies' costs, and eventually avoids potential environmental liabilities.

- Create new markets: The environment can be at the basis of the creation of new markets for remanufactured products. The processing facilities should be located close to possible end-users. Such a policy would ease the direct delivery of used products from end-users. 
- Manage additional uncertainty: In recovery situations only a part of the flow is valuable, but it is difficult to say beforehand which part. This means that sorting and initial testing should be decentralized to separate junk from valuable returns. Companies that manipulate materials and energy should be organized in such a way that they can respond rapidly to changes in management and processes.

- Match the network design with the recovery option: Typical characteristics of reverse logistics networks associated with end-of-life products include 3 parts. The convergent part is associated with collection and transportation from a disposer market to recovery facilities, the divergent part is associated with distribution to a reuse market, and the intermediate part is associated with the recovery processing steps required. Moreover, reverse supply chains derive typical types of networks per recovery option, where they distinguish networks for material recycling, remanufacturing, reusable components, reusable packaging, warranty and commercial returns.

- Enhance design for recycling: Environmental concerns also raise the issue of product design as a critical element. Decisions to be made concern modularity, type of materials used, involvement of suppliers, disassemblability, life cycle considerations (long or short life cycle), type of equipment used and standardization of modules/components in the product. Parameters affecting these decisions include pollution generated, energy use, residual waste, life cycle cost, production technology, secondary materials, by-products, recyclability, product complexity, product function, and so on. 
- Enhance quality and rate of return: In some of models, quality and rate of return are more important that the impact of product design and logistics network structure.

\subsection{Decision Making in the Integration of a Reverse Supply Chain and a Forward Supply Chain}

A wide variety of decisions need to be made in the integration of a reverse logistics system an existing forward supply chain. The nature of the decisions associated with the reverse logistics system is much different than those of the forward supply chains.

A general classification of logistical system decisions according to time frame is given by the following (Hax and Candea, 1984):

Strategic decisions: The strategic level deals with decisions that have a long-lasting effect on the firm. The time length for strategies is arbitrary, but is probably two, three, or perhaps as many as five years in duration. This time length is generally determined by how far in the future the organization is committing its resources. This includes decisions related to the number, location, and capacities of warehouses and manufacturing/remanufacturing facilities, or the flow of material through the logistics network.

Tactical decisions: The tactical level typically involves decisions that are updated anywhere between once every quarter and once every year. This includes decisions 
regarding purchasing and production, inventory policies, and transportation strategies including the frequency with which customers are visited.

Operational decisions: The operational level refers to day-to-day decisions, regarding for example, scheduling, routing, and loading of trucks.

Some of the features of a reverse supply chain system that differentiates it from the forward supply chain and makes the process of decision making more complex are as follows (Lambert, 2003):

- Uncertainty exists with regard to the quality and quantity of returns.

- Disassembly is usually not performed to its full extent, as most of the time incomplete disassembly is often preferred.

- The assembly process is often not completely reversible (decisions need to be made between destructive and non-destructive disassembly).

- A supply of a variety of products might be present.

- There may be high demand for certain parts and materials as a result of disassembly as compared to other low demand parts.

- Humans as opposed to automated lines and robots, carry out most operations associated with reverse logistics.

- Environmental constraints due to legislation require the removal of hazardous parts and materials, such as batteries, elements like mercury and lead. 


\subsection{Problem Definition}

As mentioned earlier, this research considers the perspective of a company that is involved in both forward and reverse supply chains. The research will concentrate on the integration decisions of forward and reverse supply chains for the following flow types:

- Products

- Subassemblies

- Parts

- Raw materials

The main motivation is the use of more economical sources of supply. If companies do the planning for the recovery of returns in a more efficient manner and more research is carried out on the automation of the recovery processes, companies involved in both forward and reverse supply chains can have an advantage over other companies that deal only in a forward supply chain. The advantage is two fold; the first is cheaper source of spares and the second the development of a better company image among the customers.

In addition, the effect of environmental legislation on the processing of electronic waste must be considered. The legislation varies from state to state within the United States and also varies from country to country. Abiding by the legislation and reducing the disposal costs is another important decision companies need to consider. Therefore, in order to improve profitability, it is essential that these decisions (economical and environmental) be made simultaneously (Sharma, 2004).

This research uses Goal Programming (GP) and its variations as a Multi Criteria Decision Making (MCDM) tool to solve a problem with multiple objectives. All the 
members considered in the supply chain have their individual goals and respective constraints in the mathematical model. The output of the goal program gives the values of deviational variables defined in different goals and helps the decision maker to analyze the output. The mathematical model considers the decision-making at operational level and can be extended to the tactical and strategic levels.

\subsection{Organization of the Dissertation}

To explicitly define the problem considered for this research, it is important to review the relevant literature published so far. Hence, in Chapter 2 four areas of research are reviewed: reverse supply chains, closed-loop supply chains, disassembly, and environmental legislation. The literature includes mathematical models and innovative processes defined in these areas. The literature review helps to defend the fact that the problem considered in this proposal has not been addressed so far in published literature.

Chapter 3 illustrates the use of two techniques for analyzing the problem. The first technique is the Why What's Stopping (WWS) heuristic, which is used to generate a network of related problems. It can allow one to see an ill-structured problem from many different perspectives. In this way, the WWS heuristic can aid in identifying alternative solutions, objectives, attributes, and decision makers. The second set of techniques is the Fundamental-Objectives Hierarchy and Means-Objectives Network. Both of these help to analyze a big problem by dividing it into smaller problems.

As mentioned in Section 1.3 an overview of Goal Programming is presented as the methodology to solve the problem considered for research. Goal programming (GP) is 
one of the oldest methodologies within the field of Multi Criteria Decision Making. GP and its variations are used to solve a problem with multiple objectives.

Chapter 4 includes a description of Goal Programming method and its variants. The goal program defined for this research includes a consolidated objective function to minimize a weighted sum of the deviational variables related to the goals considered in the model. The constraints defined in the model include objective constraints, inventory constraints, demand constraints, and non-negativity constraints.

Chapter 5 includes the solution methodology. The mathematical model has been solved using a commercially available optimization software LINGO. LINGO uses a dual simplex method approach to solve a Linear Programming (LP) problem.

Chapter 6 includes conclusions of the goal programming model and also potential opportunities for future research. 


\section{CHAPTER II - LITERATURE SURVEY}

The literature surveyed has been divided into four main categories as, literature on reverse supply chains, closed-loop supply chains, disassembly, and environmental legislation.

\subsection{Literature on Reverse Supply Chains}

Fleischmann et al., (1997), presented an overview of various issues that arise in dealing with reverse logistics. The paper classified three main areas: reverse distribution planning (modeling reverse flow separately and combined reverse and forward flow), inventory control (deterministic and stochastic models), and production planning (selection of recovery options and scheduling) and for each of these areas presented the mathematical models proposed in the literature.

Ravi, Shankar, and Tiwari, (2005), presented a decision model based on the Analytic Network Process (ANP) for structuring the problem related to options in reverse logistics

for End-Of-Life (EOL) computers. ANP structures the problem in a hierarchical form and links the determinants (economic factors, legislation, corporate citizenship, environment and green issues), dimensions (customer, internal business, innovation and learning, and finance), and enablers of reverse logistics with alternatives (third party demanufacturing, 
symbiotic logistics concept, virtual reverse logistics network for PCs) available to the decision maker. The dimensions for the model were taken from the four perspectives derived from the balanced scorecard approach (Ravi, Shankar, and Tiwari, 2005). This ANP model was developed and evaluated for an actual computer manufacturing company. The company has implemented the virtual reverse logistics approach in their organization. Virtual reverse logistics turned out to be the best choice in terms of information flow coordination and better visibility in the system.

Fleischmann et al., (2000), addressed the physical design of logistics networks for product recovery activities. A range of general characteristics of product recovery networks including commonalities among networks, comparison with other logistics networks, and modeling aspects have been shown. They also presented a classification scheme for different types of recovery networks based on different network structures and types.

Kroon and Vrijens (1995), presented a quantitative model used in the planning of a return logistics system for reusable containers. They developed a Mixed Integer Linear Program (MILP) with the objective of minimizing the total logistics costs. The actors of the system considered are: a central agency owning the containers; senders; recipients; a logistics service provider responsible for storing, delivering and collecting empty containers; and transportation carriers. The objective is to minimize total logistics costs, which includes distribution costs, collection costs, relocation costs, and fixed costs of the container depots. Continuous decision variables are used to represent the number of 
containers sent from a distribution center to a sender, from a receiver to a distribution center, and from a distribution center to another distribution center. Binary decision variables are used to represent the locations of distribution centers. The constraints of the model are derived from the following restrictions: the number of containers distributed to a sender must equal the number of containers used by the sender, the number of containers collected from a recipient must equal the number of containers sent to a recipient, the number of containers relocated to a container depot must equal the number of containers distributed from the container depot, the number of containers recovered by the container depot must equal the number of containers relocated from the container depot, and containers are distributed to and collected from a distribution center only if it acts as a container depot. A similar system as described in the case study has been operating in Germany successfully for a number of years.

Rogers and Tibben-Lembke, (1998), presented an overview of reverse logistics practices. They covered topics including the importance of reverse logistics both economically and ecologically, reverse logistics markets, industry trends in Europe and future trends in reverse logistics.

Brito et al., (2002), presented a literature review of the studies related to reverse logistics and also identified the critical factors for the practice of reverse logistics. They discussed case studies based on the following: network structures, relationships, inventory management and planning and control of recovery activities along with the quantitative models presented in these areas. 
Schultmann, Zumkeller, and Rentz, (2005), formulated a model for the planning of vehicle routing within product recovery networks. The model is formulated according to the established system for end-of-life vehicle recovery in Germany. A total of about 1200 known dismantlers were considered. The objective of the model was to minimize the total lengths of all tours necessary with the available information on the locations of reprocessing facilities and the number of dismantlers to be served per collection period. A Mixed Integer Linear Program (MILP) was presented. Binary decision variables were used to represent the following: if a dismantler was served in a tour and if a node was a successor of another node. Continuous decision variables were used to represent distance between a pair of nodes, and load collectible at a dismantler. Following were the constraints: tour distance is not exceeded from maximum distance per tour, trucks capacity is not exceeded from maximum capacity per tour, each dismantler is served and belong to one tour and every tour starts and ends at the depot.

Jayaraman, Guide Jr., and Srivastava, (1999), formulated a Mixed Integer Linear Programming (MILP) model for finding the optimal locations of remanufacturing/distribution facilities, and also the transshipment, production, and stocking of the optimal quantities of remanufactured products and cores. The objective function minimizes the sum of the costs to acquire the core, transport it to the remanufacturing facility, remanufacture the core into the product, and transport the remanufactured product back to the customer, the costs of carrying the cores and remanufactured products in the facilities, and the fixed cost of opening and operating the facilities. Continuous decision variables are used to represent quantity of core type 
shipped from collection zone to the facility location, quantity of remanufactured product type distributed from a facility location to a customer zone, and the maximum number of facilities that can be opened. Binary decision variable is used to represent decision on opening a facility at a location. Following are the constraints: total number of products remanufactured does not exceed the demand for the products for all customer zones, total quantity of a remanufactured product produced at any facility cannot exceed the quantity of cores that are supplied by the collection zone, amount of remanufactured products that can be stored cannot exceed the capacity to store them, amount of cores that can be stored cannot exceed the capacity to store them, the maximum number of facilities that can be opened, limits the amount of cores that can be supplied from a collection zone, non negativity and binary nature of the decision variables. They analyzed the logistics network of an electronics remanufacturing company in the United States. The paper also presented managerial uses of the model for logistics decision-making.

Barros, Dekker, and Scholten, (1998), presented a case study on the design of a logistics network for recycling sand coming free from processing construction waste in The Netherlands. The free incoming sand is analyzed and categorized as clean, half clean, and polluted sand. Clean sand can be used as is, half-clean sand can be used for special applications, and polluted sand needs to be treated before being reused. The recycling network included four levels namely crushing companies yielding sieved sand from construction waste, regional depots specifying the pollution level and storing clean and half-clean sand, treatment facilities cleaning and storing polluted sand, and infrastructure projects where sand can be reused. A multi-level capacitated facility location model for 
this problem formulated as a Mixed Integer Linear Program (MILP) is proposed. The objective function include sum of fixed costs of facilities (regional depot and treatment facility) and transportation costs to the regional depots and treatment facilities. Continuous decision variables are used to represent amount of sieved sand shipped from sorting facility to regional depot, amount of polluted sand shipped from regional depot to treatment facility, amount of clean sand shipped from treatment facility to a project, and amount of a sand type shipped from regional depot to a project. Binary decision variables are used to represent the locations of regional depots and treatment facilities. Following are the constraints: inflow is equal to outflow at the sorting facilities and regional depots, demand is satisfied at all the projects, storage and processing capacities at regional depots are not exceeded and non negativity and binary constraints.

\subsection{Literature on Closed-Loop Supply Chains}

Thierry et al., (1995), presented different strategic issues in product recovery management along with a categorization of product recovery options. They also presented an explicit description of reprocessing activities. Some of the traits of proactive manufacturers that already have established product recovery management includes, accurate information gathering, adequate selection from the available product recovery options, set recycling targets, product redesign, cooperation within supply chain, and cooperation between companies. They assumed that the recovered products would be sold under same conditions as the new ones. 
Thierry, (1997), for the model formulation assumed all facility locations fixed. The objective was to reduce the variable costs related to production, handling, inspection, repair, disposal and transportation costs. An LP was formulated to solve the problem optimally.

Fleischmann, Nunen, and Grave, (2003), developed an inventory control model and a simulation model for analyzing the throughput from various recovery options as a source of spare parts which can be sent to the service network. The study was a part of five-year research collaboration (REVLOG 2002) and was conducted for IBM at The Netherlands. The products can be PCs, larger computers, network servers, and printers as a source of spare parts. In the simulation model they compared six alternative policies, based on two alternative channel designs (push and pull) and three alternative coordination mechanisms (reactive, proactive, and theoretically derived optimal policy). The decisions need to be made include, recovery opportunities to use, the channel design, and the coordinating alternative supply sources. In all cases, procurement costs outweighed inventory related costs. Some of the findings include, advance information on returns may allow IBM to reduce its inventory of parts significantly, from cost perspective netting policy turned out to be very close to optimal policy in many cases.

Beamon and Fernandes, (2004), considered a closed-loop supply chain in which the original equipment manufacturer produced new products and remanufactured products. The network considered in the study comprised of four echelons: manufacturers, warehouses, customer zones, and collection centers. They presented a multi-period 
mixed-integer-programming model using the present worth (PW) method to jointly analyze investment and operational costs. The objective is to minimize the present loss that is defined as "The investment costs plus the present equivalent of the future operational costs over a horizon length affected by an interest rate". Binary decision variables are used to represent the decision on which warehouses and collection centers should be open, and which warehouses should have sorting capabilities. Continuous decision variables are used to represent the quantity needs to be transported between each pair of sites. Constraints are imposed on both the forward and the reverse flow of products. Following are the constraints: Flow constraints are imposed on quantity transported from manufacturer to warehouse, warehouse to customer zone, customer to warehouse and collection center, and collection center to warehouse. Opening constraints are if-then constraints imposed on warehouses and collection centers. If there are products leaving or arriving at a facility, then that facility must be open. The Installation constraints imply that if there is a warehouse, it may or may not have a sorting capability. Inspection constraints imply that customers send returns to the warehouse only if it has sorting capability. Capacity constraints imply quantity transported from all the customer zones to a warehouse or a collection center cannot exceed their respective sorting capacities. A sensitivity analysis of the model is also performed.

Krikke, Bloemhof-Ruwaard, and Wassenhove, (2001), presented an integrated approach of considering various product designs and related logistics using Mixed Integer Linear programming (MILP). The model considered both the economic costs and environmental impacts and was run on different scenarios using different parameter 
settings such as centralized versus decentralized logistics, alternative product designs, varying return quality and quantity, and potential environmental legislation based on producer responsibility. The objective function minimizes the sum of supply chain costs, energy use, and residual waste with different weights allotted to them. There are 11 continuous and 1 binary variable defined in the model. Following are the constraints: Logical constraints on transportation costs, energy use for transportation, and residual waste so that they do not exceed the target value. Flow balance constraints on both forward and reverse supply chain. Some of the weaknesses of the study did not include the facts that the model did not consider interests of various actors of supply chain (which are conflicting many times) nor did it consider multiple periods.

Krikke, et al., (2001), presented a survey of both old and new design principles for Closed-Loop supply chains found in the literature. They looked at the case of Honeywell Closed-Loop supply chain. Some of the new design principles are to impose sustainability standards on suppliers, create new markets, match network design with recovery options, manage uncertainties, and enhance the quality and rate of returns (quality and rate of returns can be enhanced with some sort of tracking sub system included in the network to track the quality and rate of returns).

Sheu, Chou, and $\mathrm{Hu}$, (2005), presented a composite multi-objective optimization model with the objectives of maximizing manufacturing chain-based net profit and reverse chain-based net profit. The continuous decision variables are used to represent time-varying inventory amounts (at raw material supplier, product manufacturer, 
wholesalers, retailers, collection points, recycle plants, disassembly plants, secondary material markets) demand of end-customer and used-product return flow. The description of the decision variables has been provided in the Appendix of the article. Factors such as the used-product return ratio and corresponding subsidies from governmental organizations for reverse logistics are considered as parameters in the model formulation. Following are the constraints: Inventory constraints for raw material suppliers, product manufacturers, wholesalers, retailers, collection points, recycle plants, disassembly plants, secondary material markets, and final disposal locations. Demand constraints imply that the demand of customer needs to be satisfied. Return resource constraints present a relationship between used-product return flow and product demand. The model claimed an increase of $21.1 \%$ in net profits of the entire chain as compared to the existing system in the case.

Vlachos, Georgiadis, and Iakovou, (2005), evaluated alternative long-term capacity planning policies for remanufacturing facilities using System Dynamics (SD). The model considered the profit of the total supply chain as a measure of alternative effectiveness instead of considering the interests of individual actors.

\subsection{Literature on Disassembly}

The literature on disassembly is reviewed to get a better understanding of the models available to handle the problem of disassembly, though the aspect of disassembly have 
not been considered in this research. Several studies have been done and are being identified on various aspects of disassembly.

They can be broadly classified into three categories (Gugnor and Gupta, 1999):

- Disassembly scheduling.

- Disassembly process planning.

- Mathematical modeling techniques to optimize the financial and environmental characteristics of disassembly.

\section{Literature on Disassembly Scheduling}

Gupta and Taleb, (1994), presented a reverse Material Requirements Planning (MRP) algorithm for disassembly scheduling. The objective of the algorithm is to determine the ordering schedule of the root item (product return) and generate a disassembly schedule for all parent items over the planning horizon. In contrast to the conventional MRP algorithm aimed at assembly, the main difference in the reverse MRP is the presence of demand for multiple products. Taleb and Gupta, (1997), included component and materials commonality in the algorithms presented in this article for disassembly scheduling. They presented two companion algorithms namely core algorithm and allocation algorithm. The objective of the core algorithm is to determine the number of units of each root item to disassemble such that the requirements of the leaf items are fulfilled while aiming to minimize the total disassembly cost. The allocation algorithm provides a disassembly schedule while inherently reducing the holding cost by delaying disassembly as much as possible. 
Guide Jr., Kraus, and Srivastava, (1997), presented a simulation model to examine two activities in remanufacturing facility namely Disassembly Release Mechanisms (DRM) and Priority Dispatching Rules (PDR). The purpose of DRM is to coordinate the release of material with the reassembly of material. 16 different priority rules are examined. The results indicated that due date PDR performed the best and DRM has very little impact on the scheduling.

\section{Literature on Disassembly Process Planning}

Gungor and Gupta, (1997), presented a heuristic algorithm to select near-optimum disassembly sequences for the disassembly of computers. This heuristic requires the following information: precedence relationships of components of the product under consideration and the average difficulty ratings for each component of the product that defines the difficulty level of removal of the components. The total time to disassemble is calculated with this information. Lambert, (1997), presented a method for determining the optimum disassembly sequence for selective disassembly of discarded complex products. The method considered the prices and masses of parts and subassemblies, and the disassembly costs to determine the optimum disassembly sequence.

Veerakamolmal and Gupta, (2002), used heuristic algorithms for generating process plans for disassembly of electronic products that consisted of different configurations of known modules. Erdos et al., (2001), presented an algorithm that focuses on the disassembly-sequencing problem with EOL options, representing products with AND/OR 
graphs and determining disassembly sequences with the objective of maximizing the total profit. Kongar and Gupta, (2002), presented a genetic algorithm for disassembly process planning. The model considers precedence relationship and additional constraints and is applicable to problems with multiple objectives.

Literature on Mathematical Modeling Techniques to Optimize the Financial and Environmental Characteristics of Disassembly

Das, Yedlarajiah, and Narendra, (2000), presented an approach for estimating the end-of life product disassembly effort and cost. They used a model to calculate the operating cost to disassemble a product. Based on seven factors: time, tools, access, instruct, hazard, fixture and force requirements, they developed a Disassembly Effort Index (DEI) score, which represented total operating cost to disassemble a product.

Kongar and Gupta, (2002), used goal programming as a multi-criteria decisionmaking approach with six goals related to the disassembly-to-order systems. The goals considered for the model included, maximize overall profit, maximize profit from material sales, minimize number disposed, minimize number stored, minimize disposal cost, and minimize preparation cost. The output of the model includes the number of reused, recycled, stored, and disposed items. 


\subsection{Literature on Environmental Legislation}

Due to the foresighted harmful effects of increasing electrical and electronics waste, nations around the world have imposed legislation both nationally and globally. The legislation is stricter in Europe and Asia than Canada, Australia and the United States. Huge amount of electronic waste (approximately 50-80\%) from the U.S. is exported to developing countries like China, India, and Pakistan. The Basel Action Network (BAN), a global watchdog network focused on toxic trade, with support from member organizations of another activist network, "Waste Not Asia", and the Silicon Valley Toxics Coalition, a coalition advocating for a clean and safe high-tech industry, conducted an investigation that provides the basis for these numbers and alarmed the world for the need of change in US policies and practices (Exporting Harm, High-Tech Trashing of Asia). Also the awareness towards green manufacturing has been constantly growing due to increasing pressure by the consumers for green products.

Waste Electronic and Electrical Equipment (WEEE) is the European Community directive on Waste Electrical and Electronic Equipment that together with the Restriction of Hazardous Substances (RoHS) Directive became European Law in February 2003, setting collection, recycling and recovery targets for all types of electrical goods. The private household users of electrical and electronic equipment can dispose WEEE free of charge, but users other than private households are partially or fully responsible for the financing of recycling operations. Producers are to be responsible for providing guarantees that future costs will be covered for all WEEE sold after August 13, 2005 (Waste Electrical and Electronic Equipment, European Union). 
According to RoHS by July 2006, heavy metals including lead, mercury, cadmium and chromium will be banned in electronic equipment (RoHS Directive).

In Japan, since October 2003 a Computer Recycling Law has been effective which mandates electronics manufacturers to collect and recycle PCs. Another legislation enacted in April 2001 requires individual consumers to pay the direct costs of transporting and recycling their goods at the point of recycling. The cost of recycling has been already included in the selling prices of most appliances. Consumers can drop off used electronic equipment at post offices, or contact the manufacturer for pick-up (Japan File, By Richard Donovan).

In Canada, a non-profit organization called Electronics Product Stewardship Canada (EPS Canada) is in the process of developing a national electronics end-of-life program in Canada. As of October 1, 2004, televisions, computers and related equipment that were going into Alberta's landfills began to be collected, reused, recycled and turned into new products and economic opportunities for Albertans (Electronic product stewardship Canada).

In the United States, legislation varies from state to state, as there is no uniform legislation across the nation. The U.S Environmental Protection Agency's (EPA's) Product Stewardship program encourages more environmentally sustainable management of a variety of products, including electronics (U.S Environmental Protection Agency). Beginning January 1, 2006, it will be illegal to dispose of computer monitors and televisions generated as wastes by households in Maine. The state has mandated a similar $\$ 6$ fee on televisions from 2005 to 2011 . The state has also approved Extended Producer Responsibility (EPR) for computer manufacturers that will start in 2006 and television 
manufacturers that will start in 2012 (Department of Environmental Protection, Maine). In Massachusetts a landfill ban is in effect on the disposal of Cathode Ray Tubes (CRTs) (Massachusetts Recycling). In California a bill on Advance Recycling Fee (ARF) of \$6$\$ 10$ on all electronic products containing CRTs has been already established (Silicon Valley Toxics Coalition). The literature shows that the United States need to have stricter legislation on the disposal of Electrical and Electronic waste as it is one of the largest source of this waste.

After reviewing the literature it has been found that the models defined so far have number of weaknesses. The research will overcome those weaknesses by considering those issues that have not been considered so far. The next chapter presents various techniques used to analyze the problem and methodology to be used for solving the problem. 


\section{CHAPTER III - PROBLEM ANALYSIS AND METHODOLOGY}

\subsection{Problem Analysis}

The process of decision-making in reverse logistics becomes extremely complex as compared to forward supply chain. This makes the problem of integrating forward and reverse supply chains an ill-structured problem. By definition "An ill-structured problem is the one for which decision makers, alternative solutions, objectives, outside factors are not readily apparent, and/or well defined" (Ellspermann, Evans, and Basadur, 2007). For an ill-structured problem it is often helpful to generate the "network" of problems associated with the original unstructured problem. A number of problem structuring techniques are available for analyzing ill-structured problems. The Why-What's Stopping (WWS) heuristic is one of the most effective techniques among the available techniques. It can allow one to see an ill-structured problem from many different perspectives. In this way, the WWS heuristic can aid in identifying alternative solutions, objectives, attributes, and decision makers. A WWS analysis starts with a single problem statement to generate a network of problems by asking:

- "Why..." and "Why else..." to generate more general problem statements.

- "What's stopping..." and "What else is stopping..." to generate more specific problem statements. 
All problem statements are started with the phrase: "How might we..." to give an optimistic tone to the problem.

"Why" and "Why else" statements are used to generate the problem network and to develop divergent thinking. "What's stopping" and "What else is stopping" are used to select a few problem statements from the network for further study and to develop “convergent thinking".

Figure 2 represents a WWS analysis for the initial problem of "how to best integrate reverse and forward supply chains." For integrating those issues there is a need to develop a decision-making approach to help the decision maker(s) in selecting among the alternatives available.

Another reason for the complexity of this problem area is the presence of multiple objectives. Some of the objectives may be conflicting and others may be reinforcing. Following are some of the main objectives considered:

- Minimize collection costs

- Minimize refurbishing costs

- Minimize disassembly costs

- Minimize testing costs

- Minimize remanufacturing, recycling costs

- Minimize inventory holding costs

- Minimize disposal costs/number disposed

- Minimize transportation costs (may be using the concept of joint routings, i.e. making use of empty rides for collection)

- Maximize profits (refurbishing, remanufacture, recycle) 


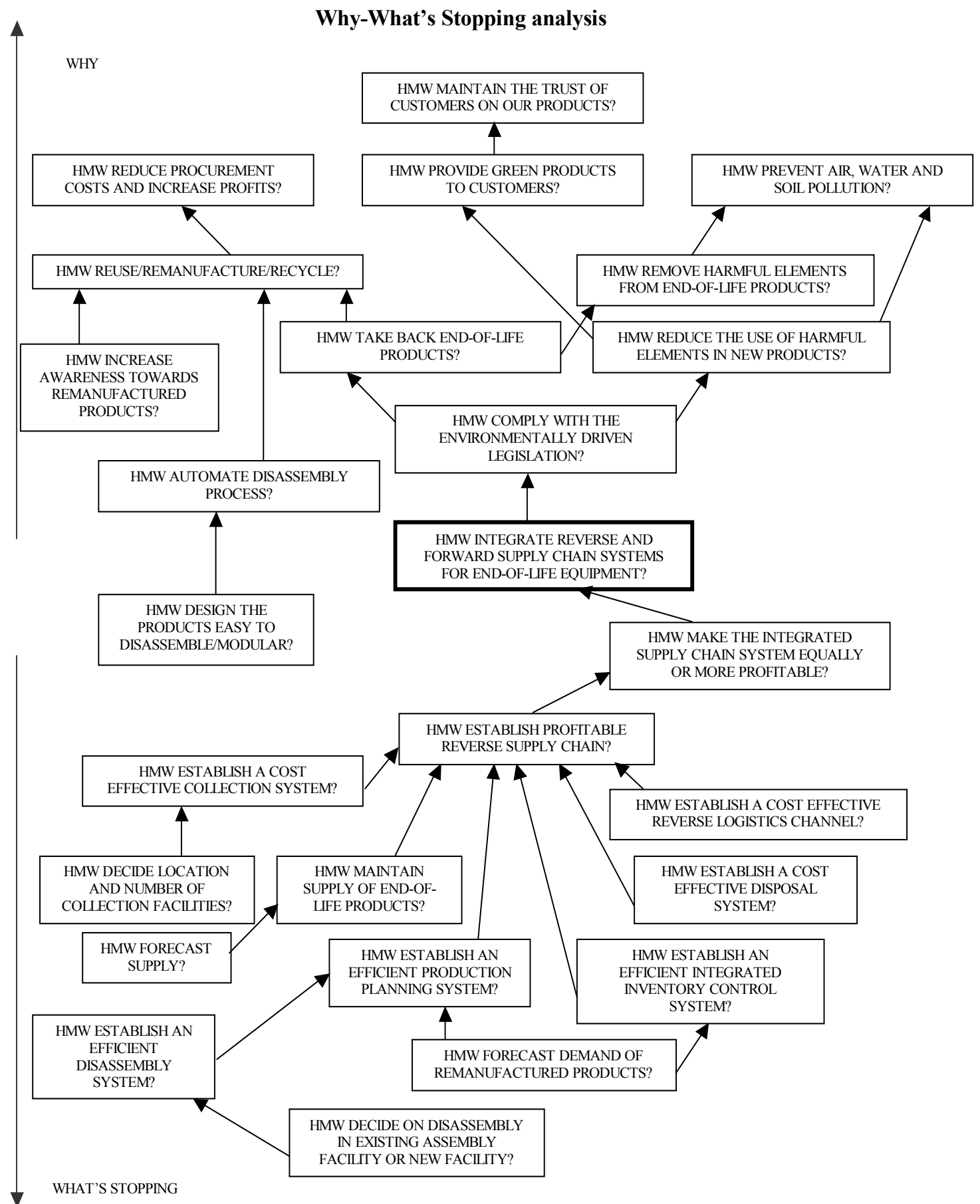

Figure 2: Why-What's Stopping Analysis for the Integration of Forward and

\section{Reverse Supply Chains}

The objectives can be further categorized into fundamental and means objectives (Clemen, 1997). Fundamental objectives are organized into hierarchies and means objectives into networks. 
For developing a means objective network following are the questions should be asked:

- Moving away from the fundamental objective - How could you achieve this?

- Moving towards the fundamental objective - Why is that important?

Following are the questions need to be asked to construct a fundamental objective hierarchy:

- Moving down the hierarchy - What do you mean by that?

- Moving up the hierarchy - Of what more general objective is this an aspect?

Figures 3 and 4 depict the means objective network and fundamental objective hierarchy for the fundamental objective of maximizing benefits from a closed-loop supply chain.

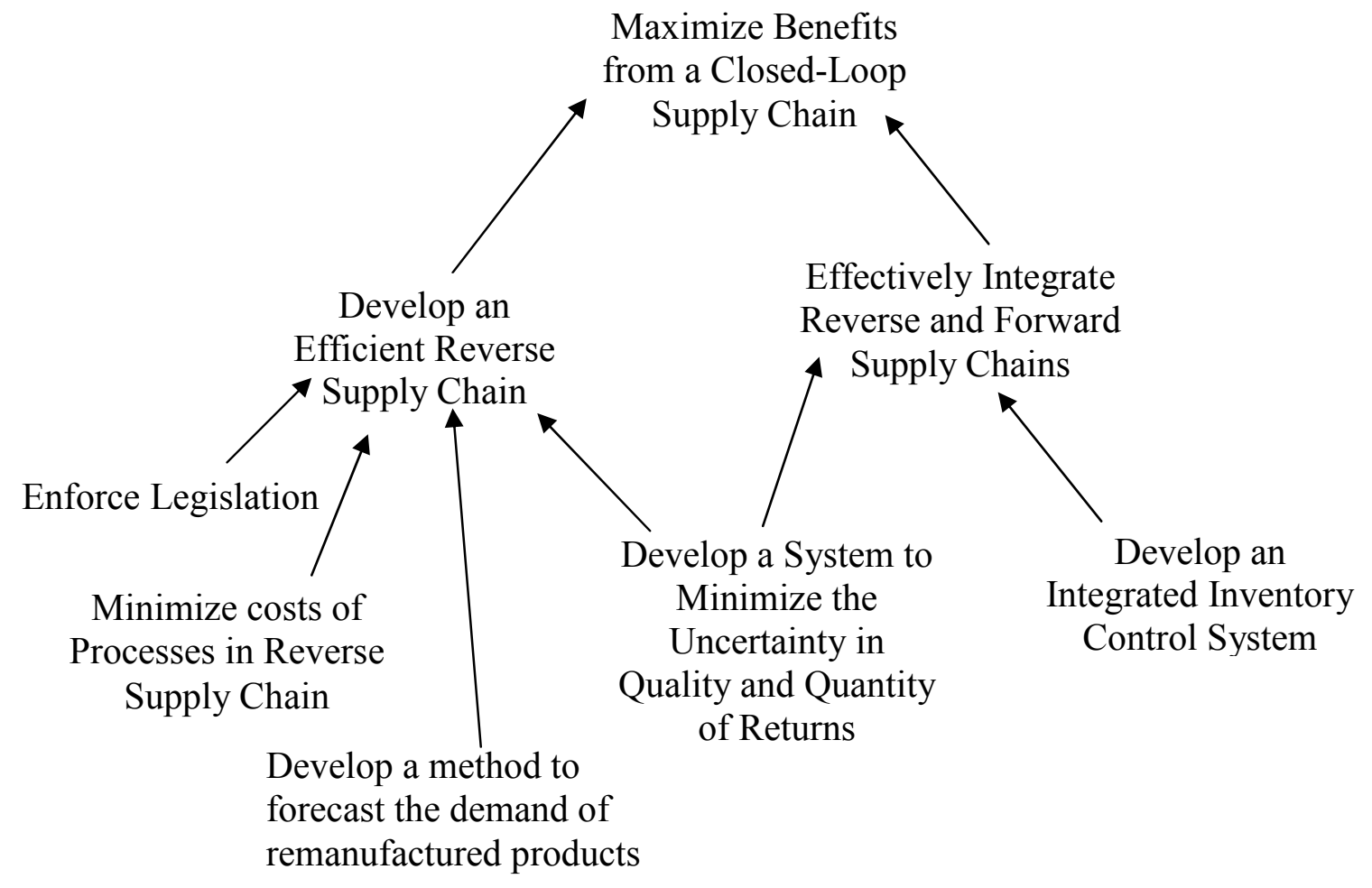

Figure 3: Means-Objectives Network 
Maximize Benefits

from a Closed-Loop

Supply Chain

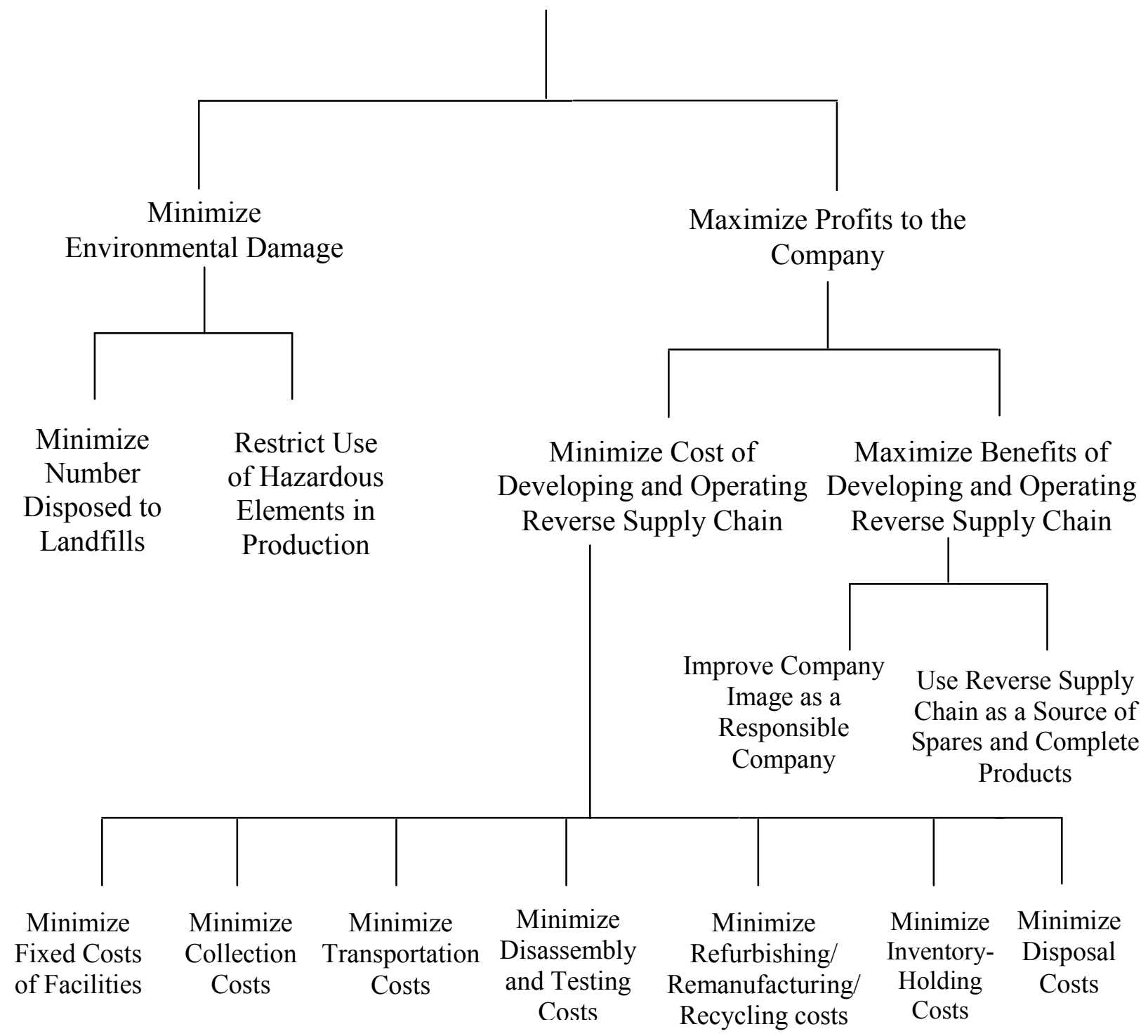

Figure 4: Fundamental-Objectives Hierarchy

\subsection{Importance of the Research}

By maintaining a smooth flow of parts from the reverse supply chain to the forward supply chain, an organization can develop a less expensive source of spare parts, 
subassemblies and products. In some cases the cost of providing spares can decrease by $60-80 \%$ (Fleischmann et al., 2003). Another driving force is "take back legislation" or "extended producer responsibility" which have already been imposed in most industrialized nations and soon will be implemented in the United States. For example, consider ISO 14001 take-back legislation in Europe. According to this legislation, producers will have to take back their products and treat them in environmentally conscious ways. In particular, in 1992 VW and Opel sold their models in Germany with the guarantee that they will take back their products at the end of their lives at no charge to the customer (Thierry et al., 1995). Some other legislative actions include disposal bans for specific products, recycled content mandates, and recycling goals. In addition, consumers demand green products and are more inclined towards recycling activities.

In this research, a Goal Programming (GP) model is developed for the design of closed-loop supply chains at the operational level. By that we mean that we assume that all the members of the supply chain already exist and we deal with the operational level planning of the existing members in the mathematical model. We are not dealing with number and location of any facility location decisions. The three analysis approaches described above helped in defining the various objectives in the goal programming model. For example in WWS analysis we see an objective of improving the disassembly processes as an extension of improving the remanufacturing processes. The meansobjectives network helped us to understand various means to achieve the objectives. This information is very useful for analyzing the output of the GP model in a situation when a goal has not been achieved or a constraint has not been satisfied. The decision maker should look at the various options in the means-objectives network to improve the value 
of the objective. Similarly at the bottom of fundamental-objectives hierarchy we see all the sub-objectives that have been defined from a fundamental objective. These subobjectives have been used as goals in GP model. The sub-objectives can be further broken down into more objectives but that leads unnecessary complexity in the model. In conclusion all the three analysis techniques helped in defining various goals and means to achieve those goals as well.

\subsection{Overview of Goal Programming (Ignizio, 1982)}

\section{General goal program model}

Find $x=\left(x_{1}, x_{2}, \ldots \ldots, x_{j}\right)$ so as to minimize

$a=f\left\{g_{1}(n, p), \ldots \ldots \ldots \ldots g_{k}(n, p)\right\}$

s.t:

$f_{i}(x)+n_{i}-p_{i}=b_{i}, i=1,2, \ldots \ldots, m$

$x, n, p \geq 0$

Goal programming (GP) is perhaps the oldest methodology within the field of Multi Criteria Decision Making. GP and its variations are used to solve a problem with multiple objectives and various sources of uncertainty. As discussed above there are multiple objectives in a closed-loop supply chain and various sources of uncertainty mainly due to the quality and quantity of returns; these factors motivated the use of GP in this research. Also, in multi objective problems there are both antithetical and reinforcing objectives. The idea of GP is to set goals for the objective values, and then choosing to meet these 
goals rather than actually trying to optimize all of the objectives (Tamiz and Jones, 1997). The solution to the problem is called a goal optimal solution. In a standard GP all criteria of the model are identified; each is defined by a linear function known as an objective and given a target value by the decision maker to represent the desired value of the objective. The sum of unwanted deviations is then minimized in an achievement function. The overall purpose of a GP model is the simultaneous satisfaction of several goals relevant to the decision-making problem under consideration.

Determination of Decision Variables

The first step in the formulation of any decision model is the determination of decision variables. The decision variables are denoted as $x_{j}$ and the aim of the model is to determine the optimal values $\left(x_{j}^{*}\right)$ of the decision variables.

Formulation of Objective Functions

The second step is formulation of the objective functions. Linear programming deals with problems having a single objective function, whereas in real life problems there are almost always more than one objective function. Some of the objectives may be conflicting and others may be reinforcing. After determination of the objectives, the next step is to attempt to eliminate some of the objectives since there is a possibility that accomplishment of one objective may eliminate the possibility of accomplishing another. In GP the objectives are termed as goals. Each goal is expressed as a function of the decision variables 


$$
G_{i}=f_{i}(x)
$$

where $f_{i}(x)$ is the function of decision variable and $G_{i}$ is the $i t h$ goal.

Once the goals are established, the required achievement level, also called the target value $\left(b_{i}\right)$ desired for each goal is determined. The target value reflects the value that $f_{i}(x)$ must exactly satisfy, exceed, or be less than:

$=$,

$f_{i}(x) \geq b_{i}$

$\leq$ respectively.

The next step involves introduction of negative $\left(n_{i}\right)$ and positive $\left(p_{i}\right)$ deviational variables. A negative deviational variable, $n_{i}$ represents the underachievement of the $i$ th goal, i.e. the number of units by which the $i$ th goal has not been satisfied with respect to the target proposed. The positive deviational variable, $p_{i}$ represents the overachievement of $i$ th goal, i.e. the number of units with which the $i$ th goal has surpassed with respect to the target proposed. A goal can be expressed as:

$f_{i}(x)+n_{i}-p_{i}=b_{i}, i=1,2, \ldots \ldots, m$

After the goals are expressed, the decision maker desires to select value of decision variable ' $x$ ' so as to achieve the objective either $\leq$ or $=$ or $\geq b_{i}$. The procedure to achieve the objective is as follows:

- $\operatorname{Min} \sum p_{i}, i=1,2, \ldots \ldots, m$

$$
f_{i}(\mathrm{x})+n_{i}-p_{i} \leq b_{i}
$$

- $\operatorname{Min} \sum n_{i}+p_{i}, i=1,2, \ldots \ldots, m$

$$
f_{i}(\mathrm{x})+n_{i}-p_{i}=b_{i}
$$

- $\operatorname{Min} \sum n_{i}, i=1,2, \ldots \ldots ., m$ 


$$
f_{i}(x)+n_{i}-p_{i} \geq b_{i}
$$

\section{Priorities to Objective Functions}

In almost all decision problems objectives have various priorities. In goal programming this can be achieved by considering the objectives with highest priority as absolute objectives and giving them top priority, P1. The remaining sets of non-absolute objectives are then grouped according to their respective priority levels. Objectives expressed in different measures can be assigned to the same priority level if they can be expressed in terms of a common unit of measure.

Achievement Function

The achievement function measures the degree of minimization of the deviation variables associated with the goals considered in the model. It associates each of the objective functions with their respective preemptive priority. The achievement function is generally denoted by 'a'.

Minimize $a=\left\{P 1\left[g_{1}(n, p)\right], P 2\left[g_{2}(n, p)\right], \ldots \ldots \ldots \ldots, P k\left[g_{k}(n, p)\right]\right\}$

\subsection{Variations of Goal Programming (Ignizio, 1982)}

The GP variations include preemptive and interactive GP approaches. Preemptive goal programming minimizes each constraint in a given priority order, maintaining all 
previous objective function values while optimizing the next constraint. Weights can also be assigned to different objectives to guarantee that the objectives are considered in their priority order. The following description forms the basis of any preemptive method (Multiobjecive programming):

- Prioritize the objectives

- Optimize the first objective subject to the original set of constraints. Let $z^{*}$ be the optimal objective value.

- Add the constraint with the objective function value $\left(z^{*}\right)$ found in step 2 and optimize next objective with this additional constraint added.

- Continue adding constraints until all objectives have been optimized.

Interactive goal programming includes the involvement of the decision maker. In a standard goal programming process all parameters are set a priori, are unalterable and there is no modeler involvement in the solution process. Interactive GP brings the flexibility in the GP process with the involvement of decision maker. The following description forms the basis of any interactive method (Tamiz, and Jones, 1997):

1) Find an initial (feasible) solution

2) Present information from the current solution to decision maker (DM)

3) If decision maker is satisfied, then stop

4) Ask the decision maker to further express his/her preferences in some way

5) Reformulate the GP in accordance with information given in step 4

6) Reoptimize the GP. Go to step 2

The next chapter presents the mathematical model defined for the research. 


\section{CHAPTER IV - MATHEMATICAL MODEL}

\subsection{Model Description}

This chapter describes the optimization model used for this research including the definitions of the decision variables, constraints, and the goals. A consolidated objective function is defined which includes all of the deviational variables considered in the goals defined in the model. The consolidated goal is to minimize the sum of all deviational variables. A preemptive goal programming approach has been used with goals being assigned different weights according to their priorities. For example, manufacturer's net profit has been assigned the largest weight. The values of the decision variables help the decision maker to decide which of the defined goals can be satisfied with the existing values of parameters.

A similar multi-objective programming approach has been presented by Sheu, Chou, and Ho (2005). They presented a linear multi-objective programming model that optimizes the operations of both a manufacturing supply chain and a reverse logistics chain. A typical 5-layer manufacturing supply chain is proposed with members classified as raw materials suppliers, manufacturers, wholesalers, retailers, and end-customers. Similarly a 5-layer reverse supply chain is proposed with members classified as collection points, recycling plants, disassembly plants, secondary material markets, and

final disposal locations of waste. The composite multi-objective function proposed in this 
research consists of two sub objectives namely, maximization of manufacturing chainbased net profit and maximization of reverse chain-based net profit. The manufacturing chain-based net profit is calculated as the difference of the aggregate revenue associated with the manufacturing chain and the sum of the aggregate costs, including raw material procurement cost, manufacturing cost, inventory cost, transportation cost and, the recycling fee paid to the EPA. The reverse chain-based net profit is calculated as the difference of the aggregate revenue associated with the reverse chain; this includes revenue and subsidies from EPA and the sum of aggregate costs including collection cost, transitional treatment cost, inventory cost, transportation cost, and disposal cost. Weights associated with each of the objective functions are specified in order to distinguish between the corresponding effects of the respective objective functions.

The model considers the consolidated profit of the reverse and forward supply chains as two individual entities. The definition of consolidated forward and reverse supply chains profit objectives used by Sheu, Chou, and Ho (2005) seems to be unrealistic as in reality each of the members of a supply chain has their own individual objectives and the related constraints. It is more realistic to consider the objectives of each of the members of the supply chain and their related constraints on an individual basis within a model. Another issue with the composite multi-objective model by Sheu, Chou, and Ho (2005) is that they considered one product only. In real time situations a manufacturer usually deals with multiple products. Finally, another aspect of our model which makes it more realistic than Sheu, Chou, and Ho's model is that we consider remanufacturing and recycling operations at the subassembly, part, and material levels. 
The initial GP model based on the closed-loop supply chain (presented in Figure 1) proposed for this research is presented in the following sections. The forward supply chain members include raw materials suppliers, parts suppliers, manufacturers, distributors, retailers, and customers. The reverse supply chain members include collection centers, repair/refurbishing facilities, disassembly facilities, testing/remanufacturing facilities, disposal sites, and recycling facilities.

\subsection{Mathematical Model}

\section{Assumptions}

The assumptions associated with this model are as follows:

- "I" types of different products have been considered in the model.

- Parts commonality exists among the products.

- Demand for different products from end-customers in a sequence of time interval is given.

- The proportions of the quantity of used products returned from end-customers in subsequent finite time intervals are given.

- Capacities of all of the facilities associated with the chain members of the considered supply chain are known.

\section{Indices for Decision Variables and Parameters}

f: $\quad$ Flow types (raw material, part, subassembly, and product)

pi: $\quad$ Product types, $\mathrm{i}=1, \ldots, \mathrm{I}$ 
sj: $\quad$ Subassembly types, $\mathrm{j}=1, \ldots, \mathrm{J}$

$n k: \quad$ Part types, $\mathrm{k}=1, \ldots, \mathrm{K}$

$m r: \quad$ Raw material types, $\mathrm{r}=1, \ldots, \mathrm{R}$

$\mathrm{t}: \quad$ Time period $, \mathrm{t}=1, \ldots, \mathrm{T}$

Fu: $\quad$ Forward supply chain member, $\mathrm{u}=1, \ldots, \mathrm{U}$

Fv: $\quad$ Reverse supply chain member, $v=1, \ldots, \mathrm{V}$

\section{Decision Variables}

Following are the decision variables considered in the model:

I: Number of units in inventory

P: Number of units produced/remanufactured/recycled

$\mathrm{T}_{\mathrm{r}}$ : Number of units transported

\section{Parameters}

Following are the parameters considered in the model:

Cs: Cost per unit of a flow type

R: Revenue per unit of a flow type

C: Storage capacity, in number of units

S: Sales in units of product

D: Demand in units of product

$\alpha$ : Proportion of number of units of refurbished products i out of total units i transported from manufacturer (member 3) to the distributor (member 4) of the forward supply chain in the period $\mathrm{t}$. 
$\beta$ : Proportion of number of units of refurbished products i out of total units i transported from distributor (member 4) to the retailer (member 5)

$\gamma$ : Proportion of number of units of refurbished products i out of total units i sold from retailer (member 5) to the customer (member 6).

a1: Factor of amount of raw material required per part.

a2: Factor of amount of subassembly required per unit of product

a3: Factor of amount of parts required per unit of product

a4: Factor of amount of parts required per unit of subassembly

\section{Constraints}

Following are the constraints considered in the model:

1) Inventory Constraints: These constraints are used to define the relationships of inbound and outbound logistics flows and corresponding storage quantities associated with various members of the supply chain. To simplify the problem one member of each of the supply chain member type has been considered.

\section{- For Raw-Material Supplier(s)}

The number of units of inventory of each raw material types associated with a raw material supplier in a particular time interval is equal to the sum of the corresponding inventory amount remaining in the previous time interval and the amount generated in that time interval, minus the total outbound raw material flow transported to the parts supplier in that time interval. The definition of number of units remains the same for all 
other chain members, only the chain members to which the flows are directed will change. In addition, the number of units is subject to an upper bound, which is available storage capacity.

$$
\begin{aligned}
& I_{m r, t}^{F 1}=I_{m r, t-1}^{F 1}+P_{m r, t}^{F 1}-T_{r} \underset{m r, t}{F 1-F 2}, \mathrm{r}=1, \ldots, \mathrm{R} ; \mathrm{t}=1, \ldots, \mathrm{T} \\
& I_{m r, t}^{F 1} \leq C_{m r, t}^{F 1}, \mathrm{r}=1, \ldots . . \mathrm{R} ; \mathrm{t}=1, \ldots, \mathrm{T}
\end{aligned}
$$

\section{- For Part Supplier(s)}

In addition to constraints on inbound and outbound flows, the number of units is subject to an upper bound, which is available storage capacity.

$$
\begin{aligned}
& I_{m r, t}^{F 2}=I_{m r, t-1}^{F 2}+T_{r} \underset{m r, t}{F 1-F 2}-P_{n k, t}^{F 2} * \mathrm{a} 1, \mathrm{r}=1, \ldots, \mathrm{R} ; \mathrm{t}=1, \ldots, \mathrm{T} \\
& I_{m r, t}^{F 2} \leq C_{m r, t}^{F 2}, \mathrm{r}=1, \ldots, \mathrm{R} ; \mathrm{t}=1, \ldots, \mathrm{T} \\
& I_{n k, t}^{F 2}=I_{n k, t-1}^{F 2}+P_{n k, t}^{F 2}-T_{r} \stackrel{F k, t}{F 2-F 3}, \mathrm{k}=1, \ldots, \mathrm{K} ; \mathrm{t}=1, \ldots, \mathrm{T} \\
& I_{n k, t}^{F 2} \leq C_{n k, t}^{F 2}, \mathrm{k}=1, \ldots, \mathrm{K} ; \mathrm{t}=1, \ldots, \mathrm{T}
\end{aligned}
$$

\section{- For Product Manufacturer(s)}

In addition to constraints on inbound and outbound flows on number of units of part, subassembly, and product types associated with a manufacturer, the numbers of units are also subject to upper bounds, which are available storage capacities.

$$
\begin{aligned}
& I_{p i, t}^{F 3}=I_{p i, t-1}^{F 3}+P_{p i, t}^{F 3}-T_{r}{ }_{p i, t}^{3-F 4}-S_{p i, t}^{F 3-F 6}, \mathrm{i}=1, \ldots, \mathrm{I} ; \mathrm{t}=1, \ldots, \mathrm{T} \\
& I_{p i, t}^{F 3} \leq C_{p i, t}^{F 3}, \mathrm{i}=1, \ldots, \mathrm{I} ; \mathrm{t}=1, \ldots, \mathrm{T} \\
& I_{s j, t}^{F 3}=I_{s j, t-1}^{F 3}+P_{s j, t}^{F 3}-\sum_{i=1}^{3} P_{p i, t}^{F 3} * a 2, \mathrm{i}=1, \ldots, \mathrm{I} ; \mathrm{j}=1, \ldots, \mathrm{J} ; \mathrm{t}=1, \ldots, \mathrm{T}
\end{aligned}
$$




$$
\begin{aligned}
& I_{s j, t}^{F 3} \leq C_{s j, t}^{F 3}, \mathrm{j}=1, \ldots, \mathrm{I} ; \mathrm{t}=1, \ldots, \mathrm{T} \\
& I_{n k, t}^{F 3}=I_{n k, t-1}^{F 3}+T_{r}{ }_{n k, t}^{F 2-F 3}-\sum_{i=1}^{3} P_{p i, t}^{F 3} * a 3-\sum_{j=1}^{3} P_{s j, t}^{F 3} * a 4, \mathrm{k}=1, \ldots, \mathrm{K} ; \mathrm{t}=1, \ldots, \mathrm{T} \\
& I_{n k, t}^{F 3} \leq C_{n k, t}^{F 3}, \mathrm{k}=1, \ldots, \mathrm{K} ; \mathrm{t}=1, \ldots, \mathrm{T}
\end{aligned}
$$

\section{- For Distributor(s)}

In addition to constraints on inbound and outbound flows, the number of units of product types is subject to an upper bound, which is available storage capacity.

$$
\begin{aligned}
& I_{p i, t}^{F 4}=I_{p i, t-1}^{F 4}+T_{r} \underset{p i, t}{F 3-F 4}-T_{r}^{F i, t} \underset{p 4-F 5}{F}, \mathrm{i}=1, \ldots, \mathrm{I} ; \mathrm{t}=1, \ldots, \mathrm{T} \\
& I_{p i, t}^{F 4} \leq C_{p i, t}^{F 4}, \mathrm{i}=1, \ldots, \mathrm{I} ; \mathrm{t}=1, \ldots, \mathrm{T}
\end{aligned}
$$

\section{- For Retailer(s)}

In addition to constraints on inbound and outbound flows, the number of units of product types is subject to an upper bound, which is available storage capacity.

$$
\begin{aligned}
& I_{p i, t}^{F 5}=I_{p i, t-1}^{F 5}+T_{r} \underset{p i, t}{F 4-F 5}-S_{p i, t}^{F 5-F 6}, \mathrm{i}=1, \ldots, \mathrm{I} ; \mathrm{t}=1, \ldots, \mathrm{T} \\
& I_{p i, t}^{F 5} \leq C_{p i, t}^{F 5}, \mathrm{i}=1, \ldots, \mathrm{I} ; \mathrm{t}=1, \ldots, \mathrm{T}
\end{aligned}
$$

\section{- For Collection Point(s)}

In addition to constraints on inbound and outbound flows, the number of units of collected product types associated with collection points is subject to an upper bound, which is available storage capacity. The flow from a collection point can either be to the disassembly or to repair/refurbishing facility after inspection. 


$$
\begin{aligned}
& I_{p i, t}^{R 1}=I_{p i, t-1}^{R 1}+R_{p i, t}^{F 6-R 1}-T_{r} \begin{array}{l}
R 1-R 2 \\
p i, t
\end{array}-T_{r}{ }_{p i, t}^{R 1-R 3}, \mathrm{i}=1, \ldots, \mathrm{I} ; \mathrm{t}=1, \ldots, \mathrm{T} \\
& I_{p i, t}^{R 1} \leq C_{p i, t}^{R 1}, \mathrm{i}=1, \ldots, \mathrm{I} ; \mathrm{t}=1, \ldots, \mathrm{T}
\end{aligned}
$$

\section{- For Refurbishing Plant(s)}

In addition to constraint on inbound and outbound flows, the number of units of return product types and refurbished product types associated with a refurbishing plant are subject to an upper, which is available storage capacity. The refurbished products are transferred to the product manufacturer.

$$
\begin{aligned}
& I_{p i, t}^{R 2}=I_{p i, t-1}^{R 2}+T_{r} \underset{p i, t}{R 1-R 2}-T_{r}{ }_{p i, t}^{R 2-F 3}, \mathrm{i}=1, \ldots, \mathrm{I} ; \mathrm{t}=1, \ldots, \mathrm{T} \\
& I_{p i, t}^{R 2} \leq C_{p i, t}^{R 2}, \mathrm{i}=1, \ldots, \mathrm{I} ; \mathrm{t}=1, \ldots, \mathrm{T}
\end{aligned}
$$

\section{- For Disassembly Plant(s)}

In addition to constraint on inbound and outbound flows, the number of units of disassembled and assembled product types associated with a disassembly plant is subject to an upper bound, which is available storage capacity. The flows from a disassembly plant can either be testing or to final disposal depending upon the condition of parts and subassemblies after disassembly.

$$
\begin{aligned}
& I_{n k, t}^{R 3}=I_{n k, t-1}^{R 3}+\sum_{i=1}^{3} P_{p i, t}^{R 3} *(1 / a 3)+\sum_{j=1}^{3} P_{s j, t}^{F 3} *(1 / a 4)-T_{r}^{R 3 k, t}-T_{r}^{R 3-R 4}, \mathrm{k}=1, \ldots, \mathrm{K} ; \mathrm{i}= \\
& 1, \ldots, \mathrm{I} ; \mathrm{j}=1, \ldots, \mathrm{J} ; \mathrm{t}=1, \ldots, \mathrm{T} \\
& I_{n k, t}^{R 3} \leq C_{n k, t}^{R 3}, \mathrm{k}=1, \ldots, \mathrm{K} ; \mathrm{t}=1, \ldots, \mathrm{T} \\
& I_{s j, t}^{R 3}=I_{s j, t-1}^{R 3}+\sum_{i=1}^{3} P_{p i, t}^{R 3} *(1 / a 2)-T_{r} \begin{array}{l}
R 3, t-R 6 \\
s j, T_{r}
\end{array} \underbrace{R 3-R 4}_{s j, t}, \mathrm{j}=1, \ldots, \mathrm{J} ; \mathrm{i}=1, \ldots, \mathrm{I} ; \mathrm{t}=1, \ldots, \mathrm{T}
\end{aligned}
$$




$$
\begin{aligned}
& I_{s j, t}^{R 3} \leq C_{s j, t}^{R 3}, \mathrm{j}=1, \ldots, \mathrm{J} ; \mathrm{t}=1, \ldots, \mathrm{T} \\
& I_{p i, t}^{R 3}=I_{p i, t-1}^{R 3}+T_{r}{ }_{p i, t}^{R 1-R 3}-P_{p i, t}^{R 3}, \mathrm{i}=1, \ldots, \mathrm{I} ; \mathrm{t}=1, \ldots, \mathrm{T} \\
& I_{p i, t}^{R 3} \leq C_{p i, t}^{R 3}, \mathrm{i}=1, \ldots, \mathrm{I} ; \mathrm{t}=1, \ldots, \mathrm{T}
\end{aligned}
$$

\section{- For Testing/Remanufacturing Plant(s)}

In addition to constraint on inbound and outbound flows, the number of units of part and subassembly types associated with a testing plant is subject to upper bounds, which are storage capacities.

$$
\begin{aligned}
& I_{n k, t}^{R 4}=I_{n k, t-1}^{R 4}+T_{r}{ }_{n k, t}^{R 3-R 4}-T_{r}{ }_{n k, t}^{R 4-F 3}-T_{r}{ }_{n k, t}^{R 4-R 5}-T_{r}{ }_{n k, t}^{R 4-R 6}, \mathrm{k}=1, \ldots, \mathrm{K} ; \mathrm{t}=1, \ldots, \mathrm{T} \\
& I_{n k, t}^{R 4} \leq C_{n k, t}^{R 4}, \mathrm{k}=1, \ldots, \mathrm{K} ; \mathrm{t}=1, \ldots, \mathrm{T} \\
& I_{s j, t}^{R 4}=I_{s j, t-1}^{R 4}+T_{r} \underset{s j, t}{R 3-R 4}-T_{r}{ }_{n k, t}^{R 4-F 3}-T_{r} \underset{n k, t}{R 4-R 5}-T_{r} \underset{n k, t}{R 4-R 6}, \mathrm{j}=1, \ldots, \mathrm{J} ; \mathrm{t}=1, \ldots, \mathrm{T} \\
& I_{s j, t}^{R 4} \leq C_{s j, t}^{R 4}, \mathrm{j}=1, \ldots, \mathrm{J} ; \mathrm{t}=1, \ldots, \mathrm{T}
\end{aligned}
$$

\section{- For Disposal Location(s)}

Final disposal locations of wastes refer to the sites where useless wastes are processed with appropriate disposal measures, e.g., landfill or incineration. The number of units of part and subassembly types disposed associated with disposal locations is subject to upper bounds, which is disposal area capacity.

$$
\begin{aligned}
& I_{n k, t}^{R 5}=I_{n k, t-1}^{R 5}+T_{r} \underset{n k, t}{R 3-R 5}+T_{r}{ }_{n k, t}^{R 4-R 5}, \mathrm{k}=1, \ldots, \mathrm{K} ; \mathrm{t}=1, \ldots, \mathrm{T} \\
& I_{n k, t}^{R 5} \leq C_{n k, t}^{R 5}, \mathrm{k}=1, \ldots, \mathrm{K} ; \mathrm{t}=1, \ldots, \mathrm{T} \\
& I_{s j, t}^{R 5}=I_{s j, t-1}^{R 5}+T_{r} \underset{s j, t}{R 3-R 5}+T_{r} \underset{s j, t}{R 4-R 5}, \mathrm{j}=1, \ldots, \mathrm{J} ; \mathrm{t}=1, \ldots, \mathrm{T} \\
& \mathrm{I}_{s j, t}^{R 5} \leq \mathrm{C}_{s j, t}^{R 5}, \mathrm{j}=1, \ldots, \mathrm{J} ; \mathrm{t}=1, \ldots, \mathrm{T}
\end{aligned}
$$


- For Recycling Plant(s)

In addition to constraint on inbound and outbound flows on inventory amounts, the amount of part and subassembly types associated with a recycling plant are subject to upper and lower bounds, which are storage capacity and 0 respectively.

$$
\begin{aligned}
& I_{n k, t}^{R 6}=I_{n k, t-1}^{R 6}+T_{r}{ }_{n k, t}^{R 4-R 6}-T_{r}{ }_{n k, t}^{R 6-F 1}, \mathrm{k}=1, \ldots, \mathrm{K} ; \mathrm{t}=1, \ldots, \mathrm{T} \\
& I_{n k, t}^{R 6} \leq C_{n k, t}^{R 6}, \mathrm{k}=1, \ldots, \mathrm{K} ; \mathrm{t}=1, \ldots, \mathrm{T} \\
& I_{s j, t}^{R 6}=I_{s j, t-1}^{R 6}+T_{r}{ }_{s j, t}^{R 4-R 6}-T_{r}{ }_{s j, t}^{R 6-F 1}, \mathrm{j}=1, \ldots, \mathrm{J} ; \mathrm{t}=1, \ldots, \mathrm{T} \\
& I_{s j, t}^{R 6} \leq C_{s j, t}^{R 6}, \mathrm{j}=1, \ldots, \mathrm{J} ; \mathrm{t}=1, \ldots, \mathrm{T}
\end{aligned}
$$

2) Demand Constraints: This constraint is used to define relationship between the endcustomer total demands and the physical flows of parts, subassemblies, and products transported to end-customers.

Demand of raw materials by the parts supplier

$D_{m r, t}^{F 2}=T_{r} \underset{m r, t}{F 1-F 2}, \mathrm{r}=1, \ldots, \mathrm{R} ; \mathrm{t}=1, \ldots, \mathrm{T}$

Demand of parts by the manufacturer

$D_{n k, t}^{F 3}=T_{r}^{F 2-F 3}, \mathrm{k}=1, \ldots, \mathrm{K} ; \mathrm{t}=1, \ldots, \mathrm{T}$

Demand of products by the distributor

$D_{p i, t}^{F 4}=T_{r}{ }_{p i, t}^{F 3-F 4}, \mathrm{i}=1, \ldots, \mathrm{I} ; \mathrm{t}=1, \ldots, \mathrm{T}$

Demand of products by the retailer

$D_{p i, t}^{F 5}=T_{r} \underset{p i, t}{F 4-F 5}, \mathrm{i}=1, \ldots, \mathrm{I} ; \mathrm{t}=1, \ldots, \mathrm{T}$

Demand of products by the consumer 
$D_{p i, t}^{F 6}=T_{r} \underset{p i, t}{F 3-F 6}+T_{r}^{F i, t} \underset{p 46}{F 4-F 6} \underset{p i, t}{F 5-F 6}, \mathrm{i}=1, \ldots, \mathrm{I} ; \mathrm{t}=1, \ldots, \mathrm{T}$

\section{3) Non-Negativity Constraints}

The number of units of different flow types associated with a member in both forward and reverse supply chains is subject to lower bounds, i.e. the number of units will always be a non negative quantity.

$$
\begin{aligned}
& I_{m r, t}^{F 1} \geq 0, \mathrm{r}=1, \ldots, \mathrm{R} ; \mathrm{t}=1, \ldots, \mathrm{T} \\
& I_{m r, t}^{F 2} \geq 0, \mathrm{r}=1, \ldots, \mathrm{R} ; \mathrm{t}=1, \ldots, \mathrm{T} \\
& I_{n k, t}^{F 2} \geq 0, \mathrm{k}=1, \ldots, \mathrm{K} ; \mathrm{t}=1, \ldots, \mathrm{T} \\
& I_{n k, t}^{F 3} \geq 0, \mathrm{k}=1, \ldots, \mathrm{K} ; \mathrm{t}=1, \ldots, \mathrm{T} \\
& I_{n k, t}^{R 3} \geq 0, \mathrm{k}=1, \ldots, \mathrm{K} ; \mathrm{t}=1, \ldots, \mathrm{T} \\
& I_{n k, t}^{R 4} \geq 0, \mathrm{k}=1, \ldots, \mathrm{K} ; \mathrm{t}=1, \ldots, \mathrm{T} \\
& I_{n k, t}^{R 5} \geq 0, \mathrm{k}=1, \ldots, \mathrm{K} ; \mathrm{t}=1, \ldots, \mathrm{T} \\
& I_{n k, t}^{R 6} \geq 0, \mathrm{k}=1, \ldots, \mathrm{K} ; \mathrm{t}=1, \ldots, \mathrm{T} \\
& I_{s j, t}^{F 3} \geq 0, \mathrm{j}=1, \ldots, \mathrm{J} ; \mathrm{t}=1, \ldots, \mathrm{T} \\
& I_{s j, t}^{R 3} \geq 0, \mathrm{j}=1, \ldots, \mathrm{J} ; \mathrm{t}=1, \ldots, \mathrm{T} \\
& I_{s j, t}^{R 4} \geq 0, \mathrm{j}=1, \ldots, \mathrm{J} ; \mathrm{t}=1, \ldots, \mathrm{T} \\
& I_{s j, t}^{R 5} \geq 0, \mathrm{j}=1, \ldots, \mathrm{J} ; \mathrm{t}=1, \ldots, \mathrm{T} \\
& I_{s j, t}^{R 6} \geq 0, \mathrm{j}=1, \ldots, \mathrm{J} ; \mathrm{t}=1, \ldots, \mathrm{T} \\
& I_{p i, t}^{F 3} \geq 0, \mathrm{i}=1, \ldots, \mathrm{I} ; \mathrm{t}=1, \ldots, \mathrm{T} \\
& I_{p i, t}^{F 4} \geq 0, \mathrm{i}=1, \ldots, \mathrm{I} ; \mathrm{t}=1, \ldots, \mathrm{T}
\end{aligned}
$$




$$
\begin{aligned}
& I_{p i, t}^{F 5} \geq 0, \mathrm{i}=1, \ldots, \mathrm{I} ; \mathrm{t}=1, \ldots, \mathrm{T} \\
& I_{p i, t}^{R 1} \geq 0, \mathrm{i}=1, \ldots, \mathrm{I} ; \mathrm{t}=1, \ldots, \mathrm{T} \\
& I_{p i, t}^{R 2} \geq 0, \mathrm{i}=1, \ldots, \mathrm{I} ; \mathrm{t}=1, \ldots, \mathrm{T} \\
& I_{p i, t}^{R 3} \geq 0, \mathrm{i}=1, \ldots, \mathrm{I} ; \mathrm{t}=1, \ldots, \mathrm{T} \\
& P_{m r, t}^{F 1} \geq 0, \mathrm{r}=1, \ldots, \mathrm{R} ; \mathrm{t}=1, \ldots, \mathrm{T} \\
& P_{n k, t}^{F 2} \geq 0, \mathrm{k}=1, \ldots, \mathrm{K} ; \mathrm{t}=1, \ldots, \mathrm{T} \\
& P_{p i, t}^{F 3} \geq 0, \mathrm{i}=1, \ldots, \mathrm{I} ; \mathrm{t}=1, \ldots, \mathrm{T} \\
& P_{s j, t}^{F 3} \geq 0, \mathrm{j}=1, \ldots, \mathrm{J} ; \mathrm{t}=1, \ldots, \mathrm{T} \\
& P_{p i, t}^{R 3}, \mathrm{i}=1, \ldots, \mathrm{I} ; \mathrm{t}=1, \ldots, \mathrm{T} \\
& P_{s j, t}^{F 3}, \mathrm{j}=1, \ldots, \mathrm{J} ; \mathrm{t}=1, \ldots, \mathrm{T} \\
& P_{p i, t}^{R 3}, \mathrm{i}=1, \ldots, \mathrm{I} ; \mathrm{t}=1, \ldots, \mathrm{T} \\
& T_{r_{m r, t}}^{F 1-F 2} \geq 0, \mathrm{r}=1, \ldots, \mathrm{R} ; \mathrm{t}=1, \ldots, \mathrm{T} \\
& T_{r_{n k, t}}^{F 2-F 3} \geq 0, \mathrm{k}=1, \ldots, \mathrm{K} ; \mathrm{t}=1, \ldots, \mathrm{T} \\
& T_{r} \underset{p i, t}{F 3-F 4} \geq 0, \mathrm{i}=1, \ldots, \mathrm{I} ; \mathrm{t}=1, \ldots, \mathrm{T} \\
& T_{r}^{F i, t} \underset{F 5}{F 4-F 5}, \mathrm{i}=1, \ldots, \mathrm{I} ; \mathrm{t}=1, \ldots, \mathrm{T} \\
& T_{r} \underset{p i, t}{R 1-R 3}, \mathrm{i}=1, \ldots, \mathrm{I} ; \mathrm{t}=1, \ldots, \mathrm{T} \\
& T_{r} \underset{p i, t}{R 1-R 2}, \mathrm{i}=1, \ldots, \mathrm{I} ; \mathrm{t}=1, \ldots, \mathrm{T} \\
& T_{r}^{R 2-F 3}, \mathrm{i}=1, \ldots, \mathrm{I} ; \mathrm{t}=1, \ldots, \mathrm{T} \\
& T_{r} \underset{n k, t}{R 3-R 6}, \mathrm{k}=1, \ldots, \mathrm{K} ; \mathrm{t}=1, \ldots, \mathrm{T}
\end{aligned}
$$




$$
\begin{aligned}
& T_{r}{ }_{n k, t}^{R 3-R 4}, \mathrm{k}=1, \ldots, \mathrm{K} ; \mathrm{t}=1, \ldots, \mathrm{T} \\
& T_{r}{ }_{p i, t}^{R 1-R 3}, \mathrm{i}=1, \ldots, \mathrm{I} ; \mathrm{t}=1, \ldots, \mathrm{T} \\
& T_{r} \underset{n k, t}{R 3-R 4}, \mathrm{k}=1, \ldots, \mathrm{K} ; \mathrm{t}=1, \ldots, \mathrm{T} \\
& T_{r}{ }_{n k, t}^{R 4-F 3}, \mathrm{k}=1, \ldots, \mathrm{K} ; \mathrm{t}=1, \ldots, \mathrm{T} \\
& T_{r}{ }_{n k, t}^{R 4-R 5}, \mathrm{k}=1, \ldots, \mathrm{K} ; \mathrm{t}=1, \ldots, \mathrm{T} \\
& T_{r}{ }_{n k, t}^{R 4-R 6}, \mathrm{k}=1, \ldots, \mathrm{K} ; \mathrm{t}=1, \ldots, \mathrm{T}
\end{aligned}
$$

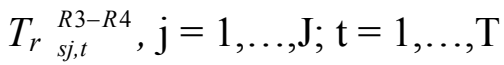

$$
\begin{aligned}
& T_{r}{ }_{n k, t}^{R 4-F 3}, \mathrm{j}=1, \ldots, \mathrm{J} ; \mathrm{t}=1, \ldots, \mathrm{T} \\
& T_{r}{ }_{n k, t}^{R 4-R 5}, \mathrm{j}=1, \ldots, \mathrm{J} ; \mathrm{t}=1, \ldots, \mathrm{T} \\
& T_{r}{ }_{n k, t}^{R 4-R 6}, \mathrm{j}=1, \ldots, \mathrm{J} ; \mathrm{t}=1, \ldots, \mathrm{T} \\
& T_{r} \underset{n k, t}{R 3-R 5}, \mathrm{k}=1, \ldots, \mathrm{K} ; \mathrm{t}=1, \ldots, \mathrm{T} \\
& T_{r}{ }_{n k, t}^{R 4-R 5}, \mathrm{k}=1, \ldots, \mathrm{K} ; \mathrm{t}=1, \ldots, \mathrm{T}
\end{aligned}
$$

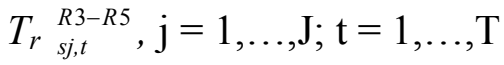

$$
\begin{aligned}
& T_{r}{ }_{s j, t}^{R 4-R 5}, \mathrm{j}=1, \ldots, \mathrm{J} ; \mathrm{t}=1, \ldots, \mathrm{T} \\
& T_{r}{ }_{n k, t}^{R 4-R 6}, \mathrm{k}=1, \ldots, \mathrm{K} ; \mathrm{t}=1, \ldots, \mathrm{T} \\
& T_{r} \underset{n k, t}{R 6-F 1}, \mathrm{k}=1, \ldots, \mathrm{K} ; \mathrm{t}=1, \ldots, \mathrm{T} \\
& T_{r}{ }_{s j, t}^{R 4-R 6}, \mathrm{j}=1, \ldots, \mathrm{J} ; \mathrm{t}=1, \ldots, \mathrm{T} \\
& T_{r}^{R 6-t, t}, \mathrm{j}=1, \ldots, \mathrm{J} ; \mathrm{t}=1, \ldots, \mathrm{T} \\
& \mathrm{S}_{p i, t}^{F 3-F 6} \geq 0, \mathrm{i}=1, \ldots, \mathrm{I} ; \mathrm{t}=1, \ldots, \mathrm{T}
\end{aligned}
$$




$$
\begin{aligned}
& S_{p i, t}^{F 5-F 6}, \mathrm{i}=1, \ldots, \mathrm{I} ; \mathrm{t}=1, \ldots, \mathrm{T} \\
& R_{p i, t}^{F 6-R 1}, \mathrm{i}=1, \ldots, \mathrm{I} ; \mathrm{t}=1, \ldots, \mathrm{T}
\end{aligned}
$$

Since the model has been defined as a linear program, the nature of all the decision variables is assumed to be continuous.

\section{Goals}

The consolidated objective in the model is to minimize a weighted sum of deviational variables related to the goals considered in the model, as described below:

Consolidated goal $=$ Goal set $1+$ Goal set 2

$=$ Maximize (Profit to raw materials supplier, Profit to parts supplier, Profit to manufacturer, Profit to distributor, Profit to retailer) + Maximize (Profit to collectors, Profit to repair/refurbishing, Profit to disassembly, Profit to testing/remanufacturing, Profit to recycler)

$$
\begin{aligned}
& =\operatorname{Min} \sum_{i=1}^{5}\left(n_{i}+p_{i}\right)+\sum_{j=1}^{6}\left(n_{j}+p_{j}\right) \\
& =\operatorname{Min} 1000000 * \mathrm{n} 3+10000 * \mathrm{n} 1+10000 * \mathrm{n} 2+10000 * \mathrm{n} 4+10000 * \mathrm{n} 5+1000 * \mathrm{n} 1 \\
& +1000 * \mathrm{n} 2+1000 * \mathrm{n} 3+1000 * \mathrm{n} 4+1000 * \mathrm{n} 5+100 * \mathrm{p} 6 ;
\end{aligned}
$$

The first set of goals is maximization of net profit for each of the members of the forward supply chain $\left(N P_{F i}\right)$. Mathematically, this can be achieved by minimizing of the negative deviation $\left(n_{i}\right)$ from the predetermined value, $N P_{F i}$. Also by putting no 
restriction on the positive deviation $\left(p_{i}\right)$, the model places no ceiling on the total profit variable to exceed $N P_{F i}$.

Goal set 1: Maximize (Profit to raw materials supplier, Profit to parts supplier, Profit to manufacturer, Profit to distributor, Profit to retailer)

The goal can be formulated as follows:

Min sum of negative deviations, $\sum_{i=1}^{5}\left(n_{i}+p_{i}\right)$

s.t. $N P_{F i}+n_{i}+p_{i}=N P_{F i},, \mathrm{i}=1, \ldots, 5$

$N P_{F 1}=T_{r} \underset{m r, t}{F 1-F 2} *\left(R v_{m r, t}^{F 1-F 2}-C s_{m m}^{F 1} \underset{m r, t}{F 1}\right)-I_{m r, t}^{F 1} * C s_{S_{m r, t}}^{F 1}$

$N P_{F 2}=T_{r} \underset{n k, t}{F 2-F 3} *\left(R v_{n k, t}^{F 2-F 3}-C s_{m_{n k, t}}^{F 2}-C s_{t r}^{F 1-F 2} \underset{m r, t}{F s^{2}}-C s_{m r, t}^{F 1-F 2}\right)-I_{n k, t}^{F 2} * C s_{s_{n k, t}}^{F 2}$

$N P_{F 3}=T_{r} \underset{p i, t}{F 3-F 4} *\left(R v_{p i, t}^{F 3-F 4}-C s_{m}^{F 3} \underset{p i, t}{F 3}-C s_{t r}^{F 2-F 3}-C s_{p_{n k, t}}^{F 2-F 3}\right)-I_{n k, t}^{F 3} * C s_{S_{n k, t}}^{F 3}-I_{s j, t}^{F 3} * C s_{s j, t}^{F 3}$

$-I_{p i, t}^{F 3} * C s_{S p i, t}^{F 3}$

$N P_{F 4}=T_{r} \underset{p i, t}{F 4-F 5} *\left(R v_{p i, t}^{F 4-F 5}-C s_{t r}^{F i, t}{ }^{F 3-F 4}-C s_{p}^{F i, t}{ }_{p 4}^{F 3-F 4}\right)-I_{p i, t}^{F 4} * C s_{s p i, t}^{F 4}$

$N P_{F 5}=T_{r} \underset{p i, t}{F 5-F 6} *\left(R v_{p i, t}^{F 5-F 6}-C s_{t r}^{F i, t}{ }_{p 4-F 5}^{F-C s_{p}} \underset{p i, t}{F 4-F 5}\right)-I_{p i, t}^{F 5} * C s_{S p i, t}^{F 5}$

The second set of goals is maximization of net profit for each of the members of the reverse supply chain $\left(N P_{R j}\right)$. Here also, the negative deviation $\left(n_{2}\right)$ from the predetermined value, $N P_{R j}$, is to be minimized.

Goal 2: Maximize (Profit to collectors, Profit to repair/refurbishing, Profit to disassembly, Profit to testing/remanufacturing, Profit to recycler)

The goal can be formulated as follows: 
Min sum of negative deviations, $\sum_{j=1}^{6}\left(n_{j}+p_{j}\right)$

s.t. $N P_{R j}+n_{j}+p_{j}=N P_{R j}{ }^{\prime}, \mathrm{j}=1, \ldots ., 6$

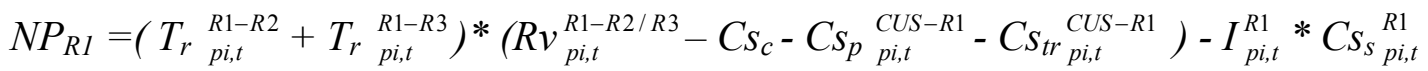

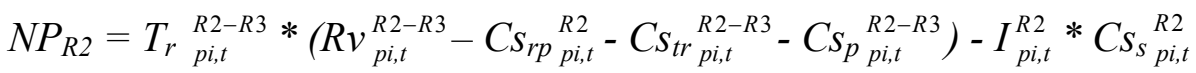

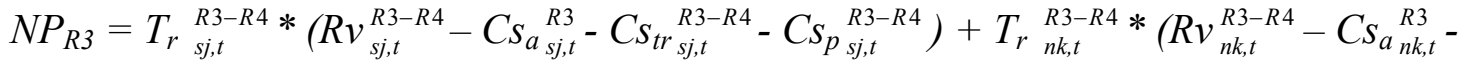

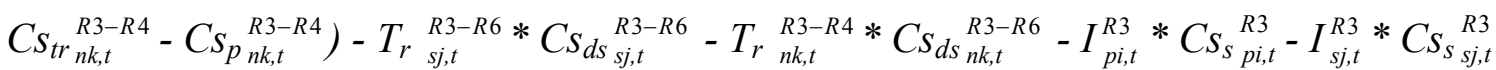

$-I_{n k, t}^{R 3} * C s_{s n k, t}^{R 3}$

$N P_{R 4}=T_{r}{ }_{s j, t}^{R 4-R 5} *\left(R v_{s j, t}^{R 4-R 5}-C s_{t s}^{R 4}{ }_{s j, t}^{R 4}-C s_{t r}^{R 4 j, t}{ }_{s-R 5}^{R 4}-C s_{p s j, t}^{R 4-R 5}\right)+T_{r}{ }_{s j, t}^{R 4-F 3} *\left(R v_{s j, t}^{R 4-F 3}-C s_{t s}{ }_{s j, t}^{R 4}-\right.$

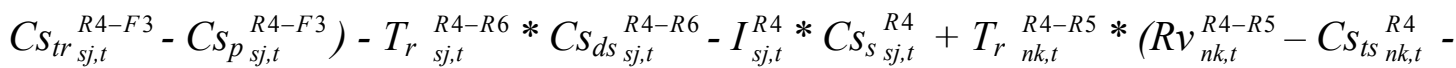



$C S_{d s_{n k, t}^{R 4-R 6}}^{R 4} I_{n k, t}^{R 4} * C S_{s_{n k, t}^{R 4}}^{R 4}$

$N P_{R 5}=T_{r} \underset{m r, t}{R 5-F 1} *\left(R v_{m r, t}^{R 5-F 1}-C S_{r c}{ }_{m r, t}^{R 5}-C S_{t r}{ }_{m r, t}^{R 5-F 1}-C s_{p}{ }_{m r, t}^{R 5-F 1}\right)-I_{s j, t}^{R 5} * C S_{S_{s j, t}}^{R 5}-I_{n k, t}^{R 5} * C S_{S_{n k, t}}^{R 5}$

Figure 5 shows the assembly structures of the three products considered for the mathematical model and for analyzing the results. 3 products, 5 subassemblies, 10 parts, and 2 types of raw materials have been considered. 


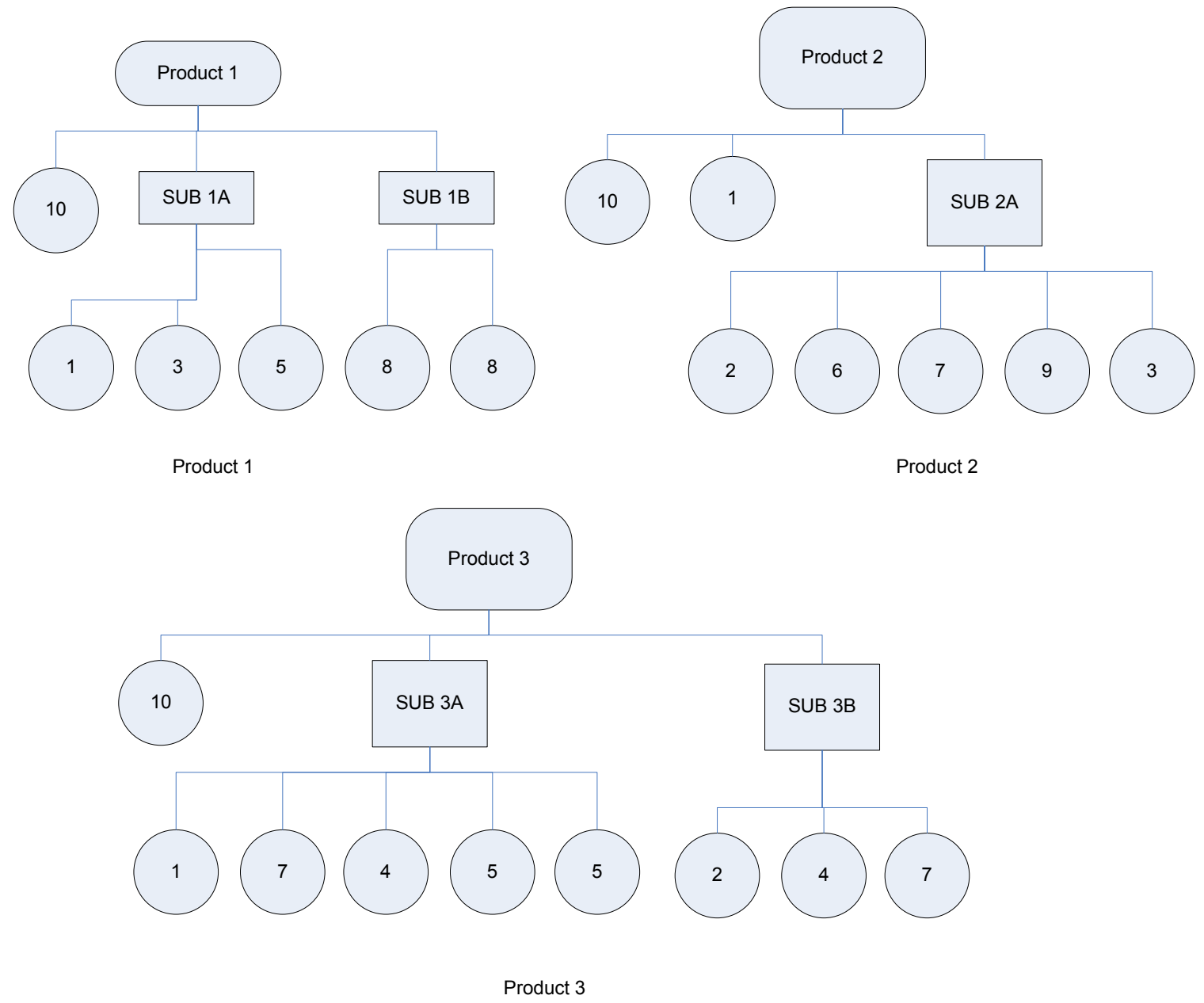

Figure 5: Assembly Structures of Products A, B and C

Following is the list of variables and the number of these variables used in the model based on Figure 5:

- $P_{p i t}^{F 3}-36$ decision variables

- $P_{s j, t}^{F 3}-60$ decision variables

- $P_{n k, t}^{F 2}-120$ decision variables

- $I_{p i, t}^{F u}-108$ decision variables 
- $\quad I_{s j, t}^{F 3}-60$ decision variables

- $\quad I_{n k, t}^{F u}-240$ decision variables

- $\quad I_{m r, t}^{F 1}-24$ decision variables

- $P_{m r, t}^{F 1}-24$ decision variables

- $\quad T_{m r, t}^{F 1-F 2}-24$ decision variables

- $\quad T_{n k, t}^{F 2-F 3}-120$ decision variables

- $\quad T_{p i, t}^{F 3-F 4}-36$ decision variables

- $\quad T_{p i, t}^{F 4-F 5}-36$ decision variables

- $S_{p i, t}^{F 5-F 6}-36$ decision variables

- $R_{p i, t}^{F 6-R 1}-36$ decision variables

- $T_{p i, t}^{R 1-R 3}-36$ decision variables

- $P_{p i, t}^{R 2}-36$ decision variables

- $P_{p i, t}^{R 3}-36$ decision variables

- $P_{s j, t}^{R 4}-60$ decision variables

- $P_{n k, t}^{R 4}-120$ decision variables

- $T_{s j, t}^{R 3-R 4}-60$ decision variables

- $T_{n k, t}^{R 3-R 6}-120$ decision variables

- $T_{s j, t}^{R 4-F 3}-60$ decision variables

- $T_{n k, t}^{R 4-F 3}-120$ decision variables 
- $T_{s j, t}^{R 4-R 5}-60$ decision variables

- $T_{n k, t}^{R 4-R 5}-120$ decision variables

- $T_{s j, t}^{R 4-R 6}-60$ decision variables

- $T_{n k, t}^{R 4-R 6}-120$ decision variables

- $T_{s j, t}^{R 5-F 3}-60$ decision variables

- $P_{s j, t}^{R 6}-60$ decision variables

- $P_{n k, t}^{R 6}-120$ decision variables

- $\quad I_{p i, t}^{R v}-144$ decision variables

- $I_{p i, t}^{R 3}-36$ decision variables

- $I_{s j, t}^{R 3}-60$ decision variables

- $I_{n k, t}^{R 3}-120$ decision variables

- $I_{s j, t}^{R 4}-60$ decision variables

- $I_{n k, t}^{R 4}-120$ decision variables

- $I_{s j, t}^{R 6}-60$ decision variables

- $I_{n k, t}^{R 6}-120$ decision variables

The total number of decision variables in the model is 2928.

Following is the list of constraints and the number of these constraints used in the model based on Figure 5:

Inventory constraints for materials for materials supplier -48 constraints 
Inventory constraints for materials for parts supplier -48 constraints Inventory constraints for parts for parts supplier - 240 constraints Inventory constraints for products for manufacturer -72 constraints Inventory constraints for subassemblies for manufacturer -180 constraints Inventory constraints for parts for manufacturer -240 constraints Inventory constraints for products for distributor -72 constraints Inventory constraints for products for retailer -72 constraints Inventory constraints for products for collection facility -72 constraints Inventory constraints for products for refurbishing facility -72 constraints Inventory constraints for parts for disassembly facility -480 constraints Inventory constraints for subassemblies for disassembly facility -240 constraints Inventory constraints for products for disassembly facility -72 constraints Inventory constraints for parts for testing/remanufacturing facility -240 constraints Inventory constraints for subassemblies for testing/remanufacturing facility -120 constraints

Inventory constraints for parts for disposal locations -240 constraints Inventory constraints for subassemblies for disposal locations -120 constraints Inventory constraints for parts for recycling facility -240 constraints Inventory constraints for subassemblies for recycling facility - 120 constraints Demand of raw materials by parts supplier -24 constraints Demand of parts by manufacturer -120 constraints Demand of products by distributor -36 constraints Demand of products by retailer -36 constraints 
Demand of products by consumer -36 constraints

Non negativity - 3984 constraints.

The total number of constraints in the model is 4634

The model is solved using commercially available optimization software, LINGO version 9.0. The model includes three products and their respective subassemblies and parts. One facility for each of the members in the supply chain has been considered. The model can be further extended to more number of products and facility types depending upon the problem considered. 


\section{CHAPTER V - MODEL RESULTS}

\subsection{LINGO}

As presented in Chapter 4, a non-preemptive goal programming approach has been used to define the mathematical model. To solve large size mathematical models there are various commercially available software, for example MPL, LINDO, LINGO etc. The mathematical model for this research is coded and solved in "LINGO", version 10.0, www.lindo.com. The base version includes the Primal and Dual Simplex solvers, which incorporate numerous enhancements for maximum speed and robustness. The consolidated objective (goal) of the model is to minimize weighted sum of the positive or negative deviations of the all the goals considered in the model. Tables 2-30 (Appendix E) show the all the variable values and the total profit values for the various members of the supply chain. For each of the members of the supply chain the first table includes the values of the variables defined in the mathematical model and the second table includes the profits generated by a member of a supply chain in each of the time periods. The first period profit for each of the members came out to be negative due to the assumption that there is no demand of the products in period 1. The respective profit tables help a particular member to make decision on the parameter values that need to be modified to increase the profits. The model also gives interesting results when solved using one individual member's objective of a consolidated objective of a set of members. 
Table 2: Profit values by period for all members of supply chain

\begin{tabular}{|c|c|c|c|c|c|c|c|c|c|c|}
\hline \multirow{2}{*}{ Period } & \multicolumn{9}{|c|}{ Profit } \\
\cline { 2 - 11 } & $\mathbf{F 1}$ & $\mathbf{F 2}$ & $\mathbf{F 3}$ & $\mathbf{F 4}$ & $\mathbf{F 5}$ & $\mathbf{R 1}$ & $\mathbf{R 2}$ & $\mathbf{R 3}$ & $\mathbf{R 4}$ & $\mathbf{R 5}$ \\
\hline $\mathbf{1}$ & -180000 & -1371651 & -930000 & -240000 & -240000 & -24000 & -24000 & -60088 & -70000 & -70000 \\
\hline $\mathbf{2}$ & 356497 & 1973623 & 5153613.2 & 1404587 & 2696550 & 8986 & 9960 & -4849 & 8992 & 10992 \\
\hline $\mathbf{3}$ & 356497 & 1973758 & 5008711.6 & 1404670 & 2696550 & 9004 & 9944 & 2431 & 8995 & 11004 \\
\hline $\mathbf{4}$ & 356504 & 1973729 & 4602858 & 1404565 & 2696558 & 9000 & 9976 & 8985 & 8992 & 10987 \\
\hline $\mathbf{5}$ & 356483 & 1973747 & 4515791.8 & 1404670 & 2696558 & 9000 & 9968 & 9008 & 8991 & 10994 \\
\hline $\mathbf{6}$ & 356496 & 1973690 & 4606154.8 & 1404662 & 2696558 & 9000 & 9936 & 9000 & 8923 & 11002 \\
\hline $\mathbf{7}$ & 356504 & 1973746 & 4484877.6 & 1404670 & 2696558 & 9002 & 9956 & -4512 & 8981 & 11011 \\
\hline $\mathbf{8}$ & 356535 & 1973744 & 4387216.8 & 1404670 & 2696558 & 9004 & 9968 & 20959 & 9009 & 11008 \\
\hline $\mathbf{9}$ & 356498 & 1973718 & 4494742.8 & 1404565 & 2696550 & 9004 & 9912 & 8998 & 8998 & 11008 \\
\hline $\mathbf{1 0}$ & 356512 & 1973715 & 4592459.8 & 1404565 & 2696550 & 9006 & 9968 & -31495 & 8999 & 10999 \\
\hline $\mathbf{1 1}$ & 356499 & 1973732 & 4339680.8 & 1404670 & 2696550 & 8996 & 9972 & 49514 & 8999 & 11010 \\
\hline $\mathbf{1 2}$ & 356502 & 1973732 & 4495414.6 & 1404662 & 2696550 & 8988 & 9956 & 8957 & 9001 & 11002 \\
\hline \multirow{2}{*}{ Total Profit } & $\mathbf{3 7 4 1 5 2 7}$ & $\mathbf{2 0 3 3 9 2 8 3}$ & $\mathbf{4 9 7 5 1 5 2 1 . 8}$ & $\mathbf{1 5 2 1 0 9 5 6}$ & $\mathbf{2 9 4 2 2 0 9 0}$ & $\mathbf{7 4 9 9 0}$ & $\mathbf{8 5 5 1 6}$ & $\mathbf{1 6 9 0 8}$ & $\mathbf{2 8 8 8 0}$ & $\mathbf{5 1 0 1 7}$ \\
\cline { 2 - 10 } & $\mathbf{3 . 7 4}$ Million & $\mathbf{2 0 . 3 4}$ Million & $\mathbf{4 9 . 7 5}$ Million & $\mathbf{1 5 . 2 1}$ Million & $\mathbf{2 9 . 4 2}$ Million & $\mathbf{7 4 K}$ & $\mathbf{8 5 K}$ & $\mathbf{1 6 K}$ & $\mathbf{2 8 K}$ & $\mathbf{5 1 K}$ \\
\hline
\end{tabular}


Table 3: Comparison of results with the change in weights of different goals in the model for Constant Demand

\begin{tabular}{|c|c|c|c|c|c|c|c|c|c|c|c|}
\hline \multirow{2}{*}{ Weights } & \multirow{2}{*}{ Solution } & \multicolumn{10}{|c|}{ Profit } \\
\hline & & F1 & $\mathrm{F} 2$ & F3 & F4 & F5 & R1 & R2 & R3 & $\mathrm{R} 4$ & R5 \\
\hline $\begin{array}{l}\mathrm{WF} 1=10000, \mathrm{WF} 2=, 10000, \mathrm{WF} 3= \\
10000000, \mathrm{WF} 4=10000, \mathrm{WF} 5= \\
10000, \\
\mathrm{WR} 1=100, \mathrm{WR} 2=100, \mathrm{WR} 3=100, \\
\mathrm{WR} 4=100, \mathrm{WR} 5=100\end{array}$ & Feasible & $3.74 \mathrm{M}$ & $20.34 \mathrm{M}$ & $49.75 \mathrm{M}$ & $15.21 \mathrm{M}$ & $29.42 \mathrm{M}$ & $74 \mathrm{~K}$ & $85 \mathrm{~K}$ & $16 \mathrm{~K}$ & $28 \mathrm{~K}$ & $51 \mathrm{~K}$ \\
\hline $\begin{array}{l}\mathrm{WF} 1=10000, \mathrm{WF} 2=, 10000, \mathrm{WF} 3= \\
10000, \mathrm{WF} 4=10000000, \mathrm{WF} 5= \\
10000, \\
\mathrm{WR} 1=100, \mathrm{WR} 2=100, \mathrm{WR} 3=100, \\
\mathrm{WR} 4=100, \mathrm{WR} 5=100\end{array}$ & Feasible & $3.62 \mathrm{M}$ & $17.41 \mathrm{M}$ & $45.64 \mathrm{M}$ & $17.4 \mathrm{M}$ & $30.72 \mathrm{M}$ & $74 \mathrm{~K}$ & $83 \mathrm{~K}$ & $16 \mathrm{~K}$ & $24 K$ & $46 \mathrm{~K}$ \\
\hline $\begin{array}{l}\mathrm{WF} 1=10000, \mathrm{WF} 2=, 10000, \mathrm{WF} 3= \\
10000, \mathrm{WF} 4=10000, \mathrm{WF} 5= \\
10000000, \\
\mathrm{WR} 1=100, \mathrm{WR} 2=100, \mathrm{WR} 3=100, \\
\mathrm{WR} 4=100, \mathrm{WR} 5=100\end{array}$ & Feasible & $3.22 \mathrm{M}$ & $18.15 \mathrm{M}$ & $43.24 \mathrm{M}$ & $13.41 \mathrm{M}$ & $32.27 \mathrm{M}$ & $69 \mathrm{~K}$ & $81 \mathrm{~K}$ & $19 \mathrm{~K}$ & $26 \mathrm{~K}$ & $49 \mathrm{~K}$ \\
\hline
\end{tabular}




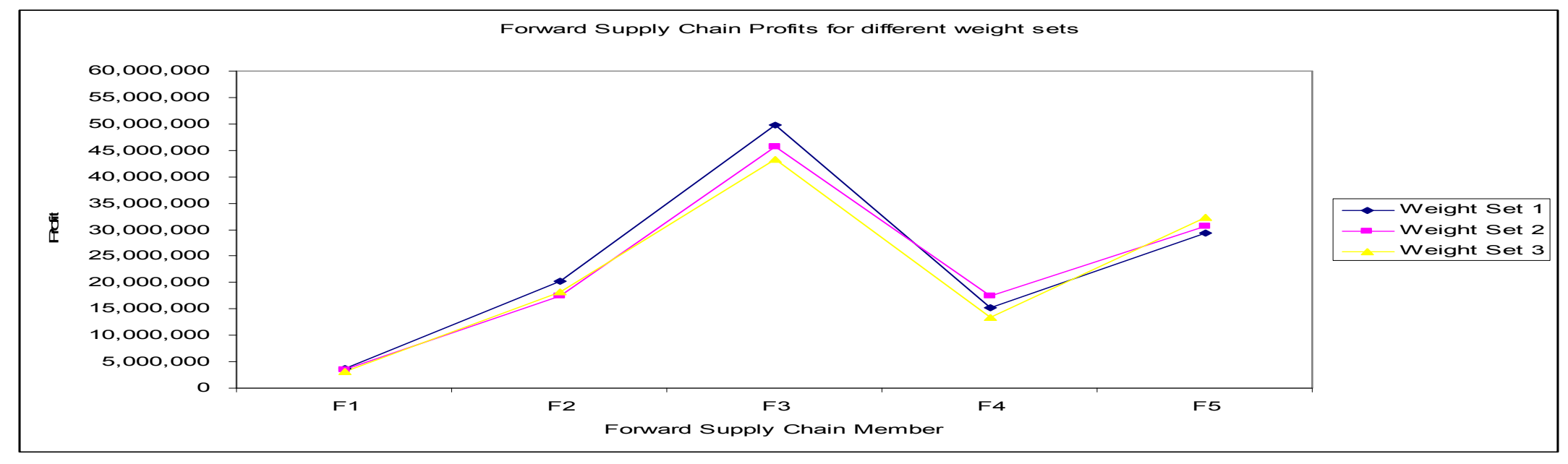

Figure 6: Comparison of profits for constant demand with different weight sets

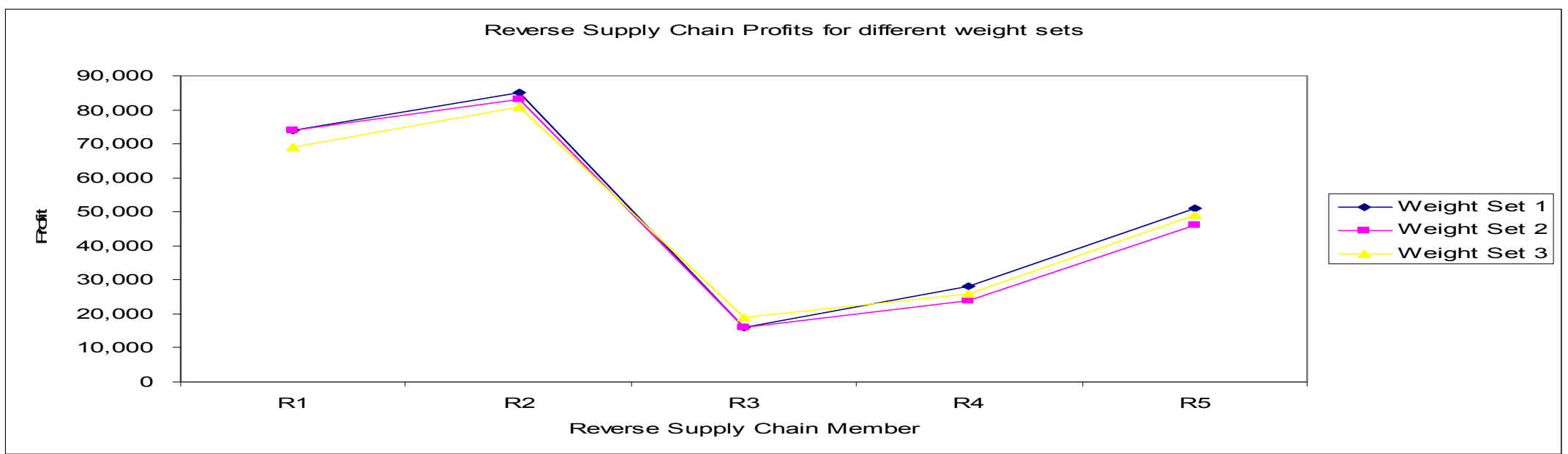

Figure 7: Comparison of profits for constant demand with different weight sets 
Table 4: Comparison of results with the change in weights of different goals in the model for Variable Demand

\begin{tabular}{|c|c|c|c|c|c|c|c|c|c|c|c|}
\hline \multirow{2}{*}{ Weights } & \multirow{2}{*}{ Solution } & \multicolumn{10}{|c|}{ Profit } \\
\hline & & F1 & F2 & F3 & F4 & F5 & $\mathrm{R} 1$ & R2 & R3 & $\mathrm{R} 4$ & R5 \\
\hline $\begin{array}{l}\mathrm{WF} 1=10000, \mathrm{WF} 2=, 10000, \mathrm{WF} 3= \\
10000000, \mathrm{WF} 4=10000, \mathrm{WF} 5=10000, \\
\mathrm{WR} 1=100, \mathrm{WR} 2=100, \mathrm{WR} 3=100, \\
\mathrm{WR} 4=100, \mathrm{WR} 5=100\end{array}$ & Feasible & $6.42 \mathrm{M}$ & $26.92 \mathrm{M}$ & $59.71 \mathrm{M}$ & $18.65 \mathrm{M}$ & $33.52 \mathrm{M}$ & $103 \mathrm{~K}$ & $96 \mathrm{~K}$ & $23 \mathrm{~K}$ & $38 \mathrm{~K}$ & $71 \mathrm{~K}$ \\
\hline $\begin{array}{l}\mathrm{WF} 1=10000, \mathrm{WF} 2=, 10000, \mathrm{WF} 3= \\
10000, \mathrm{WF} 4=10000000, \mathrm{WF} 5=10000, \\
\mathrm{WR} 1=100, \mathrm{WR} 2=100, \mathrm{WR} 3=100, \\
\mathrm{WR} 4=100, \mathrm{WR} 5=100\end{array}$ & Feasible & $6.05 \mathrm{M}$ & $27.65 \mathrm{M}$ & $56.6 \mathrm{M}$ & $21.47 \mathrm{M}$ & $29.15 \mathrm{M}$ & $97 \mathrm{~K}$ & $89 \mathrm{~K}$ & $26 \mathrm{~K}$ & $36 \mathrm{~K}$ & $68 \mathrm{~K}$ \\
\hline $\begin{array}{l}\mathrm{WF} 1=10000, \mathrm{WF} 2=, 10000, \mathrm{WF} 3= \\
10000, \mathrm{WF} 4=10000, \mathrm{WF} 5=10000000, \\
\mathrm{WR} 1=100, \mathrm{WR} 2=100, \mathrm{WR} 3=100, \\
\mathrm{WR} 4=100, \mathrm{WR} 5=100\end{array}$ & Feasible & $6.17 \mathrm{M}$ & $27.54 \mathrm{M}$ & $58.9 \mathrm{M}$ & $14.9 \mathrm{M}$ & $36.33 \mathrm{M}$ & $99 \mathrm{~K}$ & $93 \mathrm{~K}$ & $22 \mathrm{~K}$ & $35 \mathrm{~K}$ & $69 \mathrm{~K}$ \\
\hline
\end{tabular}




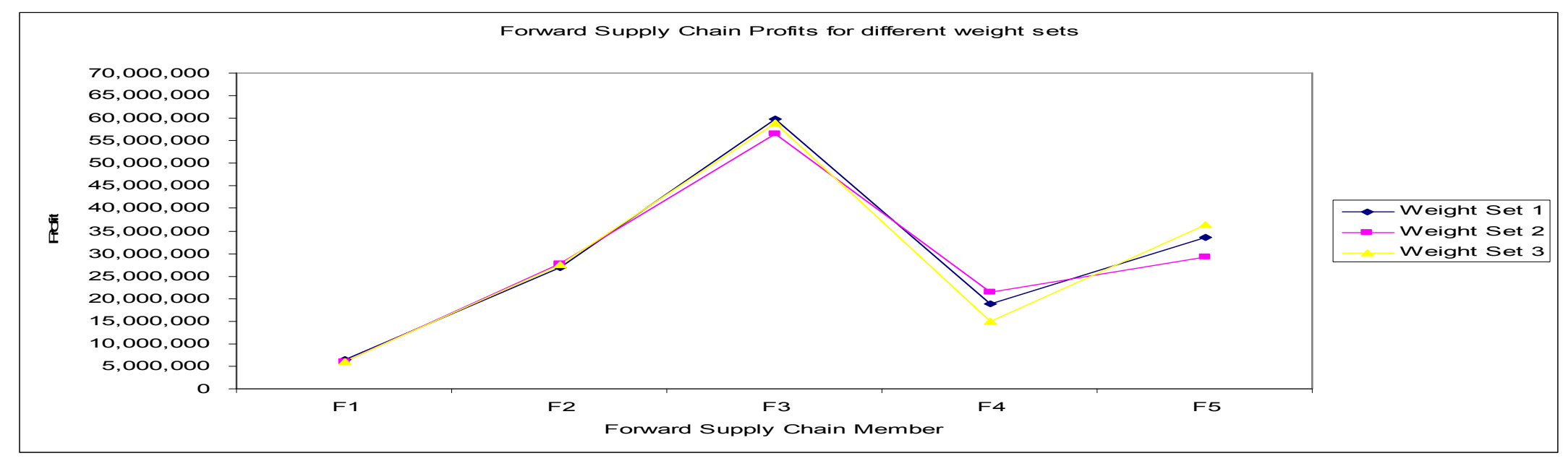

Figure 8: Comparison of profits for variable demand with different weight sets

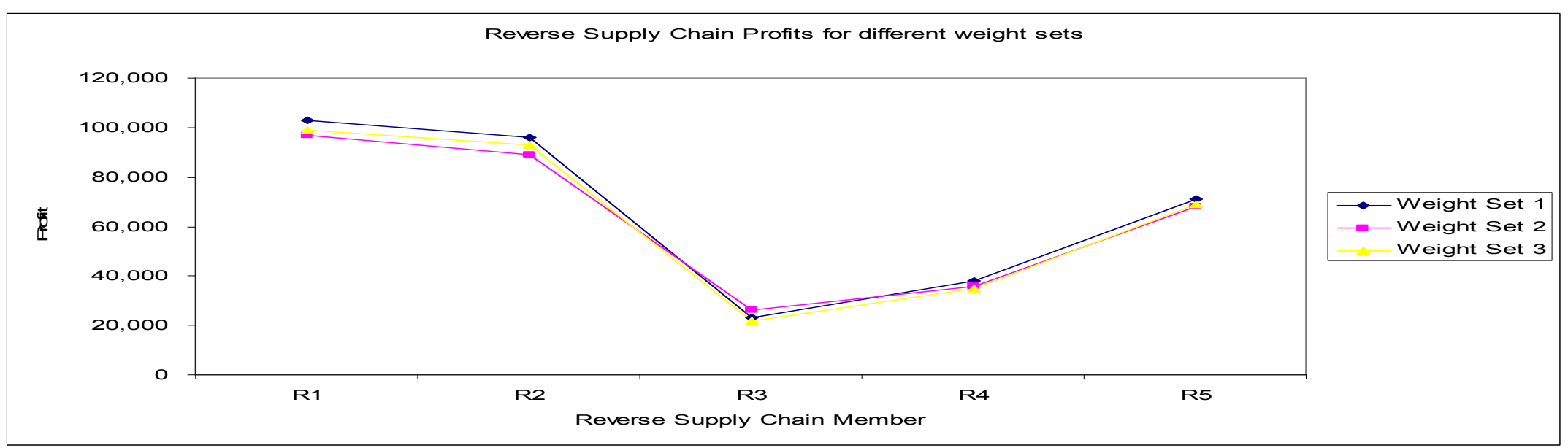

Figure 9: Comparison of profits for variable demand with different weight sets 
Table 2 shows profit values of all the members in the supply chain. Table 3 shows the variations in profit values on changing the weights of the goals in the mathematical model with constant demand. Table 4 shows the variations in profit values on changing the weights of the goals in the mathematical model with variable demand. As seen in tables 3 and 4, the profit values improve when the weight associated with the goal is improved. This is in accordance with the fundamentals of preemptive goal programming. Appendix E (Table 5-32) shows profit values for each of the supply chain member in each period.

\subsection{Applications of the GP Model}

The major application of the GP model will be for a company representing all or majority of the members of the supply chain i.e., a company involved in all or majority of operations of the closed loop supply chain. The decision maker can run the model from the perspective of different members and develop the company's overall strategy comparing the different outputs. For example, the company can look at the profits achieved from different reverse logistics operations by giving large weights to the members of reverse supply chain and analyze the effects on other operations of supply chain. One scenario might be that the company is able to modify their forward supply chain members planning strategies while improving the goals of reverse supply chain.

This research will be a useful contribution in the field of collaborative planning also. Collaborative planning addresses supply planning and demand fulfillment decisionmaking among all the players belonging to a company's supply chain network. 
Information shared between members of supply chain aids in planning and satisfying customer demands through a supportive system of shared information. This allows for continuous updating of inventory and upcoming requirements, making the end-to-end supply chain process more efficient. Each of the members of the supply chain can run the model from their perspective and define their planning strategies to maximize their benefits. In the presence of clashing planning strategies, two members of the supply chain will need to come to a mutual compromise which is equally beneficial for both the members. Another application in the area of collaborative planning can be for a particular member to explore other operations of the supply chain. For example, if a manufacturer would want to explore reverse logistics operations. By modifying its objectives and constraints as well as for the operations the manufacturer is interested in, the manufacturer can see different aspects of getting involved into those operations. 


\section{CHAPTER VI}

\section{CONCLUSIONS AND FUTURE RESEARCH}

This chapter is divided into two sections. The first section consists of conclusions about the proposed mathematical model and the solution methodology developed in this dissertation. The second section proposes possible future research.

\section{A. Conclusions}

The objective of this dissertation was to develop and illustrate an optimization model that can be used as a decision making tool for different members of supply chain for analyzing the target values of the objectives they tries to achieve. Various approaches have been used to solve the problem at single product level. However, no dominant approach has been reported for solving the problem involving multiple products, subassemblies, parts and materials. Each of the members in the forward supply chain has an objective of maximizing their individual profits with the required production planning and inventory control processes. The reverse supply chain is dependent on the output from the forward supply chain, i.e. return products. Also there are more output uncertainties from different members of reverse supply chain than forward supply chain i.e. the quantity of the products returned in various periods of planning horizon, quality of 
the products received, lead times of the products returned, and demand of the refurbished/remanufactured parts, subassemblies, and products.

In order to solve the optimization model, we proposed a goal-programming approach. The algorithm is coded in LINGO, version 10.0. The values of parameters have been assumed in the absence of actual data. The model output gives the deviational variable values based on the values of the parameters input in the model. The values of the deviational variables (positive or negative) help a decision maker to analyze the model. Looking at these values, the decision maker can decide that by changing the values of which parameters a member of the supply chain can achieve the target value. 


\section{B. Future Research}

The optimization model presented here for operational planning of a closed-loop supply chain using goal programming method has never been reported in literature. Since in this research we used preemptive goal programming approach, extending the problem using other solution methodologies would be interesting and worthwhile. Some of the opportunities for future research are as follows:

- Interactive goal programming can be used as one of the variant of goal programming approach. Interactive goal programming includes the involvement of the decision maker. In a standard goal programming process all parameters are set a priori, are unalterable and there is no modeler involvement in the solution process. Interactive goal programming brings the flexibility in the goal programming process with the involvement of decision maker.

- An application of goal-programming to optimize an Arena-based simulation of a closed-loop supply chain can be an extension to the proposed research. The Arenabased simulation modeling can be used to consider various stochastic aspects of the problem. The stochastic aspects include the quantity of the products returned in various periods of planning horizon, quality of the products received, lead times of the products returned, and demand of the refurbished products and parts. Since simulation modeling is a better approach than mathematical modeling when there are lots of uncertainties involved in the system, it will be interesting to see the application of goal programming to a simulation model.

- Another potential research extension can be application of the defined model in this research in the area of collaborative planning. The L-Shaped method can be applied 
to the problem considered in the research. L-Shaped method is an extension to stochastic mixed integer programs. Each player in the supply chain can be modeled associated with an independent sub-problem with its private objective function, e.g., suppliers trying to maximize the quantity of sales, OEMs trying to get material as soon as possible, etc. The players do not have to disclose all their lead-time, cost information and constraints. All players will be assumed to have a set of common variables that are communicated to the master problem: cost, lead-time, and quantity of the item that is transacted. An iterative method is developed during which feasibility and optimality cuts are added by the sub problems on the master problem. At each stage of the iteration, a list of current problems is maintained. 


\section{REFERENCES}

[1] Al-Aomar, R., (2002), A robust simulation based multi criteria optimization methodology. Proceedings of 2002 winter simulation conference, 1932-1939.

[2] Barros, A. I., Dekker, R., and Scholten, V., (1998), A two-level network for recycling sand: A case study. European Journal of Operational Research, 110, $199-214$.

[3] Beamon, B. M., and Fernandes, C., (2004), Supply chain network configuration for product recovery. Production planning and Control, 15(3), 270-281.

[4] Brito, M. P. de., Flapper, S. D. P., and Dekker, R., (2002), Reverse Logistics: a review of case studies. ERIM report series research in management.

[5] Clemen, R. T., (1997), Making Hard Decisions: An Introduction to Decision Analysis. Duxbury press.

[6] Das, S. K., Yedlarajiah, P., and Narendra, R., (2000), An approach for estimating the end-of life product disassembly effort and cost. International Journal of Production Research, 38(3), 657-673. 
[7] Dekker, R. and van der Laan E. A., (2002), "Inventory control in Reverse Logistics" in V.D.R. Guide Jr. and L.N. van Wassenhove (eds.), Closed-loop supply chains, Pittsburgh.

[8] Du, F. and Evans, G. W., "A Bi-Objective Reverse Logistics Network Analysis for Post-Sales Service” to appear in Computers and Operations Research.

[9] Ellspermann, S. J., Evans, G.W., and Basadur, M., (2007), "The Impact of Training on the Formulation of Ill-Structured Problems", Omega, 35(2), 221-236.

[10] E-waste guide (http://www.ewaste.ch/facts_and_figures/economics/quantities/)

[11] Fleischmann, M., Bloemhof-Ruwaard, J. M., Dekker, R., Van Der Laan, E., Van Nunen, J. A., and Van Wassenhove, L. N., (1997), Quantitative models for reverse logistics: a review. European Journal of Operational Research, 103, 1-17.

[12] Fleischmann, M., Krikke, H.R., Dekker R., and Flapper, S.D.P., (2000), A Characterization of Logistics Networks for Product Recovery. Omega, the international journal of Management Science, 28(6), 653-666 
[13] Fleischmann, M., Nunen, Jo A E E van, and Grave, B., (2003), Integrating Closed-Loop Supply Chains and Spare-Parts Management at IBM. Interfaces, 33(6), 44-56.

[14] Gugnor, A. and Gupta, S. M., (1997), An evaluation methodology for disassembly processes. Computers and Industrial Engineering, 33(1-2), 329-332.

[15] Gugnor, A. and Gupta, S. M., (1999), Issues in environmentally conscious manufacturing and product recovery: a survey. Computers and Industrial Engineering, 36, 811-853.

[16] Guide Jr, V. D., Kraus, M. E., and Srivastva, R., (1997), Scheduling policies for remanufacturing. International Journal of Production Research, 48, 187-204.

[17] Gupta, S. M. and Taleb, K. N., (1994), Scheduling disassembly. International Journal of Production Research, 3(8), 1857-1866.

[18] Hamilton, A., (2001), How do you junk your computer. Time, 157(6), 70-71.

[19] Hammond, D. and Beullens, P., (2006), Closed-loop supply chain network equilibrium under legislation, European Journal of Operational Research, 183(2), 895-908.

[20] Hax, A.C. and Candea, D., (1984), Production and Inventory Management. Prentice-Hall, Englewood Cliffs, NJ 
[21] Ignizio, J. P. (1976). Goal Programming and Extensions. Lexington Books, Massachusetts

[22] Jayaraman, V., Guide, JR, V., and Srivastava, R., (1999), A closed-loop logistics model for remanufacturing. Journal of the Operational Research Society, 50, 497508.

[23] Kara, S., Rugrungruang, F., and Kaebernisk, H., (2006). Simulation Modeling of Reverse Logistics Networks. International Journal of Production Economics, 106(1), 61-69.

[24] Kelle, P and Silver, E. A., (1989), Forecasting of Returns of Reusable Containers, Journal of Operations Management, 8, 17-35.

[25] Kongar, E. and Gupta, S. M., (2002), A multi-criteria decision making approach for disassembly-to-order systems, Journal of Electronics Manufacturing, 11(2), $171-183$.

[26] Krikke, H. R., Van Harten, A., and Schurr, P. C., (1999), Business case Oce: reverse logistic network re-design for copiers. OR Spektrum, 21, 381-409.

[27] Krikke, H., Bloemhof-Ruwaard, J. M., Van Wassenhove, L. N., (2001), Design of Closed-Loop supply chains: A production and return network for refrigerators. ERIM report series research in management. 
[28] Krikke, H., Pappis, C. P., Tsoulfas, G. T., and Bloemhof-Ruwaard, J. M., (2001) Design principles for Closed-Loop supply chains: Optimizing economic, logistic and environmental performance. ERIM report series research in management.

[29] Kroon, L., and Vrijens, G., (1995), Returnable containers: an example of reverse logistics. International Journal of Physical Distribution and Logistics Management, 25(2), 56-68.

[30] Lambert, A. J. D., (1997), Optimal disassembly of complex products. International journal of production research, 35 (9), $2509-2523$

[31] Lambert, A. J. D., (2003), Disassembly sequencing: a survey. International Journal of Production Research, 41(16), 3721-3759.

[32] Ravi, V., Shankar, R., and Tiwari, M.K., (2005), Analyzing alternatives in reverse logistics for end-of-life computers: ANP and balanced scorecard approach, Computers \& Industrial Engineering, 48, 327-356.

[33] Rogers, D. S., \& Tibben-Lembke, R. S., (1998), Going backwards: Reverse logistics trends and practices. Pittsburgh, PA: Reverse Logistics Executive Council: Center for Logistics Management.

[34] Schultmann, F., Zumkeller, M., and Rentz, O., (2005), Modeling reverse logistic tasks within closed-loop supply chains: An example from the automotive industry. European Journal of Operational Research, 1-18. 
[35] Sharma, M., (2004) Reverse logistics and environmental considerations in equipment leasing and asset management, PhD Dissertation. Georgia Institute of Technology, Atlanta GA.

[36] Sheu, J-B., Chou, Y-H., Hu, C-C., (2005), An integrated logistics operational model for green-supply chain management. Transportation Research, 41, 287313.

[37] Taleb, K. N., and Gupta, S. M., (1997), Disassembly of multiple product structures. Computers and Industrial Engineering, 32(4), 949-961.

[38] Tamiz, M., and Jones, D. F., (1997), Interactive frameworks for investigation of goal programming models: Theory and Practice. Journal of multi-criteria decision analysis, 6, 52-60.

[39] Teunter, R., Van Der Laan, E., Vlachos, D., (2002), Inventory strategies for systems with fast remanufacturing. ERIM report series research in management.

[40] Thierry, M., Salomon, M., Van Nunen, J., and Van Wassenhove, L. (1995). Strategic issues in product recovery management. California Management Review, 37(2), 114-135. 
[41] Thierry, M., (1997), An analysis of impact of product recovery management on manufacturing companies, $\mathrm{PhD}$ thesis. Erasmus University Rotterdam, The Netherlands.

[42] Veerkamolmal, P. and Gupta, S. M., (2002), A case-based reasoning approach for automating disassembly process planning. Journal of Intelligent Manufacturing, 13(1), 47-60.

[43] Vlachos, D., Georgiadis, P., and Iakovou, E., (2005), A system dynamics model for dynamic capacity planning of remanufacturing in closed-loop supply chains. Computers and Operations Research, 1-28.

\section{$\underline{\text { References from Websites }}$}

[44] Exporting Harm, High-Tech Trashing of Asia http://www.svtc.org/cleancc/pubs/technotrash.pdf

[45] Waste Electrical and electronic equipment, European Union http://europa.eu.int/comm/environment/waste/weee_index.htm

[46] RoHS Directive, http://www.rohsdirective.com/

[47] Japan File, By Richard Donovan http://www.japanfile.com/environment/features/electronic_waste.shtml 
[48] Electronic product stewardship Canada, http://www.epsc.ca/about.html

[49] Alberta Government, Environment Protection, http://www3.gov.ab.ca/env/waste/ewaste/index.html

[50] U.S Environmental Protection Agency, http://www.epa.gov

[51] Department of Environmental Protection, Maine http://www.maine.gov/dep/rwm/recycle/computerrecy.htm

[52] Massachusetts Recycling, http://www.mass.gov/dep/recycle/crt/crthome.htm

[53] Silicon Valley Toxics Coalition, http://www.svtc.org/cleancc/4ht_letters.htm

[54] Multiobjective programming, http://www.unc.edu/ provan/classes/OR211/lect10_multi.pdf 
APPENDICES 
APPENDIX A

LINGO Formulation for Goal Program 


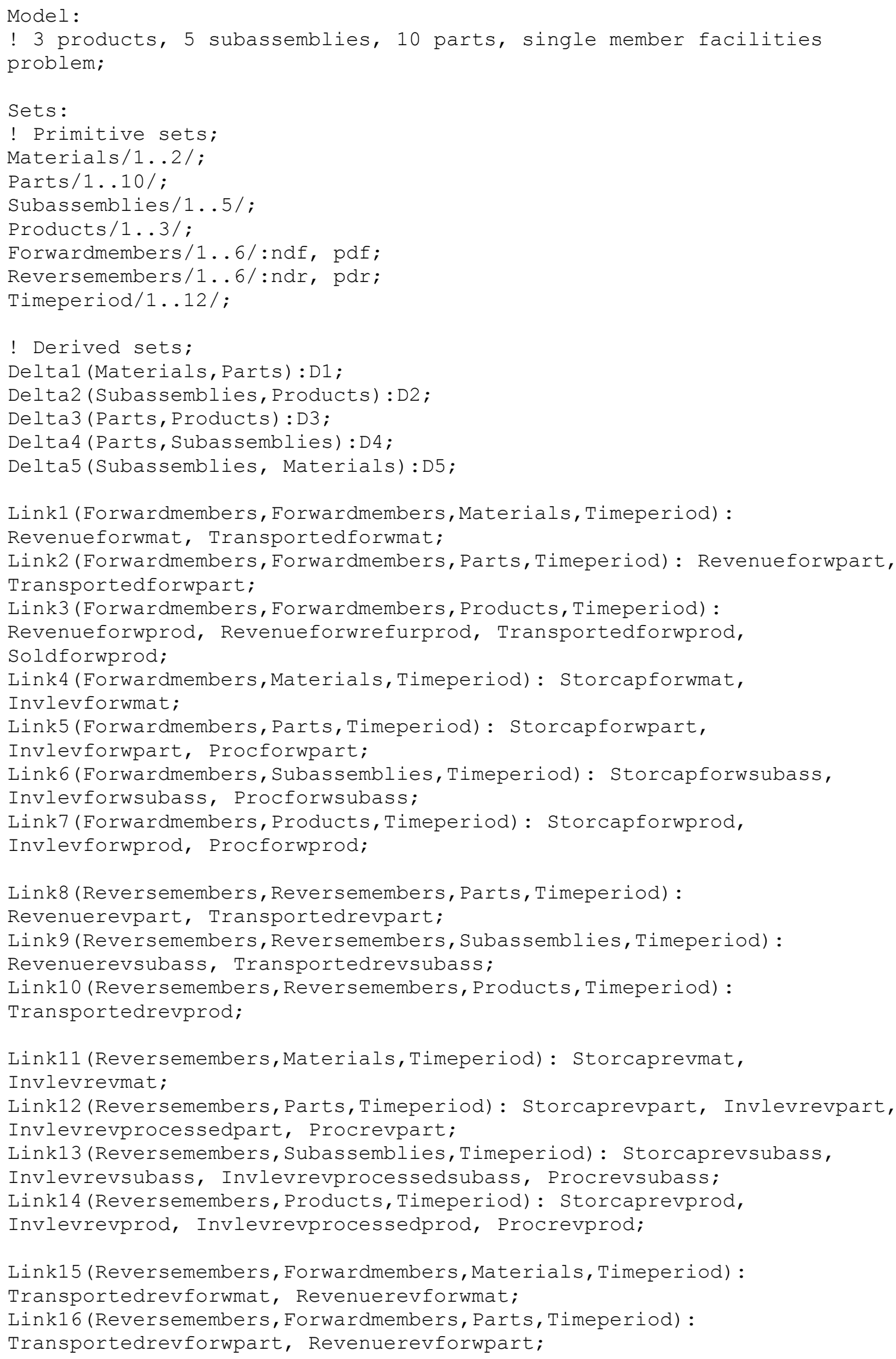


Link17 (Reversemembers, Forwardmembers, Subassemblies, Timeperiod) : Transportedrevforwsubass, Revenuerevforwsubass;

Link18 (Reversemembers, Forwardmembers, Products, Timeperiod) :

Transportedrevforwprod, Revenuerevforwprod;

Link19 (Products, Timeperiod): Demandprod, Returnprod;

Cost1 (Materials, Timeperiod): Costofmatproc, Costofmat, Costofmattrans, Costofmatstor;

Cost2 (Parts, Timeperiod) : Costofpartproc, Costofpartmfg,

Costofparttrans, Costofpartstor;

Cost3 (Products, Timeperiod): Costofprodproc, Costofprodmfg, Costofprodtrans, Costofprodstor;

Cost4 (Subassemblies, Timeperiod) : Costofsubassstor, Costofsubasstrans, Costofsubassproc;

Endsets

Data:

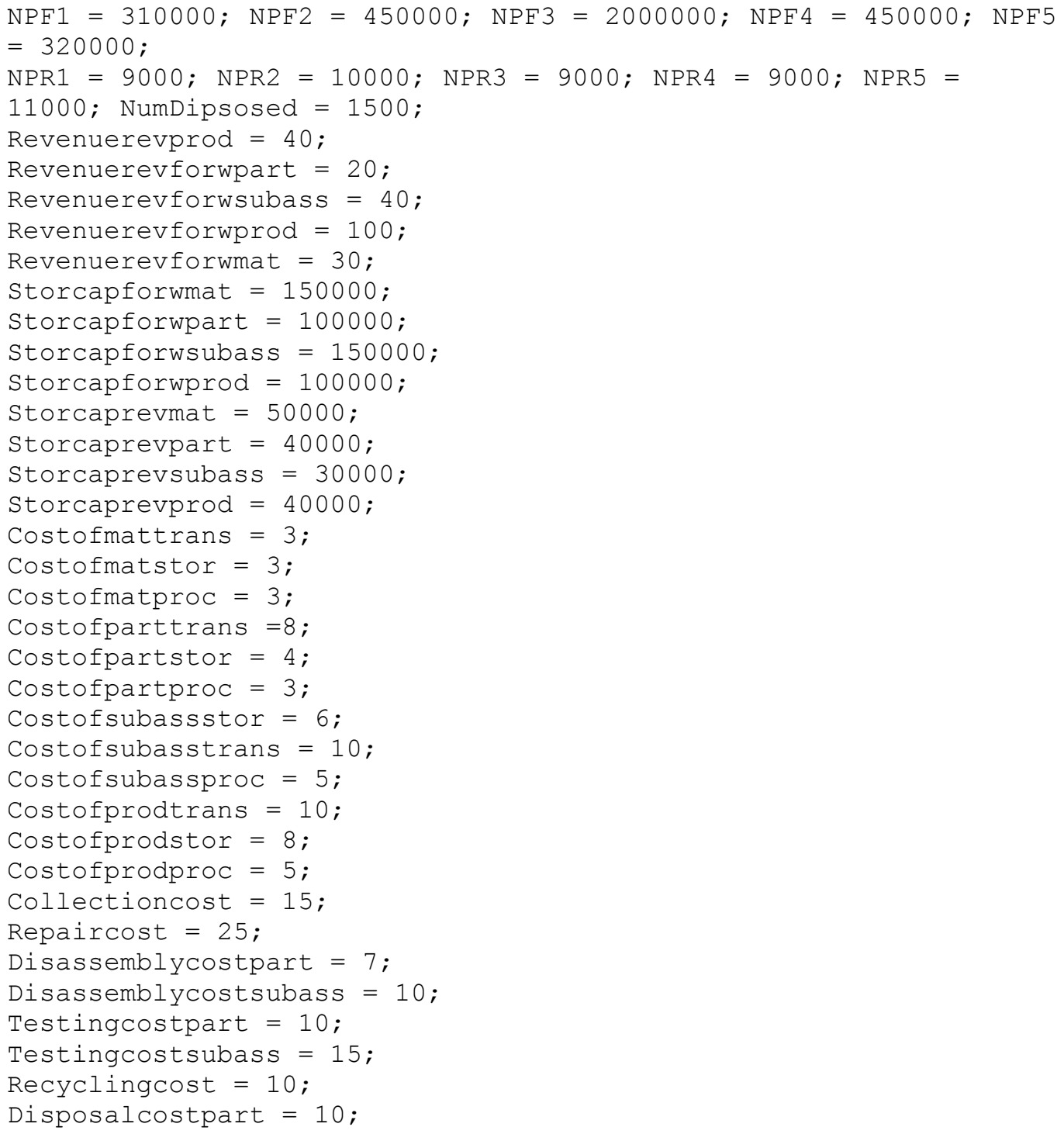




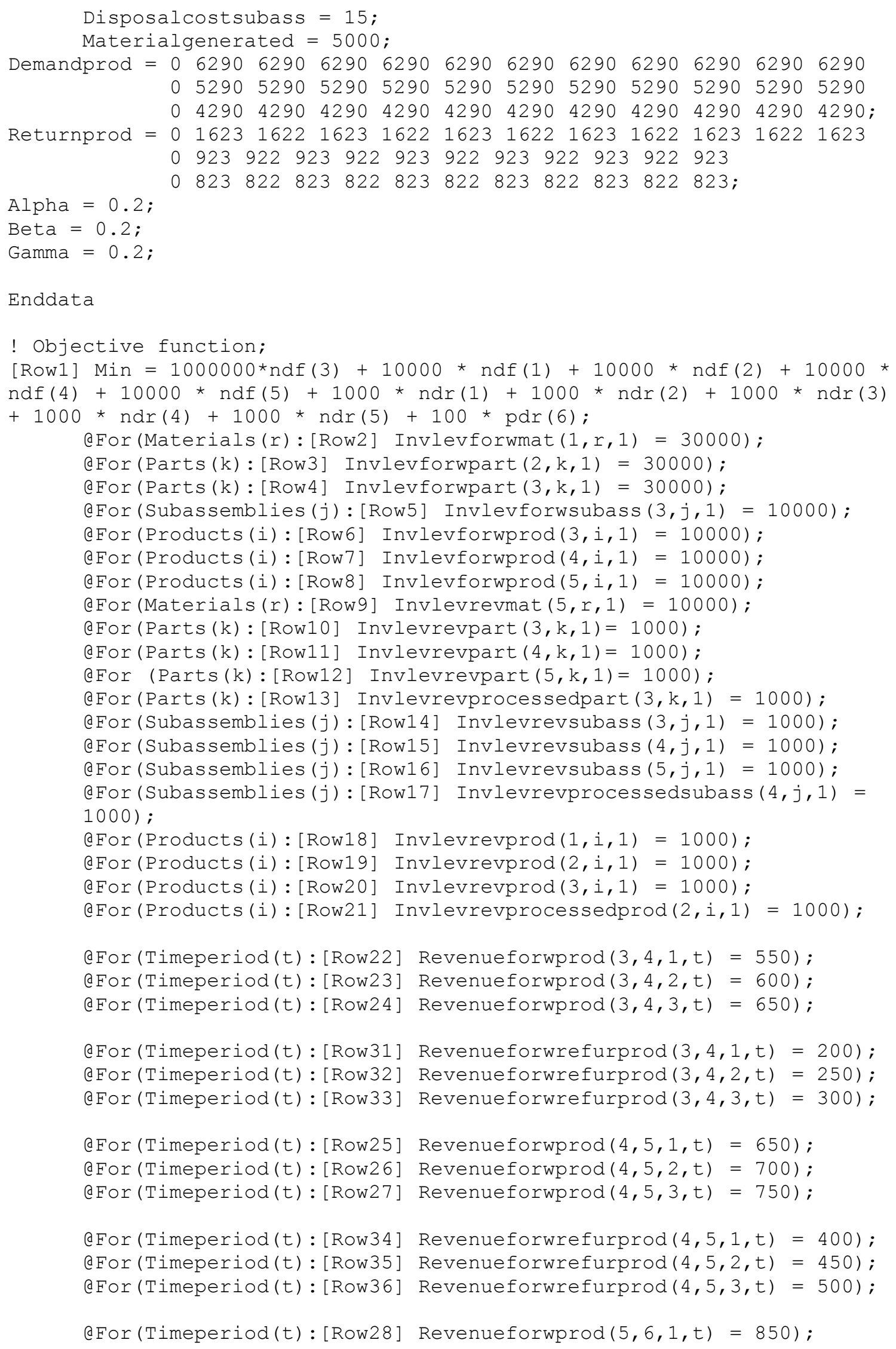


aFor (Timeperiod(t): [Row29]

aFor (Timeperiod (t) : [Row30]

@For (Timeperiod(t): [Row37]

@For (Timeperiod (t) : [Row38]

aFor (Timeperiod (t) : [Row39]

aFor (Timeperiod(t): [Row40]

aFor (Timeperiod (t) : [Row41]

aFor (Timeperiod (t) : [Row42]

aFor (Timeperiod (t) : [Row43]

aFor (Timeperiod(t) : [Row44]

aFor (Timeperiod (t) : [Row45]

@For (Timeperiod (t) : [Row46]

aFor (Timeperiod (t) : [Row47]

@For (Timeperiod (t) : [Row48]

@For (Timeperiod (t) : [Row49]

aFor (Timeperiod (t) : [Row50]

aFor (Timeperiod (t) : [Row51]

aFor (Timeperiod(t) : [Row52]

@For (Timeperiod (t) : [Row53]

aFor (Timeperiod (t) : [Row54]

aFor (Timeperiod (t) : [Row55]

aFor (Timeperiod (t) : [Row56]

@For (Timeperiod(t) : [Row57]

@For (Timeperiod (t) : [Row58]

aFor (Timeperiod(t): [Row59]

aFor (Timeperiod (t) : [Row60]

aFor (Timeperiod (t) : [Row61]

aFor (Timeperiod (t) : [Row62]

@For (Timeperiod(t) : [Row63]

aFor (Timeperiod (t) : [Row64]

@For (Timeperiod (t) : [Row65]

aFor (Timeperiod (t) : [Row66]

@For (Timeperiod(t): [Row67]

aFor (Timeperiod(t): [Row68]

aFor (Timeperiod(t) : [Row69]

aFor (Timeperiod (t) : [Row70]

aFor (Timeperiod (t) : [Row71]

aFor (Timeperiod (t) : [Row77]

aFor (Timeperiod (t) : [Row78]

aFor (Timeperiod (t) : [Row79]

aFor (Timeperiod (t) : [Row80]

aFor (Timeperiod (t) : [Row81]

@For (Timeperiod(t): [Row87]

@For (Timeperiod(t) : [Row88]

aFor (Timeperiod(t) : [Row89]

@For (Timeperiod (t) : [Row90]

aFor (Timeperiod (t) : [Row91]
Revenueforwprod $(5,6,2, t)=900)$;

Revenueforwprod $(5,6,3, t)=950)$;

Revenueforwrefurprod $(5,6,1, t)=600)$;

Revenueforwrefurprod $(5,6,2, t)=650)$;

Revenueforwrefurprod $(5,6,3, t)=700)$;

Revenueforwmat $(1,2,1, t)=30)$;

Revenueforwmat $(1,2,2, t)=35)$;

Revenueforwpart $(2,3,1, t)=50)$;

Revenueforwpart $(2,3,2, t)=55)$;

Revenueforwpart $(2,3,3, t)=60)$;

Revenueforwpart $(2,3,4, t)=65)$;

Revenueforwpart $(2,3,5, t)=70)$;

Revenueforwpart $(2,3,6, t)=75)$;

Revenueforwpart $(2,3,7, t)=80)$;

Revenueforwpart $(2,3,8, t)=85)$;

Revenueforwpart $(2,3,9, t)=90)$;

Revenueforwpart $(2,3,10, t)=95)$;

Revenuerevpart $(3,4,1, t)=20)$;

Revenuerevpart $(3,4,2, t)=22)$;

Revenuerevpart $(3,4,3, t)=24)$;

Revenuerevpart $(3,4,4, t)=26)$;

Revenuerevpart $(3,4,5, t)=28)$;

Revenuerevpart $(3,4,6, t)=30)$;

Revenuerevpart $(3,4,7, t)=32)$;

Revenuerevpart $(3,4,8, t)=34)$;

Revenuerevpart $(3,4,9, t)=36)$;

Revenuerevpart $(3,4,10, t)=38)$;

Revenuerevpart $(4,5,1, t)=22)$;

Revenuerevpart $(4,5,2, t)=24)$;

Revenuerevpart $(4,5,3, t)=26)$;

Revenuerevpart $(4,5,4, t)=28)$;

Revenuerevpart $(4,5,5, t)=30)$;

Revenuerevpart $(4,5,6, t)=32)$;

Revenuerevpart $(4,5,7, t)=34)$;

Revenuerevpart $(4,5,8, t)=36)$;

Revenuerevpart $(4,5,9, t)=38)$;

Revenuerevpart $(4,5,10, t)=40)$;

Revenuerevsubass $(3,4,1, t)=40)$;

Revenuerevsubass $(3,4,2, t)=44)$;

Revenuerevsubass $(3,4,3, t)=48)$;

Revenuerevsubass $(3,4,4, t)=52)$;

Revenuerevsubass $(3,4,5, t)=56)$;

Revenuerevsubass $(4,5,1, t)=45)$;

Revenuerevsubass $(4,5,2, t)=50)$;

Revenuerevsubass $(4,5,3, t)=55)$;

Revenuerevsubass $(4,5,4, t)=60)$;

Revenuerevsubass $(4,5,5, t)=65)$;

aFor(Timeperiod(t): [Row92] Costofmat $(1, t)=10)$;

@For(Timeperiod(t): [Row93] Costofmat $(2, t)=15)$; 


\begin{abstract}
@For (Timeperiod(t): [Row94] Costofpartmfg( $1, t)=5$ ); @For (Timeperiod(t): [Row95] Costofpartmfg $(2, t)=6)$; @For (Timeperiod(t): [Row96] Costofpartmfg $(3, t)=5)$; @For (Timeperiod(t): [Row97] Costofpartmfg $(4, t)=6)$; @For (Timeperiod(t): [Row98] Costofpartmfg $(5, t)=5)$; @For (Timeperiod(t): [Row99] Costofpartmfg $(6, t)=6)$; @For (Timeperiod(t): [Row100] Costofpartmfg $(7, t)=5)$; @For(Timeperiod(t): [Row101] Costofpartmfg $(8, t)=6)$; @For (Timeperiod(t): [Row102] Costofpartmfg $(9, t)=5)$; @For (Timeperiod(t): [Row103] Costofpartmfg $(10, t)=6)$;

@For(Timeperiod(t): [Row104] Costofprodmfg( $1, t)=100)$; @For (Timeperiod(t): [Row105] Costofprodmfg(2,t) = 150); @For (Timeperiod (t) : [Row106] Costofprodmfg(3,t) = 200);
\end{abstract}

[ROw107] $\mathrm{D} 1(1,1)=1 ; \mathrm{D} 1(1,2)=1 ; \mathrm{D} 1(1,3)=1 ; \mathrm{D} 1(1,4)=1 ; \mathrm{D} 1(1,5)=$ 1;

[Row108] $\mathrm{D} 1(1,6)=1 ; \mathrm{D} 1(1,7)=1 ; \mathrm{D} 1(1,8)=0 ; \mathrm{D} 1(1,9)=1 ; \mathrm{D} 1(1,10)=$ 0 ; [Row109] $\mathrm{D} 1(2,1)=0 ; \mathrm{D} 1(2,2)=0 ; \mathrm{D} 1(2,3)=0 ; \mathrm{D} 1(2,4)=0 ; \mathrm{D} 1(2,5)=$ 0 ; $[\operatorname{Row} 110] \mathrm{D} 1(2,6)=0 ; \mathrm{D} 1(2,7)=0 ; \mathrm{D} 1(2,8)=1 ; \mathrm{D} 1(2,9)=0 ; \mathrm{D} 1(2,10)=$ $1 ;$

$[\operatorname{Row} 111] \mathrm{D} 2(1,1)=1 ; \mathrm{D} 2(1,2)=0 ; \mathrm{D} 2(1,3)=0 ; \mathrm{D} 2(2,1)=1 ; \mathrm{D} 2(2,2)=$ 0 ; $[\operatorname{Row} 112] \mathrm{D} 2(2,3)=0 ; \mathrm{D} 2(3,1)=0 ; \mathrm{D} 2(3,2)=1 ; \mathrm{D} 2(3,3)=0 ; \mathrm{D} 2(4,1)=$ 0 ;

[Row113] $\mathrm{D} 2(4,2)=0 ; \mathrm{D} 2(4,3)=1 ; \mathrm{D} 2(5,1)=0 ; \mathrm{D} 2(5,2)=0 ; \mathrm{D} 2(5,3)=$ 1 ;

$[\operatorname{Row} 114] \mathrm{D} 3(1,1)=0 ; \mathrm{D} 3(2,1)=0 ; \mathrm{D} 3(3,1)=0 ; \mathrm{D} 3(4,1)=0 ; \mathrm{D} 3(5,1)=$ 0 ;

$[\operatorname{Row} 115] \mathrm{D} 3(6,1)=0 ; \mathrm{D} 3(7,1)=0 ; \mathrm{D} 3(8,1)=0 ; \mathrm{D} 3(9,1)=0 ; \mathrm{D} 3(10,1)=$ 1 ; $[\operatorname{Row} 116] \mathrm{D} 3(1,2)=1 ; \mathrm{D} 3(2,2)=0 ; \mathrm{D} 3(3,2)=0 ; \mathrm{D} 3(4,2)=0 ; \mathrm{D} 3(5,2)=$ 0 ; $[\operatorname{Row} 117] \mathrm{D} 3(6,2)=0 ; \mathrm{D} 3(7,2)=0 ; \mathrm{D} 3(8,2)=0 ; \mathrm{D} 3(9,2)=0 ; \mathrm{D} 3(10,2)=$ $1 ;$ [Row118] $\mathrm{D} 3(1,3)=0 ; \mathrm{D} 3(2,3)=0 ; \mathrm{D} 3(3,3)=0 ; \mathrm{D} 3(4,3)=0 ; \mathrm{D} 3(5,3)=$ 0 ; [Row119] $\mathrm{D} 3(6,3)=0 ; \mathrm{D} 3(7,3)=0 ; \mathrm{D} 3(8,3)=0 ; \mathrm{D} 3(9,3)=0 ; \mathrm{D} 3(10,3)=$ 1 ;

$[\operatorname{Row} 120] \mathrm{D} 4(1,1)=1 ; \mathrm{D} 4(2,1)=0 ; \mathrm{D} 4(3,1)=1 ; \mathrm{D} 4(4,1)=0 ; \mathrm{D} 4(5,1)=$ 1 ; $[\operatorname{Row} 121] \mathrm{D} 4(6,1)=0 ; \mathrm{D} 4(7,1)=0 ; \mathrm{D} 4(8,1)=0 ; \mathrm{D} 4(9,1)=0 ; \mathrm{D} 4(10,1)=$ 0 ; $[\operatorname{Row} 122] \mathrm{D} 4(1,2)=0 ; \mathrm{D} 4(2,2)=0 ; \mathrm{D} 4(3,2)=0 ; \mathrm{D} 4(4,2)=0 ; \mathrm{D} 4(5,2)=$ 0 ;

[Row123] $\mathrm{D} 4(6,2)=0 ; \mathrm{D} 4(7,2)=0 ; \mathrm{D} 4(8,2)=2 ; \mathrm{D} 4(9,2)=0 ; \mathrm{D} 4(10,2)=$ 0 ; $[\operatorname{ROw} 124] \mathrm{D} 4(1,3)=0 ; \mathrm{D} 4(2,3)=1 ; \mathrm{D} 4(3,3)=1 ; \mathrm{D} 4(4,3)=0 ; \mathrm{D} 4(5,3)=$ 0 ;

$[\operatorname{Row} 125] \quad \mathrm{D} 4(6,3)=1 ; \mathrm{D} 4(7,3)=1 ; \mathrm{D} 4(8,3)=0 ; \mathrm{D} 4(9,3)=1 ; \mathrm{D} 4(10,3)=$ 0 ; 


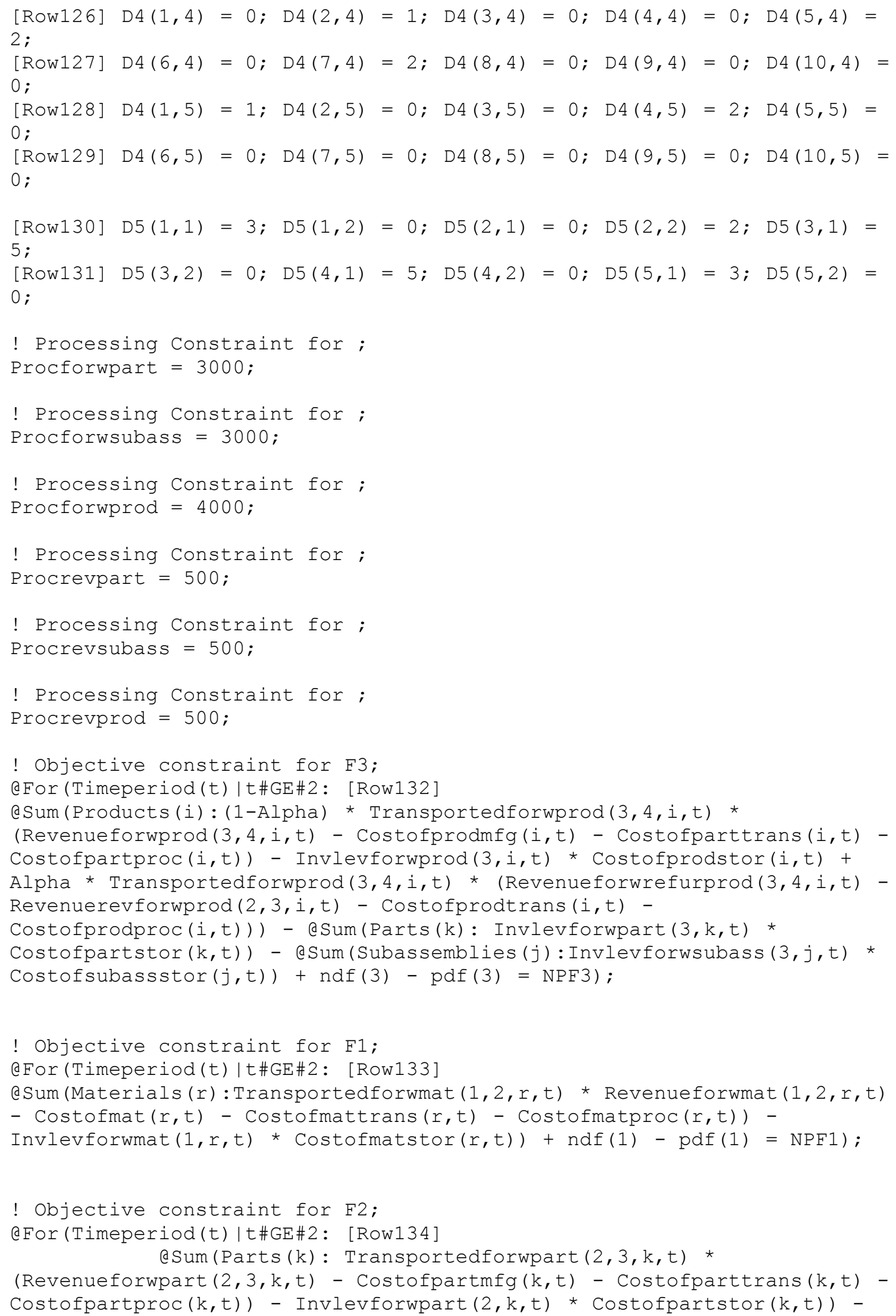


@Sum (Materials $(r)$ : Invlevforwmat $(2, r, t)$ *

Costofmatstor $(r, t))+\operatorname{ndf}(2)-\operatorname{pdf}(2)=\mathrm{NPF} 2)$;

! Objective constraint for F4;

@For (Timeperiod (t)|t\#GE\#2: [Row135]

aSum (Products (i) : (1-Beta) * Transportedforwprod $(4,5, i, t)$ *

(Revenueforwprod $(4,5, i, t)$ - Revenueforwprod $(3,4, i, t)-$

Costofprodtrans (i,t) - Costofprodproc(i,t)) - Invlevforwprod $(4, i, t)$ *

Costofprodstor $(i, t)$ + Beta * Transportedforwprod $(4,5, i, t)$ *

(Revenueforwrefurprod $(4,5, i, t)$ - Revenueforwrefurprod $(3,4, i, t)$ -

Costofprodtrans (i,t) - Costofprodproc (i,t))) + ndf(4) - pdf(4) = NPF4);

! Objective constraint for F5;

aFor(Timeperiod (t)|t\#GE\#2: [Row136]

(Sum (Products (i) : (1-Gamma) * Soldforwprod $(5,6, i, t)$ *

(Revenueforwprod $(5,6, i, t)$ - Revenueforwprod $(4,5, i, t))$ -

Invlevforwprod $(5, i, t)$ * Costofprodstor $(i, t)$ + Gamma *

Soldforwprod $(5,6, i, t)$ * (Revenueforwrefurprod $(5,6, i, t)$ -

Revenueforwrefurprod $(4,5, i, t)$ - Costofprodtrans $(i, t)$ -

Costofprodproc $(i, t)))+\operatorname{ndf}(5)-\operatorname{pdf}(5)=\operatorname{NPF} 5)$;

! Objective constraint for R1;

@For (Timeperiod (t)|t\#GE\#2: [Row137]

@Sum (Products (i): (Transportedrevprod $(1,2, i, t)+$

Transportedrevprod $(1,3, i, t)) *$ (Revenuerevprod - Collectioncost Costofprodtrans (i, t) - Costofprodproc (i, t)) - Invlevrevprod $(1, i, t)$ *

Costofprodstor $(i, t))+\operatorname{ndr}(1)-\operatorname{pdr}(1)=\operatorname{NPR} 1)$;

! Objective constraint for R2;

aFor (Timeperiod (t)|t\#GE\#2: [Row138]

(Sum (Products (i) : Transportedrevforwprod $(2,3, i, t)$ *

(Revenuerevforwprod $(2,3, i, t)$ - Repaircost - Costofprodtrans $(i, t)$ Costofprodproc $(i, t))$ - Invlevrevprod $(2, i, t)$ * Costofprodstor $(i, t))+$ $\operatorname{ndr}(2)-\operatorname{pdr}(2)=$ NPR2);

! Objective constraint for R3;

@For(Timeperiod(t)|t\#GE\#2: [Row139]

@Sum (Subassemblies (j) : Transportedrevsubass $(3,4, j, t)$ * (Revenuerevsubass (3

$, 4, j, t)$ - Disassemblycostsubass - Costofsubasstrans $(j, t)$ -

Costofsubassproc $(j, t))$ - Invlevrevsubass $(3, j, t)$ * Costofsubassstor $(j, t)-$ Transportedrevsubass $(3,6, j, t) *$ Disposalcostsubass $)+$

@Sum (Parts (k) : Transportedrevpart $(3,4, k, t)$ * (Revenuerevpart $(3,4, k, t)$ -

Disassemblycostpart - Costofparttrans $(k, t)$ - Costofpartproc $(k, t))$ -

Invlevrevpart $(3, k, t)$ * Costofpartstor $(k, t)-\operatorname{Transportedrevpart~}(3,6, k, t)$

* Disposalcostpart) - eSum(Products(i): Invlevrevprod $(3, i, t)$ *

Costofprodstor $(i, t))+\operatorname{ndr}(3)-\operatorname{pdr}(3)=$ NPR3);

! Objective constraint for R4;

aFor (Timeperiod(t)|t\#GE\#2: [Row140] 
@Sum (Subassemblies (j) : Transportedrevsubass ( $4,5, j, t)$ * (Revenuerevsubass ( 4 $, 5, j, t)$ - Testingcostsubass - Costofsubasstrans $(j, t)$ -

Costofsubassproc $(j, t))$ + Transportedrevforwsubass $(4,3, j, t)$ *

(Revenuerevforwsubass $(4,3, j, t)$ - Testingcostsubass -

Costofsubasstrans $(j, t)$ - Costofsubassproc $(j, t))-\operatorname{Invlevrevsubass}(4, j, t)$

* Costofsubassstor $(j, t)$ - Transportedrevsubass $(4,6, j, t)$ *

Disposalcostsubass) + eSum(Parts (k):Transportedrevpart $(4,5, k, t)$ *

(Revenuerevpart $(4,5, \mathrm{k}, \mathrm{t})$ - Testingcostpart - Costofparttrans $(\mathrm{k}, \mathrm{t})$ -

Costofpartproc $(\mathrm{k}, \mathrm{t}))$ + Transportedrevforwpart $(4,3, \mathrm{k}, \mathrm{t})$ *

(Revenuerevforwpart

$(4,3, k, t)$ - Testingcostpart - Costofparttrans $(k, t)$ -

Costofpartproc $(k, t))$ - Invlevrevpart $(4, k, t)$ *

Costofpartstor $(k, t)$ - Transportedrevpart $(4,6, k, t)$ * Disposalcostpart) + $\operatorname{ndr}(4)-\operatorname{pdr}(4)=\operatorname{NPR} 4)$;

! Objective constraint for R5;

@For (Timeperiod (t) | t\#GE\#2: [Row141]

@Sum (Materials (r) : Transportedrevforwmat $(5,1, r, t)$ * (Revenuerevforwmat $(5,1$ $, r, t)$ - Recyclingcost - Costofmattrans $(r, t))$ ) -

Sum (Subassemblies (j) : Invlevrevsubass $(5, j, t)$ * Costofsubassstor $(j, t)$ ) aSum (Parts (k) : Invlevrevpart $(5, k, t) *$ Costofpartstor $(k, t))+n d r(5)-$ $\operatorname{pdr}(5)=$ NPR5);

! Objective constraint for minimizing number to landfills;

@For (Timeperiod (t)|t\#GE\#2: [Row142]

@Sum (Parts $(\mathrm{k})$ : Transportedrevpart $(4,6, \mathrm{k}, \mathrm{t})+$

Transportedrevpart $(3,6, k, t))+$

@Sum (Subassemblies (j) : Transportedrevsubass $(4,6, j, t)+$

Transportedrevsubass $(3,6, j, t))+\operatorname{ndr}(6)-\operatorname{pdr}(6)=$ NumDipsosed);

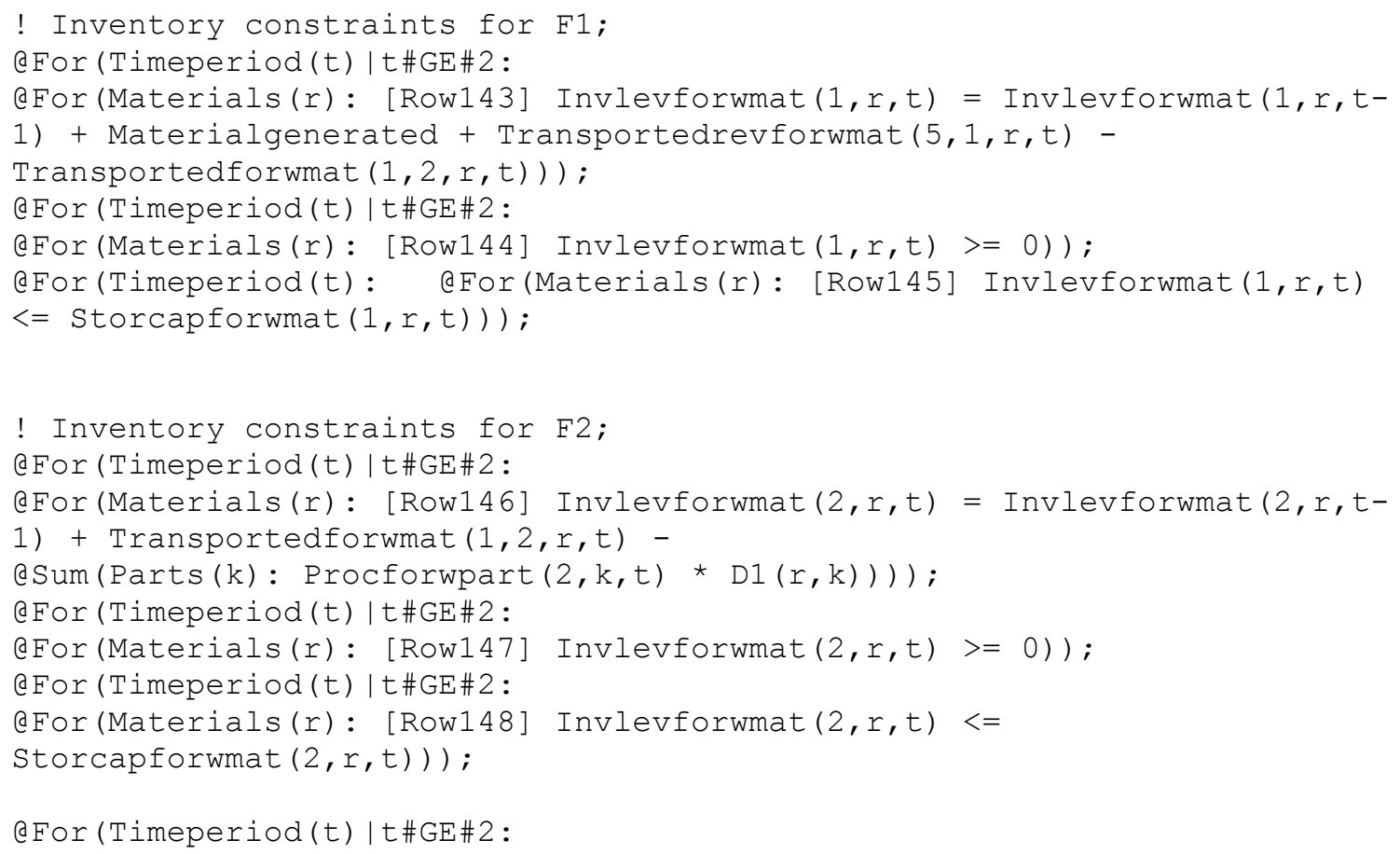


(aFor(Parts (k): [Row149] Invlevforwpart $(2, \mathrm{k}, \mathrm{t})=\operatorname{Invlevforwpart}(2, \mathrm{k}, \mathrm{t}-1)$

$+\operatorname{Procforwpart}(2, \mathrm{k}, \mathrm{t})$ - Transportedforwpart $(2,3, \mathrm{k}, \mathrm{t})))$;

@Eor (Timeperiod (t) | t\#GE\#2:

@For(Parts (k): [Row150] Invlevforwpart $(2, k, t)>=0)$ );

@For (Timeperiod ( $t) \mid$ t\#GE\#2:

@For (Parts $(\mathrm{k})$ : [Row151] Invlevforwpart $(2, \mathrm{k}, \mathrm{t})<=$

Storcapforwpart $(2, k, t)))$;

! Inventory constraints for F3;

aFor (Timeperiod (t) | t\#GE\#2:

@For (Parts $(k)$ : [Row152] Invlevforwpart $(3, k, t)=\operatorname{Invlevforwpart~}(3, k, t-1)$

+ Transportedforwpart $(2,3, \mathrm{k}, \mathrm{t})$ + Transportedrevforwpart $(4,3, \mathrm{k}, \mathrm{t})$ -

@Sum (Subassemblies (j) : Procforwsubass $(3, j, t)$ * D4 $(k, j))$ -

aSum (Products(i): $\operatorname{Procforwprod}(3, i, t) \star D 3(k, i))))$;

@For (Timeperiod ( t) | t\#GE\#2:

@For(Parts(k): [Row153] Invlevforwpart $(3, \mathrm{k}, \mathrm{t})>=0)$ );

@For(Timeperiod(t)|t\#GE\#2: @For(Parts(k): [Row154]

Invlevforwpart $(3, k, t)<=\operatorname{Storcapforwpart}(3, k, t)))$;

@For (Timeperiod ( t) | t\#GE\#2:

@For (Subassemblies $(j)$ : [Row155] Invlevforwsubass $(3, j, t)=$

Invlevforwsubass $(3, j, t-1)+\operatorname{Procforwsubass}(3, j, t)+$

Transportedrevforwsubass $(4,3, j, t)$ - esum(Products (i) :

Procforwprod $(3, i, t) * D 2(j, i))))$;

@For (Timeperiod (t) | t\#GE\#2:

aFor (Subassemblies (j): [Row156] Invlevforwsubass $(3, j, t) \quad>=0)$ );

@For (Timeperiod ( $t) \mid t \# G E \# 2$ :

@For (Subassemblies (j): [Row157] Invlevforwsubass $(3, j, t)<=$

Storcapforwsubass $(3, j, t)))$;

@For (Timeperiod (t) | t\#GE\#2:

@For(Products(i): [Row158] Invlevforwprod $(3, i, t)=$

Invlevforwprod $(3, i, t-1)+\operatorname{Procforwprod}(3, i, t)+$

Transportedrevforwprod $(2,3, i, t)$ - Transportedforwprod $(3,4, i, t)))$;

@For (Timeperiod ( $t) \mid$ t\#GE\#2:

aFor(Products(i): [Row159] Invlevforwprod(3,i,t) >= 0));

(aFor (Timeperiod (t) | t\#GE\#2:

aFor(Products(i): [Row160] Invlevforwprod $(3, i, t)<=$

Storcapforwprod $(3, i, t)))$;

\author{
! Inventory constraints for F4; \\ @For (Timeperiod ( $t) \mid$ t\#GE\#2: \\ @For(Products(i): [Row161] Invlevforwprod $(4, i, t)=$ \\ Invlevforwprod $(4, i, t-1)+$ Transportedforwprod $(3,4, i, t)$ - \\ Transportedforwprod $(4,5, i, t)))$; \\ @For (Timeperiod (t) | t\#GE\#2: \\ @For(Products(i): [Row162] Invlevforwprod (4,i,t) >= 0)); \\ @For (Timeperiod ( $t) \mid$ t\#GE\#2: \\ @For(Products(i): [Row163] Invlevforwprod (4,i,t) $<=$ \\ Storcapforwprod $(4, i, t)))$;
}


! Inventory constraints for F5;

aFor (Timeperiod (t) | t\#GE\#2:

@For(Products(i): [Row164] Invlevforwprod $(5, i, t)=$

Invlevforwprod $(5, i, t-1)+\operatorname{Transportedforwprod}(4,5, i, t)-$

Soldforwprod $(5,6, i, t)))$;

@For (Timeperiod ( $t) \mid t \# G E \# 2$ :

aFor(Products(i): [Row165] Invlevforwprod (5,i,t) > = 0));

@For (Timeperiod (t) | t\#GE\#2:

aFor(Products(i): [Row166] Invlevforwprod (5,i,t) $<=$

Storcapforwprod (5,i,t)));

! Inventory constraints for R1;

@For (Timeperiod ( $t) \mid$ t\#GE\#2:

aFor(Products(i): [Row167] Invlevrevprod(1,i,t) = Invlevrevprod $(1, i, t-$

1) + Returnprod (i,t) -

Transportedrevprod $(1,2, i, t)$ - Transportedrevprod $(1,3, i, t)))$;

@For (Timeperiod (t) | t\#GE\#2:

@For(Products(i): [Row168] Invlevrevprod(1,i,t) >=0));

@For (Timeperiod (t) | t\#GE\#2:

@For(Products(i): [Row169] Invlevrevprod $(1, i, t)<=$

Storcaprevprod $(1, i, t)))$;

! Inventory constraints for R2;

aFor (Timeperiod (t) | t\#GE\#2:

aFor(Products(i): [Row170] Invlevrevprod $(2, i, t)=\operatorname{Invlevrevprod}(2, i, t-$

$1)+$ Transportedrevprod $(1,2, i, t)-\operatorname{Procrevprod}(2, i, t)))$;

@For (Timeperiod (t) | t\#GE\#2:

@For(Products(i): [Row171] Invlevrevprocessedprod $(2, i, t)=$

Invlevrevprocessedprod $(2, i, t-1)+\operatorname{Procrevprod}(2, i, t)-$

Transportedrevforwprod $(2,3, i, t)))$;

@For (Timeperiod (t)|t\#GE\#2:

@For(Products(i): [Row172] Invlevrevprod(2,i,t) +

Invlevrevprocessedprod $(2, i, t)>=0)$ );

@For (Timeperiod ( $t) \mid$ t\#GE\#2:

@For(Products(i): [Row173] Invlevrevprod $(2, i, t)+$

Invlevrevprocessedprod $(2, i, t)<=\operatorname{Storcaprevprod}(2, i, t)))$;

! Inventory constraints for R3;

@For (Timeperiod ( $t) \mid t \# G E \# 2$ :

aFor (Parts $(\mathrm{k})$ : [Row174] Invlevrevpart $(3, \mathrm{k}, \mathrm{t})=\operatorname{Invlevrevpart}(3, \mathrm{k}, \mathrm{t}-1)+$ @Sum (Products (i) : Procrevprod $(3, i, t) * D 3(k, i))+$

@Sum (Subassemblies (j) : Procrevsubass $(3, j, t) * D 4(k, j))-$

Transportedrevpart $(3,4, \mathrm{k}, \mathrm{t})-\operatorname{Transportedrevpart}(3,6, \mathrm{k}, \mathrm{t})))$;

@For (Timeperiod ( $t) \mid t \# G E \# 2$ :

@For (Parts (k): [Row175] Invlevrevpart $(3, k, t)>=0))$;

@For (Timeperiod (t) | t\#GE\#2:

@For(Parts $(\mathrm{k})$ : [Row176] Invlevrevpart $(3, \mathrm{k}, \mathrm{t}) \quad<=$

Storcaprevpart $(3, k, t)))$;

@Eor (Timeperiod ( $t) \mid t \# G E \# 2$ :

aFor (Subassemblies $(j):$ [Row177] Invlevrevsubass $(3, j, t)=$

Invlevrevsubass $(3, j, t-1)+$ asum(Products $(i): \operatorname{Procrevprod}(3, i, t)$ * 


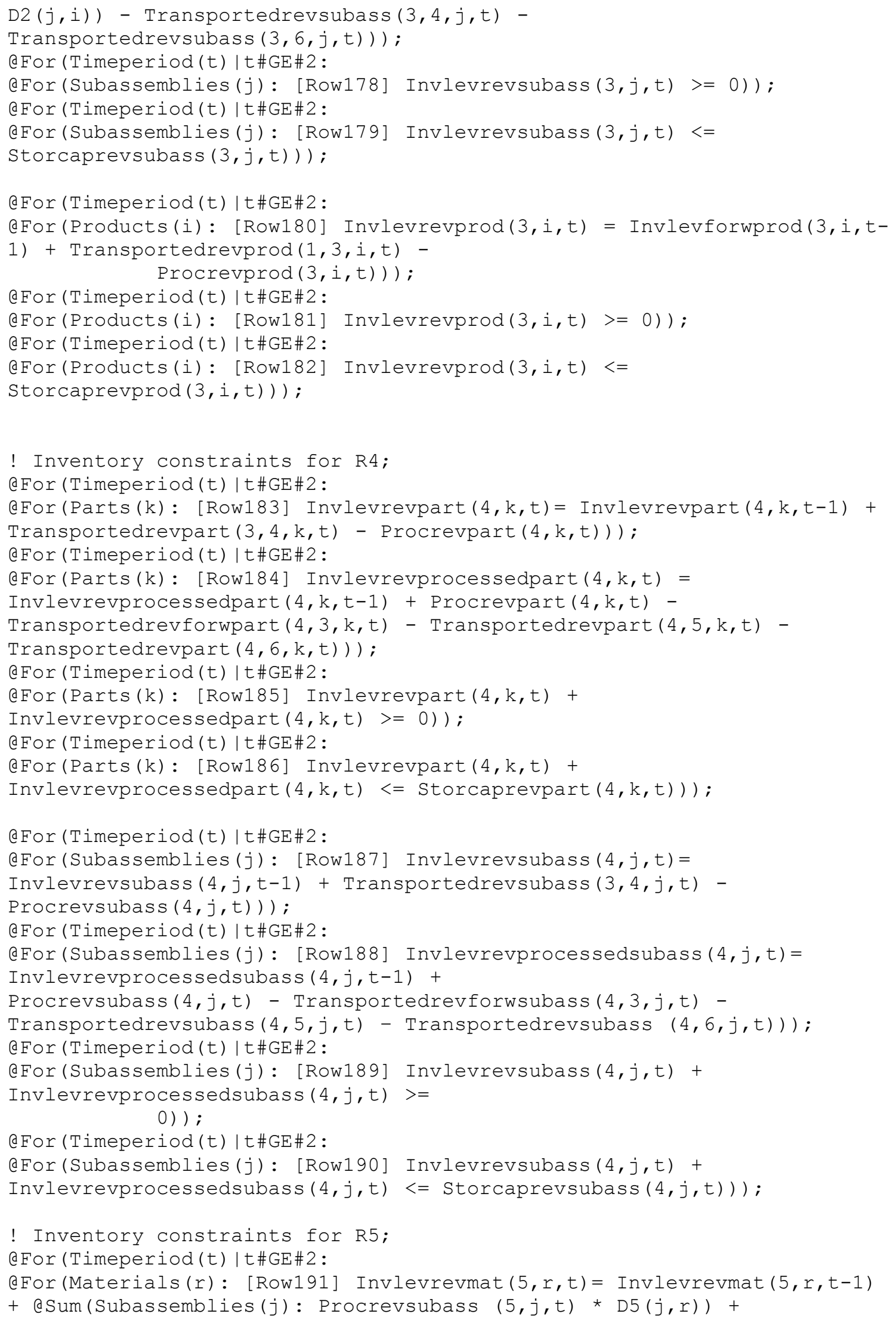




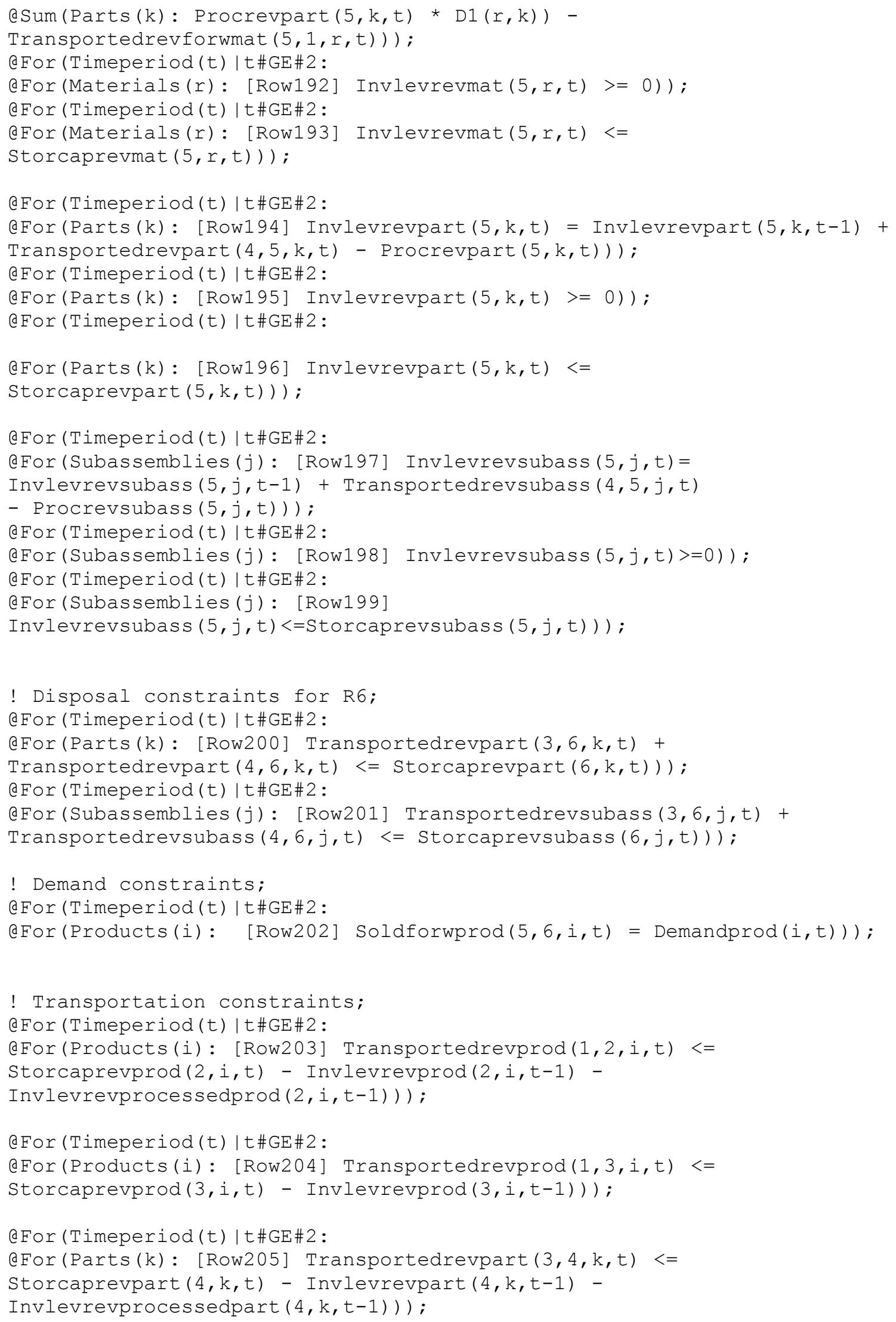


aFor (Timeperiod (t) | t\#GE\#2:

@For (Subassemblies (j): [Row206] Transportedrevsubass $(3,4, j, t)<=$ Storcaprevsubass $(4, j, t)$ - Invlevrevsubass $(4, j, t-1)$ -

Invlevrevprocessedsubass $(4, j, t-1))$ );

QFor (Timeperiod (t) | t\#GE\#2:

@For (Parts (k): [Row207] Transportedrevpart $(4,5, k, t)<=$

Storcaprevpart $(5, \mathrm{k}, \mathrm{t})-\operatorname{Invlevrevpart}(5, \mathrm{k}, \mathrm{t}-1)))$;

@For (Timeperiod ( $t) \mid$ t\#GE\#2:

@For (Subassemblies $(j)$ : [Row208] Transportedrevsubass $(4,5, j, t)<=$ Storcaprevsubass $(5, j, t)-\operatorname{Invlevrevsubass}(5, j, t-1)))$;

end 
APPENDIX B

EXPLANATION ON DECISION VARIABLES 


\section{Variable Definition}

$P_{p i, t}^{F 3}$

The number of units of a product type i manufactured by the

manufacturer (member 3) of the forward supply chain in the period t.

$P_{s j, t}^{F 3} \quad$ The number of units of a subassembly type $\mathrm{j}$ manufactured by the manufacturer (member 3) of the forward supply chain in the period $t$.

$P_{n k, t}^{F 2} \quad$ The number of units of a part type k manufactured by the parts supplier (member 2) of the forward supply chain in the period t.

$I_{p i, t}^{F u} \quad$ The number of units of a product type i stored by the manufacturer/

distributor/retailer (member 3, member 4, and member 5) of the forward supply chain in the period t.

$I_{s j, t}^{F 3} \quad$ The number of units of a subassembly type $\mathrm{j}$ stored by the manufacturer of the forward supply chain in the period $t$.

$I_{n k, t}^{F u} \quad$ The number of units of a part type k stored by the parts supplier/ Manufacturer (member 2 and member 3) of the forward supply chain in the period $t$.

$I_{m r, t}^{F 1} \quad$ The number of units of a raw material $\mathrm{r}$ type stored by the raw materials supplier (member 1) of the forward supply chain in the period $t$.

$P_{m r, t}^{F 1} \quad$ The number of units of a raw material type r produced by the raw materials supplier (member 1) of the forward supply chain in the period t.

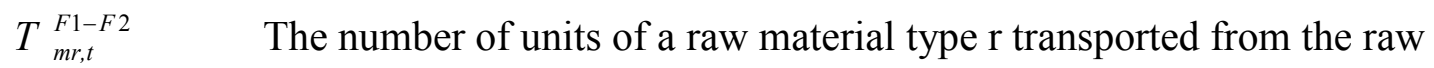
materials supplier (member 1) to the parts supplier (member 2) of the 


\section{Variable Definition}

forward supply chain in a in the period $t$.

$T_{n k, t}^{F 2-F 3} \quad$ The number of units of a part type $\mathrm{k}$ transported from the parts supplier (member 2) to the manufacturer (member 3 ) of the forward supply chain in the period $t$.

$T_{p i, t}^{F 3-F 4} \quad$ The number of units of a product type i transported from the Manufacturer (member 3) to the distributor (member 4) of the forward supply chain in the period $t$.

$T_{p i, t}^{F 4-F 5} \quad$ The number of units of a product type i transported from a distributor (member 4) to the retailer (member 5) of the forward supply chain in the period $\mathrm{t}$.

$S_{p i, t}^{F 5-F 6}, \quad$ The number of units of a product type i sold from a retailer (member 5) to the end customer (member 6) of the forward supply chain in the period $t$.

$R_{p i, t}^{F 6-R 1} \quad$ The number of units of a product type $\mathrm{i}$ returned from end-customer (member 6) of the forward supply chain to the collection center (member 1) of the reverse supply chain in the period t.

$T_{p i, t}^{R 1-R 2} \quad$ The number of units of a product type i transported from the collection $T_{p i, t}^{R 1-R 3} \quad$ center (member 1) to the repair/refurbishing (member 2) and the disassembly facility (member 3) of the reverse supply chain in the period t.

$P_{p i, t}^{R 2} \quad$ The number of units of a product type i repaired at the 
repair/refurbishing facility (member 2) of the reverse supply chain in the period $\mathrm{t}$.

$P_{p i, t}^{R 3} \quad$ The number of units of a product type i disassembled at the disassembly facility (member 3) of the reverse supply chain in the period $t$.

$P_{s j, t}^{R 4}, \quad$ The number of units of a subassembly and a part type, $\mathrm{j}$ and $\mathrm{k}$ tested at

$P_{n k, t}^{R 4} \quad$ the testing facility (member 4) of the reverse supply chain in the period t.

$T_{s j, t}^{R 3-R 4}, \quad$ The number of units of a subassembly and a part type, $\mathrm{j}$ and $\mathrm{k}$

$T_{n k, t}^{R 3-R 6} \quad$ transported from the disassembly facility (member 3 ) to the testing facility (member 4) and the disposal (member 6) of the reverse supply chain in the period t.

$T_{s j, t}^{R 4-F 3}, T_{n k, t}^{R 4-F 3}$ The number of units of a subassembly and a part type, $\mathrm{j}$ and $\mathrm{k}$

$T_{s j, t}^{R 4-R 5}, T_{n k, t}^{R 4-R 5}$ transported from the testing facility (member 4 ) to the remanufacturing $T_{s j, t}^{R 4-R 6}, T_{n k, t}^{R 4-R 6}$ facility/manufacturer/recycler/ disposal (member, member 4, member 4, member 4) of the forward and reverse supply chain in the period t.

$T_{s j, t}^{R 5-F 3} \quad$ The number of units of a subassembly type $\mathrm{j}$ transported from the remanufacturing facility (member 4 ) to the manufacturer of the forward supply chain in the period $t$.

$P_{s j, t}^{R 6}, \quad$ The number of units of a subassembly and a part type, $\mathrm{j}$ and $\mathrm{k}$ recycled $P_{n k, t}^{R 6} \quad$ at the recycling facility (member 6) of the reverse supply chain in the period $\mathrm{t}$. 

supply chain in the period t.

$I_{p i, t}^{R 3}$, The number of units of a part, subassembly and a product type, $k, j$, and $\mathrm{i}$ stored by the disassembly facility (member 3 ) of the reverse supply chain $I_{n k, t}^{R 3} \quad$ in the period t.

$I_{s j, t}^{R 4}$, The number of units of a part and subassembly type, $\mathrm{k}$ and jstored by the testing/remanufacturing facility (member 1 and member 2 ) of the reverse supply chain in the period t.

$I_{s j, t}^{R 6}$, The number of units a part and subassembly type, $\mathrm{k}$ and $\mathrm{j}$ stored $I_{n k, t}^{R 6}$ by the recycling facility (member 6) of the reverse supply chain in the period $\mathrm{t}$. 
APPENDIX C

EXPLANATION ON PARAMETERS 
Parameter

$\alpha$

$\beta$

$\gamma$

$C s_{m m} \underset{m r, t}{\stackrel{F}{m}}$

$C S_{m}{ }_{n k, t}^{F 2}$

$C s_{m}^{F 3, t}$

$C s_{m}^{F 3}{ }_{s j, t}^{F 3}$

$C s_{S i / s j / n k / m r, t}^{F u / F v}$

$C S_{p}^{F u / F v-F u / F v}$

\section{Definition}

Proportion of number of units of refurbished products i out of total units i transported from manufacturer (member 3 ) to the distributor (member 4) of the forward supply chain in the period t. Proportion of number of units of refurbished products i out of total units i transported from distributor (member 4) to the retailer (member 5)

Proportion of number of units of refurbished products i out of total units i sold from retailer (member 5) to the customer (member 6).

Unit cost of a material type $r$ incurred by the material supplier (member 5) of the forward supply chain in the period $t$. Unit cost of manufacturing a part, $\mathrm{k}$, manufactured by a parts supplier (member 2) of the forward supply chain in the period $t$. Unit cost of manufacturing a subassembly and a product type, $\mathrm{j}$ and i manufactured by the manufacturer (member 3 ) of the forward supply chain in the period t.

Unit cost of storing a raw material, part, subassembly, and a product type, $r, \mathrm{k}, \mathrm{j}$, and $\mathrm{i}$ associated with a chain member in the period $t$.

Unit cost of procuring the number of units of a raw material, part, subassembly, and a product type, $\mathrm{r}, \mathrm{k}, \mathrm{j}$, and i from a 


\begin{tabular}{|c|c|}
\hline Parameter & Definition \\
\hline & given chain member of the forward supply chain in the period t. \\
\hline \multirow[t]{3}{*}{$C S_{t r}^{F u / F v-F u / F v}$} & Unit cost of transporting a raw material, part, subassembly, and a \\
\hline & product type, $\mathrm{r}, \mathrm{k}, \mathrm{j}$, and $\mathrm{i}$ from a chain member to another chain \\
\hline & member in the period $t$. \\
\hline \multirow[t]{4}{*}{$R v_{p i / s j / n k / m r, t}^{F u / F v-F u / F v}$} & Unit revenue generated by selling a raw material, part, \\
\hline & subassembly, and a product type, $\mathrm{r}, \mathrm{k}, \mathrm{j}$, and i from a chain \\
\hline & member to another chain member of the forward or reverse supply \\
\hline & chain in the period $t$. \\
\hline \multirow[t]{4}{*}{$C S_{C}^{F 6-R 1}$} & Unit cost of collecting a used product type i returned from an \\
\hline & end-customer (member 6) of the forward supply chain to a \\
\hline & collection center (member 1) of the reverse supply chain in the \\
\hline & period t. \\
\hline \multirow[t]{2}{*}{$C S_{r p}{ }^{R 2}$} & Unit cost of repairing a product type $i$ at the repair/refurbishing \\
\hline & facility (member 2) of the reverse supply chain in the period t. \\
\hline \multirow[t]{2}{*}{$C s_{d}^{R 3} \stackrel{R i, t}{2}$} & Unit cost of disassembling a product type $i$ at the disassembly \\
\hline & facility (member 3 ) of the reverse supply chain in the period t. \\
\hline \multirow[t]{3}{*}{$C s_{t s}^{R 4}$ flowtype, } & Unit cost of testing a subassembly or part type $\mathrm{j}$ or $\mathrm{k}$ at the \\
\hline & testing/remanufacturing facility (member 4 ) of the reverse supply \\
\hline & chain in the period $t$. \\
\hline$C S_{r c}^{R j / n k, t}$ & Unit cost of recycling a subassembly or part type $\mathrm{j}$ or $\mathrm{k}$ at the \\
\hline
\end{tabular}




\section{Definition}

recycling facility (member 6) of the reverse supply chain in the period $\mathrm{t}$.

$C s_{d s_{s j / n k, t}^{R 5}}$ Unit cost of disposing (fee charged by EPA) a subassembly or part type $\mathrm{j}$ or $\mathrm{i}$ to the final disposal location (member 5 ) of the reverse logistics chain in the period $t$.

$C_{p i / s j / n k / m r, t}^{F u / F v}$ Facility capacity available at a given chain member and for a raw material, part, subassembly, and a product type, $\mathrm{r}, \mathrm{k}, \mathrm{j}$, and i in the period $t$.

$D_{p i, t}^{F 6}$ Product demand of end-customer (member 6) in the forward supply chain in the period $t$.

$R_{p i, t}^{F 6-R 1}$ Product returned by the customer (member 6) of the forward supply chain to the collection point (member 1) of the reverse supply chain in the period $t$. 
APPENDIX D

PARAMETER VALUES 
$P_{n k, t}^{F 2}$, Part manufacturing capacity of parts supplier $=3000$

$P_{s j, t}^{F 3}$, Subassembly manufacturing capacity of manufacturer $=3000$

$P_{p i, t}^{F 3}$, Product manufacturing capacity of manufacturer $=4000$

$P_{n k, t}^{R 3}$, Part processing capacity of disassembly/testing facility $=500$

$P_{s j, t}^{R 3}$, Subassembly processing capacity of disassembly/testing facility $=500$

$P_{p i, t}^{R 1}$, Product processing capacity of collection/repair facility $=500$

$C_{m r, t}^{F 1}$, Material storage capacity of materials supplier/parts supplier $=150000$

$C_{n k, t}^{F 2}$, Part storage capacity of parts supplier/manufacturer $=100000$

$C_{s j, t}^{F 3}$, Subassembly storage capacity of manufacturer $=150000$

$C_{p i, t}^{F 3}$, Product storage capacity of manufacturer/distributor/retailer $=100000$

$C_{n k, t}^{R 3}$, Material storage capacity of recycling facility $=50000$

$C_{n k, t}^{R 6}$, Part storage capacity of disassembly/testing $=40000$

$C_{s j, t}^{R 3}$, Subassembly storage capacity of disassembly/testing facility $=30000$

$C_{p i, t}^{R 1}$, Product storage capacity of collection/repair facility $=40000$

$C s_{t r} \underset{m r, t}{F u-F v}$, Cost of material transportation $=3$

$C s_{s_{m r, t}}^{F 1}$, Cost of material storage $=3$

$C s_{p}{ }_{m r, t}^{F 1-F 2}$, Cost of material procurement $=3$

$C s_{t r}{ }_{n k, t}^{F 2-F 3}$, Cost of part transportation $=8$

$C s_{S_{n k, t}}^{F 2}$, Cost of part storage $=4$ 
$C s_{p}{ }_{n k, t}^{F 2-F 3}$, Cost of part procurement $=3$

$C S_{S_{s j, t}}^{F 3}$, Cost of subassembly storage $=6$

$C S_{t r}^{F i, t}{ }^{F 3-F 4}, C s_{t r}^{F i, t}{ }^{F 4-F 5}$, Cost of product transportation $=10$

$C s_{s p i, t}^{F 3}, C s_{s p i, t}^{F 4}, C s_{s i, t}^{F 5}$, Cost of product storage $=8$

$C s_{p p i, t}^{F 3-F 4}, C s_{p p i, t}^{F 3-F 4}$, Cost of product procurement $=5$

$C s_{c}$, Cost of collection $=15$

$C s_{r p}{ }_{p i, t}^{R 2}$, Cost of product repair $=25$

$C s_{d}^{R 3, t}$, , Cost of part disassembly $=7$

$C s_{d s, t,}^{R 3}$, Cost of subassembly disassembly $=10$

$\operatorname{Cs}_{t s}{ }_{n k, t}^{R 4}$, Cost of part testing $=10$

$C S_{t s}^{R 4}{ }_{s, t}^{R}$, Cost of subassembly testing $=15$

$C S_{r c}^{R 4}{ }_{n k, t}^{R 4}$, Cost of recycling $=10$

$C s_{d s}^{R 5, t}$, , Cost of part disposal $=10$

$C S_{d s}^{R 5, t}$, Cost of subassembly disposal $=15$

$C s_{m m} \underset{m r, t}{F 1}$, Cost of materials $=10,15$

$C s_{m} \underset{n k, t}{F 2}$, Cost of manufacturing parts $=5,6,5,6,5,6,5,6,5,6$

$C S_{m} \underset{p i, t}{F 2}$, Cost of manufacturing products $=100,150,200$

$P_{m r, t}^{F 1}$, Material generation capacity of materials supplier $=5000$

$I_{m r, 1}^{F 1}$, Initial inventory level of each material type stored by materials supplier $=30000$ 
$I_{n k, 1}^{F 2}$, Initial inventory level of each part type stored by parts supplier $=30000$

$I_{n k, 1}^{F 3}$, Initial inventory level of each part type stored by manufacturer $=30000$

$I_{s j, 1}^{F 3}$, Initial inventory level of each subassembly type stored by manufacturer $=10000$

$I_{p i, 1}^{F 3}$, Initial inventory level of each product type stored by manufacturer $=10000$

$I_{p i, 1}^{F 4}$, Initial inventory level of each product type stored by distributor $=10000$

$I_{p i, 1}^{F 5}$, Initial inventory level of each product type stored by retailer $=10000$

$I_{m r, 1}^{R 6}$, Initial inventory level of each material type stored by recycling facility $=10000$

$I_{n k, 1}^{R 3}$, Initial inventory level of each part type stored by disassembly facility $=1000$

$I_{n k, 1}^{R 4}$, Initial inventory level of each part type stored by testing/remanufacturing facility = 1000

$I_{n k, 1}^{R 6}$, Initial inventory level of each part type stored by recycling facility $=1000$

$I_{s j, 1}^{R 3}$, Initial inventory level of each subassembly type stored by disassembly facility = 1000

$I_{s j, 1}^{R 4}$, Initial inventory level of each subassembly type stored by testing/remanufacturing facility $=1000$

$I_{s j, 1}^{R 6}$, Initial inventory level of each subassembly type stored by recycling facility $=1000$

$I_{p i, 1}^{R 1}$, Initial inventory level of each product type stored by collection facility $=1000$

$I_{p i, 1}^{R 2}$, Initial inventory level of each product type stored by repair facility $=1000$

$I_{p i, 1}^{R 3}$, Initial inventory level of each product type stored by disassembly facility $=1000$ 
$R v_{p i, t}^{F 4-F 3}$, Revenue from products from distributor to manufacturer $=550,600,650$

$R v_{p i, t}^{F 4-F 3}$, Revenue from refurbished products from distributor to manufacturer $=200$,

250,300

$R v_{p i, t}^{F 5-F 4}$, Revenue from products from retailer to distributor $=650,700,750$

$R v_{p i, t}^{F 5-F 4}$, Revenue from refurbished products from retailer to distributor $=400,450,500$

$R v_{p i, t}^{F 6-F 5}$, Revenue from products from customer to retailer $=850,900,950$

$R v_{p i, t}^{F 6-F 5}$, Revenue from refurbished products from retailer to distributor $=600,650,700$

$R v_{m r, t}^{F 2-F 1}$, Revenue from materials from parts supplier to materials supplier $=30,35,50$

$R v_{n k, t}^{F 3-F 2}$, Revenue from parts from manufacturer to parts supplier $=55,60,65,70,75,80$,

$85,90,95$

$R v_{n k, t}^{R 4-R 3}$, Revenue from parts from testing/remanufacturing to disassembly facility $=20$,

$22,24,26,28,30,32,34,36,38$

$R v_{n k, t}^{R 6-R 4}$, Revenue from parts from recycling to testing/remanufacturing $=22,24,26,28$

$30,32,34,36,38,40$

$R v_{s j, t}^{R 4-R 3}$, Revenue from subassemblies from testing/remanufacturing to disassembly

facility $=40,44,48,52,56$

$R v_{s j, t}^{R 6-R 4}$, Revenue from subassemblies from recycling to testing/remanufacturing $=45$,

$50,55,60,65$

$R v_{p i, t}^{R 3-R 1}$, Revenue from returned product, from disassembly to collection facility $=40$

$R v_{n k, t}^{R 4-F 1}$, Revenue from part, from manufacturer to testing/remanufacturing facility $=20$ 
$R v_{s j, t}^{R 4-F 1}$, Revenue from subassembly from manufacturer to testing/remanufacturing

facility $=40$

$R v_{p i, t}^{F 1-R 2}$, Revenue from returned product, from manufacturer to repair facility $=100$

$R v_{m r, t}^{F 1-R 6}$, Revenue from material, from materials supplier to recycling facility $=30$ 
APPENDIX E

VALUES OF DECISION VARIABLES AND PROFIT FOR DIFFERENT

MEMBERS OF THE SUPPLY CHAIN 


\section{F1 (Raw Materials Supplier)}

Table 5: Material transported and inventory for Raw Materials Supplier

\begin{tabular}{|c|c|c|}
\hline Material & Transported & Inventory \\
\hline \multirow{12}{*}{1} & 0 & 30000 \\
\hline & 0 & 41952 \\
\hline & 31634 & 23344 \\
\hline & 29437 & 0 \\
\hline & 16676 & 0 \\
\hline & 10111 & 8372 \\
\hline & 22028 & 7296 \\
\hline & 27285 & 3485 \\
\hline & 27607 & 0 \\
\hline & 0 & 7356 \\
\hline & 29337 & 4593 \\
\hline & 30387 & 2492 \\
\hline \multirow{12}{*}{2} & 0 & 30000 \\
\hline & 34550 & 449 \\
\hline & 0 & 5449 \\
\hline & 0 & 18538 \\
\hline & 11390 & 12147 \\
\hline & 17147 & 0 \\
\hline & 5000 & 0 \\
\hline & 0 & 5000 \\
\hline & 0 & 10000 \\
\hline & 28430 & 6480 \\
\hline & 0 & 13480 \\
\hline & 0 & 20480 \\
\hline
\end{tabular}


Table 6: Profit values by period for Raw Materials Supplier

\begin{tabular}{|c|c|}
\hline Period & Profit \\
\hline 1 & -180000 \\
\hline 2 & 356497 \\
\hline 3 & 356497 \\
\hline 4 & 356504 \\
\hline 5 & 356483 \\
\hline 6 & 356496 \\
\hline 7 & 356504 \\
\hline 8 & 356535 \\
\hline 9 & 356498 \\
\hline 10 & 356512 \\
\hline 11 & 356499 \\
\hline 12 & 356502 \\
\hline
\end{tabular}


F2 (Parts Supplier)

Table 7: Parts transported and inventory for Parts Supplier

\begin{tabular}{|c|c|c|}
\hline Part & Transported & Inventory Parts \\
\hline \multirow{12}{*}{1} & 0 & 30000 \\
\hline & 3500 & 29500 \\
\hline & 0 & 32500 \\
\hline & 0 & 35500 \\
\hline & 0 & 38500 \\
\hline & 0 & 41500 \\
\hline & 0 & 44500 \\
\hline & 0 & 47500 \\
\hline & 10000 & 40500 \\
\hline & 43500 & 0 \\
\hline & 3000 & 0 \\
\hline & 3000 & 0 \\
\hline \multirow{12}{*}{2} & 0 & 30000 \\
\hline & 5000 & 28000 \\
\hline & 0 & 31000 \\
\hline & 0 & 34000 \\
\hline & 0 & 37000 \\
\hline & 0 & 40000 \\
\hline & 0 & 43000 \\
\hline & 12000 & 34000 \\
\hline & 0 & 37000 \\
\hline & 6000 & 34000 \\
\hline & 37000 & 0 \\
\hline & 3000 & 0 \\
\hline \multirow{12}{*}{3} & 0 & 30000 \\
\hline & 2771 & 30228 \\
\hline & 0 & 33228 \\
\hline & 0 & 36228 \\
\hline & 0 & 39228 \\
\hline & 0 & 42228 \\
\hline & 0 & 45228 \\
\hline & 0 & 48228 \\
\hline & 0 & 51228 \\
\hline & 0 & 54228 \\
\hline & 21671 & 35556 \\
\hline & 38556 & 0 \\
\hline \multirow{3}{*}{4} & 0 & 30000 \\
\hline & 32000 & 1000 \\
\hline & 0 & 4000 \\
\hline
\end{tabular}




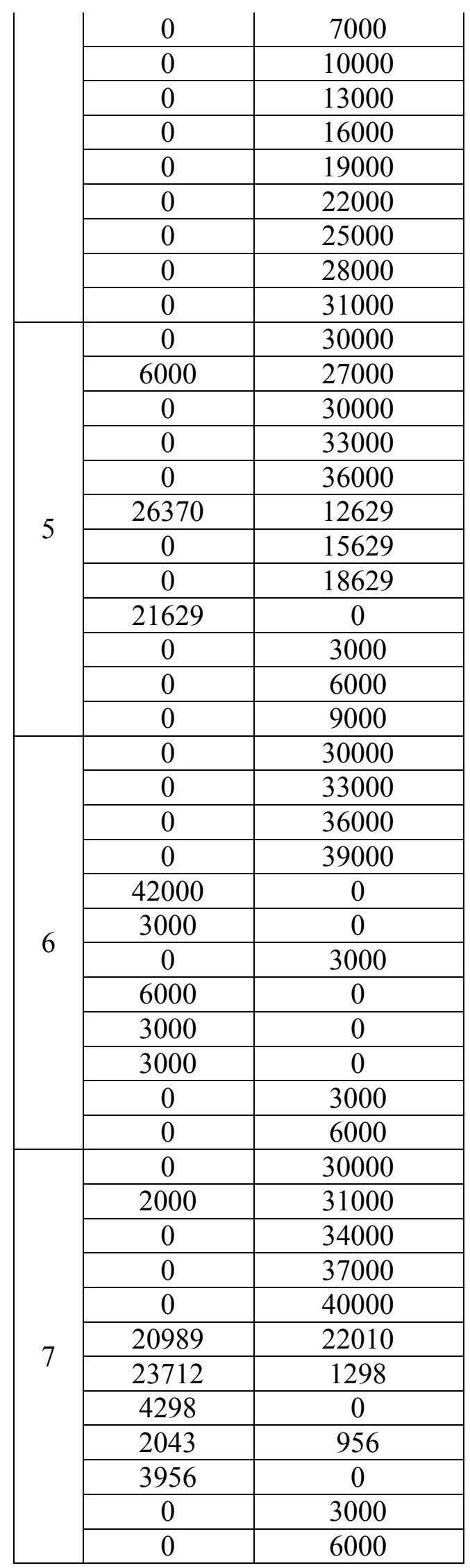




\begin{tabular}{|c|c|c|}
\hline \multirow{12}{*}{8} & 0 & 30000 \\
\hline & 9519 & 23480 \\
\hline & 7325 & 19155 \\
\hline & 0 & 22155 \\
\hline & 8750 & 16405 \\
\hline & 0 & 19405 \\
\hline & 0 & 22405 \\
\hline & 25405 & 0 \\
\hline & 0 & 3000 \\
\hline & 0 & 6000 \\
\hline & 0 & 9000 \\
\hline & 0 & 12000 \\
\hline \multirow{12}{*}{9} & 0 & 30000 \\
\hline & 0 & 33000 \\
\hline & 36000 & 0 \\
\hline & 3000 & 0 \\
\hline & 0 & 3000 \\
\hline & 0 & 6000 \\
\hline & 9000 & 0 \\
\hline & 0 & 3000 \\
\hline & 6000 & 0 \\
\hline & 3000 & 0 \\
\hline & 0 & 3000 \\
\hline & 0 & 6000 \\
\hline \multirow{12}{*}{10} & 0 & 30000 \\
\hline & 1848 & 31151 \\
\hline & 0 & 34151 \\
\hline & 37151 & 0 \\
\hline & 0 & 3000 \\
\hline & 0 & 6000 \\
\hline & 9000 & 0 \\
\hline & 0 & 3000 \\
\hline & 6000 & 0 \\
\hline & 3000 & 0 \\
\hline & 0 & 3000 \\
\hline & 6000 & 0 \\
\hline
\end{tabular}


Table 8: Material inventory for Parts Supplier

\begin{tabular}{|c|c|}
\hline Materials & Inventory Materials \\
\hline \multirow{12}{*}{1} & 57217 \\
\hline & 27217 \\
\hline & 34852 \\
\hline & 40289 \\
\hline & 32966 \\
\hline & 19078 \\
\hline & 17106 \\
\hline & 20392 \\
\hline & 24000 \\
\hline & 0 \\
\hline & 5337 \\
\hline & 11725 \\
\hline \multirow{12}{*}{2} & 0 \\
\hline & 28550 \\
\hline & 22550 \\
\hline & 16550 \\
\hline & 21941 \\
\hline & 33088 \\
\hline & 32088 \\
\hline & 26088 \\
\hline & 20088 \\
\hline & 42519 \\
\hline & 36519 \\
\hline & 30519 \\
\hline
\end{tabular}


Table 9: Profit values by period for Parts Supplier

\begin{tabular}{|c|c|}
\hline Period & Profit \\
\hline 1 & -1371651 \\
\hline 2 & 1973623 \\
\hline 3 & 1973758 \\
\hline 4 & 1973729 \\
\hline 5 & 1973747 \\
\hline 6 & 1973690 \\
\hline 7 & 1973746 \\
\hline 8 & 1973744 \\
\hline 9 & 1973718 \\
\hline 10 & 1973715 \\
\hline 11 & 1973732 \\
\hline 12 & 1973732 \\
\hline
\end{tabular}




\section{F3 (Manufacturer)}

Table 10: Products transported and inventory for Manufacturer

\begin{tabular}{|c|c|c|}
\hline Product & Transported & Inventory Products \\
\hline \multirow{12}{*}{ Product 1} & 0 & 10000 \\
\hline & 13994 & 500 \\
\hline & 4740 & 500 \\
\hline & 0 & 4500 \\
\hline & 0 & 8500 \\
\hline & 9204 & 3506 \\
\hline & 1998 & 5507 \\
\hline & 1817 & 7689 \\
\hline & 11143 & 2203 \\
\hline & 1296 & 4907 \\
\hline & 5520 & 4387 \\
\hline & 10783 & 0 \\
\hline \multirow{12}{*}{ Product 2} & 0 & 10000 \\
\hline & 3537 & 10462 \\
\hline & 12103 & 2358 \\
\hline & 0 & 6358 \\
\hline & 6535 & 3823 \\
\hline & 0 & 7823 \\
\hline & 9728 & 3328 \\
\hline & 8811 & 500 \\
\hline & 0 & 4500 \\
\hline & 9554 & 500 \\
\hline & 5349 & 379 \\
\hline & 4879 & 0 \\
\hline \multirow{10}{*}{ Product 3} & 0 & 10000 \\
\hline & 0 & 14000 \\
\hline & 0 & 18000 \\
\hline & 15870 & 7118 \\
\hline & 9334 & 3020 \\
\hline & 6665 & 1629 \\
\hline & 4142 & 1987 \\
\hline & 5241 & 745 \\
\hline & 4726 & 593 \\
\hline & 5019 & 500 \\
\hline
\end{tabular}




\begin{tabular}{|c|c|c|}
\hline \multirow{2}{*}{5000} & 0 \\
\cline { 2 - 3 } & 206 & 3793 \\
\hline
\end{tabular}

Table 11: Subassembly inventory for Manufacturer

\begin{tabular}{|c|c|}
\hline Subassembly & Inventory Subassemblies \\
\hline \multirow{12}{*}{ Subassembly 1} & 10000 \\
\hline & 9000 \\
\hline & 8000 \\
\hline & 7000 \\
\hline & 6000 \\
\hline & 5000 \\
\hline & 4000 \\
\hline & 3000 \\
\hline & 4000 \\
\hline & 3000 \\
\hline & 2000 \\
\hline & 1000 \\
\hline \multirow{12}{*}{ Subassembly 2} & 10000 \\
\hline & 9000 \\
\hline & 8000 \\
\hline & 7325 \\
\hline & 6441 \\
\hline & 5441 \\
\hline & 4441 \\
\hline & 3441 \\
\hline & 2441 \\
\hline & 2000 \\
\hline & 1500 \\
\hline & 1000 \\
\hline \multirow{9}{*}{ Subassembly 3} & 10000 \\
\hline & 9000 \\
\hline & 8000 \\
\hline & 7000 \\
\hline & 6000 \\
\hline & 5000 \\
\hline & 4000 \\
\hline & 3000 \\
\hline & 3000 \\
\hline
\end{tabular}




\begin{tabular}{|c|c|}
\hline & 2000 \\
\hline & 2000 \\
\hline & 1000 \\
\hline & 10000 \\
\hline & 9000 \\
\hline & 8000 \\
\hline & 7000 \\
\hline & 6000 \\
\hline Suhaccembly 4 & 5000 \\
\hline Süassentury 4 & 4000 \\
\hline & 3000 \\
\hline & 2000 \\
\hline & 1000 \\
\hline & 1000 \\
\hline & 500 \\
\hline & 10000 \\
\hline & 9000 \\
\hline & 8000 \\
\hline & 7000 \\
\hline & 6000 \\
\hline Cupromblo 5 & 5000 \\
\hline Süassentuty & 4000 \\
\hline & 3000 \\
\hline & 2000 \\
\hline & 1500 \\
\hline & 1000 \\
\hline & 500 \\
\hline
\end{tabular}

Table 12: Parts inventory for Manufacturer

\begin{tabular}{|c|c|}
\hline Part & Inventory Parts \\
\hline \multirow{4}{*}{ Part 1 } & 30000 \\
\cline { 2 - 2 } & 60000 \\
\cline { 2 - 2 } & 50000 \\
\cline { 2 - 2 } & 40000 \\
\hline & 30000 \\
\hline
\end{tabular}




\begin{tabular}{|c|c|}
\hline & 10000 \\
\hline & 0 \\
\hline & 0 \\
\hline & 34500 \\
\hline & 27500 \\
\hline & 20500 \\
\hline \multirow{12}{*}{ Part 2} & 30000 \\
\hline & 29000 \\
\hline & 23000 \\
\hline & 17500 \\
\hline & 12000 \\
\hline & 6000 \\
\hline & 0 \\
\hline & 6000 \\
\hline & 0 \\
\hline & 0 \\
\hline & 31000 \\
\hline & 28000 \\
\hline \multirow{12}{*}{ Part 3} & 30000 \\
\hline & 26771 \\
\hline & 20771 \\
\hline & 14771 \\
\hline & 9771 \\
\hline & 6000 \\
\hline & 0 \\
\hline & 25771 \\
\hline & 19771 \\
\hline & 14771 \\
\hline & 30943 \\
\hline & 64000 \\
\hline \multirow{9}{*}{ Part 4} & 30000 \\
\hline & 56000 \\
\hline & 50000 \\
\hline & 44000 \\
\hline & 38000 \\
\hline & 32000 \\
\hline & 26000 \\
\hline & 20000 \\
\hline & 14000 \\
\hline
\end{tabular}




\begin{tabular}{|c|c|}
\hline & 11000 \\
\hline & 5500 \\
\hline & 0 \\
\hline \multirow{12}{*}{ Part 5} & 30000 \\
\hline & 27000 \\
\hline & 18000 \\
\hline & 9000 \\
\hline & 0 \\
\hline & 17370 \\
\hline & 42370 \\
\hline & 33870 \\
\hline & 46500 \\
\hline & 37500 \\
\hline & 29500 \\
\hline & 20500 \\
\hline \multirow{12}{*}{ Part 6} & 30000 \\
\hline & 27000 \\
\hline & 24000 \\
\hline & 21000 \\
\hline & 71003 \\
\hline & 71003 \\
\hline & 68003 \\
\hline & 72503 \\
\hline & 72503 \\
\hline & 7350 \\
\hline & 71003 \\
\hline & 68003 \\
\hline \multirow{12}{*}{ Part 7} & 30000 \\
\hline & 25500 \\
\hline & 16500 \\
\hline & 9000 \\
\hline & 0 \\
\hline & 11989 \\
\hline & 26701 \\
\hline & 22000 \\
\hline & 16543 \\
\hline & 20088 \\
\hline & 11088 \\
\hline & 2088 \\
\hline
\end{tabular}




\begin{tabular}{|c|c|}
\hline \multirow{12}{*}{ Part 8} & 30000 \\
\hline & 33519 \\
\hline & 34844 \\
\hline & 28844 \\
\hline & 31594 \\
\hline & 25594 \\
\hline & 37360 \\
\hline & 56765 \\
\hline & 50765 \\
\hline & 45765 \\
\hline & 39765 \\
\hline & 33765 \\
\hline \multirow{12}{*}{ Part 9} & 30000 \\
\hline & 27000 \\
\hline & 60000 \\
\hline & 60000 \\
\hline & 57000 \\
\hline & 54000 \\
\hline & 60000 \\
\hline & 57000 \\
\hline & 60000 \\
\hline & 60000 \\
\hline & 57000 \\
\hline & 54000 \\
\hline \multirow{12}{*}{ Part 10} & 30000 \\
\hline & 23848 \\
\hline & 12348 \\
\hline & 37500 \\
\hline & 28500 \\
\hline & 16500 \\
\hline & 13500 \\
\hline & 4500 \\
\hline & 0 \\
\hline & 17000 \\
\hline & 5500 \\
\hline & 0 \\
\hline
\end{tabular}


Table 13: Profit values by period for Manufacturer

\begin{tabular}{|c|c|}
\hline Period & Net Profit \\
\hline 1 & -930000 \\
\hline 2 & 5153613.2 \\
\hline 3 & 5008711.6 \\
\hline 4 & 4602858 \\
\hline 5 & 4515791.8 \\
\hline 6 & 4606154.8 \\
\hline 7 & 4484877.6 \\
\hline 8 & 4387216.8 \\
\hline 9 & 4494742.8 \\
\hline 10 & 4592459.8 \\
\hline 11 & 4339680.8 \\
\hline 12 & 4495414.6 \\
\hline
\end{tabular}




\section{F4 (Distributor)}

Table 14: Product transported and inventory for Distributor

\begin{tabular}{|c|c|c|}
\hline Product & Transported & Inventory Products \\
\hline \multirow{12}{*}{ Product 1} & 0 & 10000 \\
\hline & 15795 & 8199 \\
\hline & 0 & 12939 \\
\hline & 8273 & 4666 \\
\hline & 0 & 4666 \\
\hline & 0 & 13871 \\
\hline & 15870 & 0 \\
\hline & 0 & 1817 \\
\hline & 12961 & 0 \\
\hline & 0 & 1296 \\
\hline & 0 & 6816 \\
\hline & 10580 & 7020 \\
\hline \multirow{12}{*}{ Product 2} & 0 & 10000 \\
\hline & 0 & 13537 \\
\hline & 8710 & 16931 \\
\hline & 7596 & 9334 \\
\hline & 15870 & 0 \\
\hline & 0 & 0 \\
\hline & 0 & 9728 \\
\hline & 0 & 18539 \\
\hline & 2908 & 15630 \\
\hline & 7814 & 17370 \\
\hline & 0 & 22720 \\
\hline & 5290 & 22310 \\
\hline \multirow{11}{*}{ Product 3} & 0 & 10000 \\
\hline & 0 & 10000 \\
\hline & 7160 & 2840 \\
\hline & 0 & 18710 \\
\hline & 0 & 28044 \\
\hline & 15870 & 18840 \\
\hline & 0 & 22982 \\
\hline & 15870 & 12354 \\
\hline & 0 & 17080 \\
\hline & 8055 & 14044 \\
\hline & 15870 & 3174 \\
\hline
\end{tabular}




\begin{tabular}{l|l|l} 
& 0 & 3381
\end{tabular}

Table 15: Profit values by period for Distributor

\begin{tabular}{|c|c|}
\hline Period & Net Profit \\
\hline 1 & -240000 \\
\hline 2 & 1404587 \\
\hline 3 & 1404670 \\
\hline 4 & 1404565 \\
\hline 5 & 1404670 \\
\hline 6 & 1404662 \\
\hline 7 & 1404670 \\
\hline 8 & 1404670 \\
\hline 9 & 1404565 \\
\hline 10 & 1404565 \\
\hline 11 & 1404670 \\
\hline 12 & 1404662 \\
\hline
\end{tabular}




\section{F5 (Retailer)}

Table 16: Product transported and inventory for Retailer

\begin{tabular}{|c|c|c|}
\hline Product & Transported & Inventory Products \\
\hline \multirow{12}{*}{ Product 1} & 0 & 10000 \\
\hline & 6290 & 19505 \\
\hline & 6290 & 13215 \\
\hline & 6290 & 15198 \\
\hline & 6290 & 8908 \\
\hline & 6290 & 2618 \\
\hline & 6290 & 12198 \\
\hline & 6290 & 5908 \\
\hline & 6290 & 12580 \\
\hline & 6290 & 6290 \\
\hline & 6290 & 0 \\
\hline & 6290 & 4290 \\
\hline \multirow{12}{*}{ Product 2} & 0 & 10000 \\
\hline & 5290 & 4710 \\
\hline & 5290 & 8130 \\
\hline & 5290 & 10436 \\
\hline & 5290 & 21016 \\
\hline & 5290 & 15726 \\
\hline & 5290 & 10436 \\
\hline & 5290 & 5146 \\
\hline & 5290 & 2765 \\
\hline & 5290 & 5290 \\
\hline & 5290 & 0 \\
\hline & 5290 & 0 \\
\hline \multirow{10}{*}{ Product 3} & 0 & 10000 \\
\hline & 4290 & 5710 \\
\hline & 4290 & 8580 \\
\hline & 4290 & 4290 \\
\hline & 4290 & 0 \\
\hline & 4290 & 11580 \\
\hline & 4290 & 7290 \\
\hline & 4290 & 18870 \\
\hline & 4290 & 14580 \\
\hline & 4290 & 18345 \\
\hline
\end{tabular}




\begin{tabular}{|l|l|l|}
\hline \multirow{2}{*}{4290} & 29925 \\
\cline { 2 - 3 } & 4290 & 25635 \\
\hline
\end{tabular}

Table 17: Profit values by period for Retailer

\begin{tabular}{|c|c|}
\hline Period & Net Profit \\
\hline 1 & -240000 \\
\hline 2 & 2696550 \\
\hline 3 & 2696550 \\
\hline 4 & 2696558 \\
\hline 5 & 2696558 \\
\hline 6 & 2696558 \\
\hline 7 & 2696558 \\
\hline 8 & 2696558 \\
\hline 9 & 2696550 \\
\hline 10 & 2696550 \\
\hline 11 & 2696550 \\
\hline 12 & 2696550 \\
\hline
\end{tabular}




\section{R1 (Collection)}

Table 18: Product transported and inventory for Collection Facility

\begin{tabular}{|c|c|c|c|}
\hline \begin{tabular}{|l|} 
Product \\
\end{tabular} & Transported $(1,2)$ & Transported $(1,3)$ & Inventory Products \\
\hline \multirow{12}{*}{ Product 1} & 0 & 0 & 1000 \\
\hline & 0 & 446 & 2176 \\
\hline & 740 & 0 & 3057 \\
\hline & 2433 & 0 & 2247 \\
\hline & 793 & 0 & 3075 \\
\hline & 2541 & 0 & 2157 \\
\hline & 3365 & 0 & 414 \\
\hline & 0 & 0 & 2037 \\
\hline & 2298 & 0 & 1361 \\
\hline & 2984 & 0 & 0 \\
\hline & 0 & 0 & 1622 \\
\hline & 160 & 0 & 3084 \\
\hline \multirow{12}{*}{ Product 2} & 0 & 0 & 1000 \\
\hline & 0 & 1923 & 0 \\
\hline & 922 & 0 & 0 \\
\hline & 923 & 0 & 0 \\
\hline & 922 & 0 & 0 \\
\hline & 0 & 0 & 923 \\
\hline & 0 & 0 & 1845 \\
\hline & 2621 & 0 & 146 \\
\hline & 1068 & 0 & 0 \\
\hline & 383 & 0 & 539 \\
\hline & 0 & 0 & 1461 \\
\hline & 2263 & 120 & 0 \\
\hline \multirow{11}{*}{ Product 3} & 0 & 0 & 1000 \\
\hline & 960 & 0 & 862 \\
\hline & 1684 & 0 & 0 \\
\hline & 0 & 0 & 823 \\
\hline & 1645 & 0 & 0 \\
\hline & 823 & 0 & 0 \\
\hline & 0 & 0 & 822 \\
\hline & 745 & 0 & 899 \\
\hline & 0 & 0 & 1721 \\
\hline & 0 & 0 & 2544 \\
\hline & 3366 & 0 & 0 \\
\hline
\end{tabular}




\begin{tabular}{|l|l|l|}
323 & 500 & 0 \\
\hline
\end{tabular}

Table 19: Profit values by period for Collection Facility

\begin{tabular}{|c|c|}
\hline Period & Profit \\
\hline 1 & -24000 \\
\hline 2 & 8986 \\
\hline 3 & 9004 \\
\hline 4 & 9000 \\
\hline 5 & 9000 \\
\hline 6 & 9000 \\
\hline 7 & 9002 \\
\hline 8 & 9004 \\
\hline 9 & 9004 \\
\hline 10 & 9006 \\
\hline 11 & 8996 \\
\hline 12 & 8988 \\
\hline
\end{tabular}




\section{R2 (Refurbishing)}

Table 20: Product transported and inventory for Refurbishing Facility

\begin{tabular}{|c|c|c|}
\hline Product & Transported & Inventory \\
\hline \multirow{12}{*}{1} & 0 & 1000 \\
\hline & 494 & 500 \\
\hline & 740 & 740 \\
\hline & 0 & 2673 \\
\hline & 0 & 2967 \\
\hline & 210 & 5008 \\
\hline & 0 & 7873 \\
\hline & 0 & 7373 \\
\hline & 1657 & 9171 \\
\hline & 0 & 11656 \\
\hline & 1000 & 11156 \\
\hline & 2395 & 10816 \\
\hline \multirow{12}{*}{2} & 0 & 1000 \\
\hline & 0 & 500 \\
\hline & 0 & 922 \\
\hline & 0 & 1345 \\
\hline & 0 & 1767 \\
\hline & 0 & 1267 \\
\hline & 1233 & 767 \\
\hline & 1982 & 2888 \\
\hline & 0 & 3457 \\
\hline & 1554 & 3340 \\
\hline & 1229 & 2840 \\
\hline & 500 & 4604 \\
\hline \multirow{11}{*}{3} & 0 & 1000 \\
\hline & 0 & 1460 \\
\hline & 0 & 2645 \\
\hline & 988 & 2145 \\
\hline & 1236 & 3290 \\
\hline & 1274 & 3613 \\
\hline & 500 & 3113 \\
\hline & 0 & 3358 \\
\hline & 573 & 2858 \\
\hline & 926 & 2358 \\
\hline & 500 & 5225 \\
\hline
\end{tabular}




\begin{tabular}{|l|l|l|} 
& 0 & 5048 \\
\hline
\end{tabular}

Table 21: Profit values by period for Refurbishing Facility

\begin{tabular}{|c|c|}
\hline Period & Profit \\
\hline 1 & -24000 \\
\hline 2 & 9960 \\
\hline 3 & 9944 \\
\hline 4 & 9976 \\
\hline 5 & 9968 \\
\hline 6 & 9936 \\
\hline 7 & 9956 \\
\hline 8 & 9968 \\
\hline 9 & 9912 \\
\hline 10 & 9968 \\
\hline 11 & 9972 \\
\hline 12 & 9956 \\
\hline
\end{tabular}




\section{R3 (Disassembly)}

Table 22: Product inventory for Disassembly Facility

\begin{tabular}{|c|c|}
\hline Product & Inventory \\
\hline \multirow{12}{*}{1} & 1000 \\
\hline & 9946 \\
\hline & 0 \\
\hline & 0 \\
\hline & 4000 \\
\hline & 8000 \\
\hline & 3006 \\
\hline & 5007 \\
\hline & 7189 \\
\hline & 1703 \\
\hline & 4407 \\
\hline & 3887 \\
\hline \multirow{12}{*}{2} & 1000 \\
\hline & 11423 \\
\hline & 9962 \\
\hline & 1858 \\
\hline & 5858 \\
\hline & 3323 \\
\hline & 7323 \\
\hline & 2828 \\
\hline & 0 \\
\hline & 4000 \\
\hline & 0 \\
\hline & 0 \\
\hline \multirow{11}{*}{3} & 1000 \\
\hline & 9500 \\
\hline & 13500 \\
\hline & 17500 \\
\hline & 6618 \\
\hline & 2520 \\
\hline & 1129 \\
\hline & 1487 \\
\hline & 245 \\
\hline & 93 \\
\hline & 0 \\
\hline
\end{tabular}




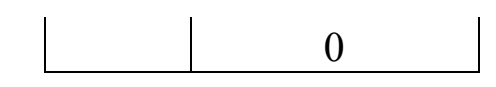

Table 23: Subassembly transported and inventory for Disassembly Facility

\begin{tabular}{|c|c|c|c|}
\hline Subassembly & Transported $(3,4)$ & Transported $(3,6)$ & Inventory \\
\hline \multirow{12}{*}{1} & 0 & 0 & 1000 \\
\hline & 1500 & 0 & 0 \\
\hline & 500 & 0 & 0 \\
\hline & 500 & 0 & 0 \\
\hline & 500 & 0 & 0 \\
\hline & 500 & 0 & 0 \\
\hline & 500 & 0 & 0 \\
\hline & 500 & 0 & 0 \\
\hline & 500 & 0 & 0 \\
\hline & 500 & 0 & 0 \\
\hline & 500 & 0 & 0 \\
\hline & 500 & 0 & 0 \\
\hline \multirow{12}{*}{2} & 0 & 0 & 1000 \\
\hline & 1500 & 0 & 0 \\
\hline & 500 & 0 & 0 \\
\hline & 0 & 500 & 0 \\
\hline & 500 & 0 & 0 \\
\hline & 500 & 0 & 0 \\
\hline & 500 & 0 & 0 \\
\hline & 265 & 0 & 234 \\
\hline & 734 & 0 & 0 \\
\hline & 0 & 0 & 500 \\
\hline & 172 & 0 & 827 \\
\hline & 1327 & 0 & 0 \\
\hline \multirow{10}{*}{3} & 0 & 0 & 1000 \\
\hline & 1500 & 0 & 0 \\
\hline & 500 & 0 & 0 \\
\hline & 500 & 0 & 0 \\
\hline & 500 & 0 & 0 \\
\hline & 500 & 0 & 0 \\
\hline & 0 & 0 & 500 \\
\hline & 443 & 556 & 0 \\
\hline & 0 & 0 & 500 \\
\hline & 0 & 0 & 1000 \\
\hline
\end{tabular}




\begin{tabular}{|c|c|c|c|}
\hline & 1500 & 0 & 0 \\
\hline & 0 & 0 & 500 \\
\hline \multirow{12}{*}{4} & 1256 & 0 & 1000 \\
\hline & 743 & 0 & 243 \\
\hline & 500 & 0 & 0 \\
\hline & 500 & 0 & 0 \\
\hline & 500 & 0 & 0 \\
\hline & 500 & 0 & 0 \\
\hline & 0 & 0 & 0 \\
\hline & 443 & 0 & 500 \\
\hline & 0 & 0 & 1000 \\
\hline & 0 & 0 & 0 \\
\hline & 1500 & 0 & 500 \\
\hline & 0 & 0 & 1000 \\
\hline \multirow{12}{*}{5} & 0 & 0 & 1000 \\
\hline & 0 & 0 & 1500 \\
\hline & 733 & 0 & 1266 \\
\hline & 985 & 0 & 781 \\
\hline & 608 & 0 & 672 \\
\hline & 788 & 0 & 384 \\
\hline & 884 & 0 & 0 \\
\hline & 0 & 500 & 0 \\
\hline & 0 & 500 & 0 \\
\hline & 239 & 0 & 260 \\
\hline & 0 & 0 & 760 \\
\hline & 1260 & 0 & 0 \\
\hline
\end{tabular}

Table 24: Product transported and inventory for Disassembly Facility

\begin{tabular}{|c|c|c|c|}
\hline Part & Transported (3,4) & Transported (3,6) & Inventory \\
\hline \multirow{4}{*}{} & 0 & 0 & 1000 \\
\cline { 2 - 4 } & 2500 & 0 & 0 \\
\cline { 2 - 4 } & 1500 & 0 & 0 \\
\cline { 2 - 4 } & 1500 & 0 & 0 \\
\cline { 2 - 4 } & 1500 & 0 & 0 \\
\cline { 2 - 4 } & 1436 & 0 & 63 \\
\cline { 2 - 4 } & 0 & 0 & 1563 \\
\cline { 2 - 4 } & 0 & 443 & 2619 \\
\hline
\end{tabular}




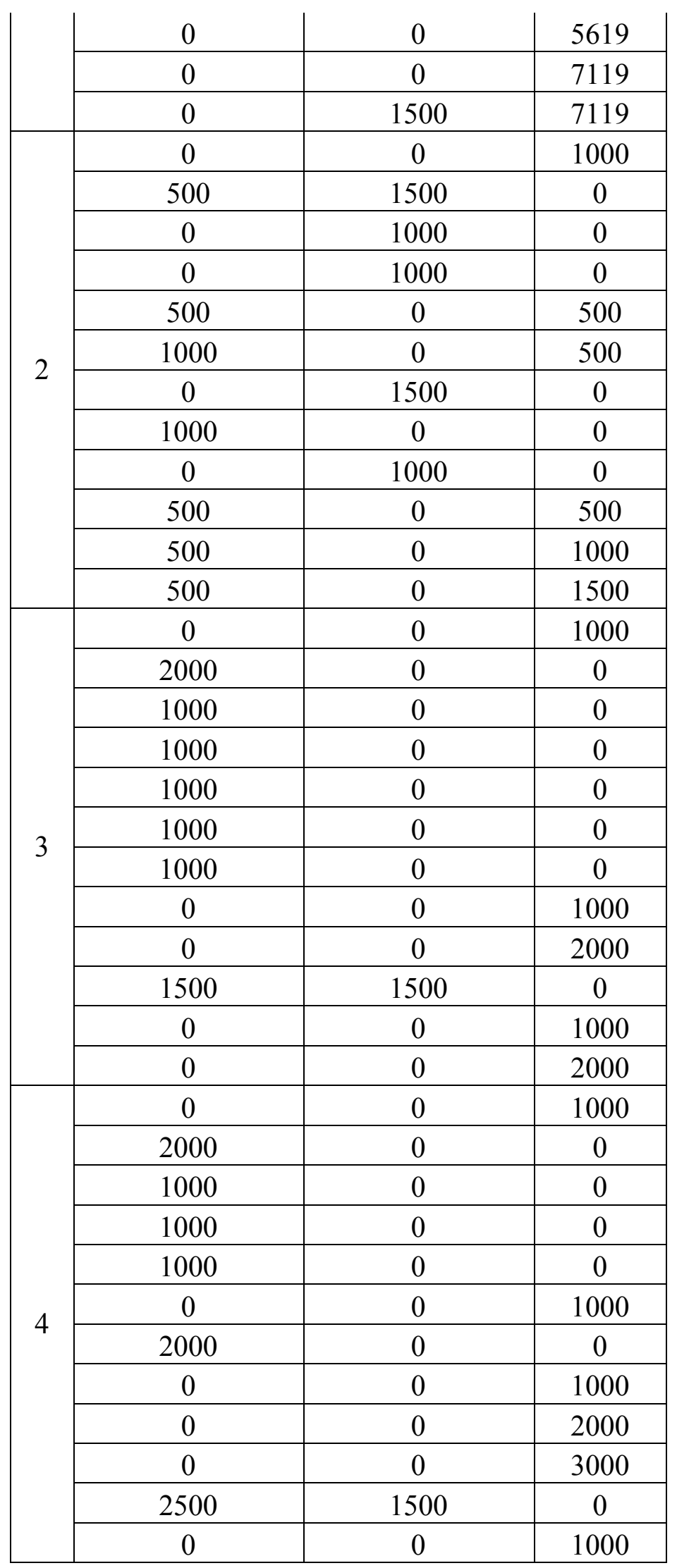




\begin{tabular}{|c|c|c|c|}
\hline \multirow{12}{*}{5} & 0 & 0 & 1000 \\
\hline & 2500 & 0 & 0 \\
\hline & 1000 & 500 & 0 \\
\hline & 1500 & 0 & 0 \\
\hline & 0 & 1500 & 0 \\
\hline & 0 & 1500 & 0 \\
\hline & 0 & 0 & 1500 \\
\hline & 3000 & 0 & 0 \\
\hline & 1500 & 0 & 0 \\
\hline & 0 & 0 & 1500 \\
\hline & 0 & 0 & 3000 \\
\hline & 0 & 0 & 4500 \\
\hline \multirow{12}{*}{6} & 0 & 0 & 1000 \\
\hline & 1500 & 0 & 0 \\
\hline & 500 & 0 & 0 \\
\hline & 500 & 0 & 0 \\
\hline & 500 & 0 & 0 \\
\hline & 500 & 0 & 0 \\
\hline & 500 & 0 & 0 \\
\hline & 500 & 0 & 0 \\
\hline & 0 & 0 & 500 \\
\hline & 0 & 0 & 1000 \\
\hline & 0 & 0 & 1500 \\
\hline & 0 & 0 & 2000 \\
\hline \multirow{12}{*}{7} & 0 & 0 & 1000 \\
\hline & 2500 & 0 & 0 \\
\hline & 1500 & 0 & 0 \\
\hline & 1500 & 0 & 0 \\
\hline & 1500 & 0 & 0 \\
\hline & 500 & 0 & 1000 \\
\hline & 0 & 0 & 2500 \\
\hline & 4000 & 0 & 0 \\
\hline & 1500 & 0 & 0 \\
\hline & 1500 & 0 & 0 \\
\hline & 1500 & 0 & 0 \\
\hline & 764 & 0 & 735 \\
\hline \multirow{3}{*}{8} & 0 & 0 & 1000 \\
\hline & 2000 & 0 & 0 \\
\hline & 1000 & 0 & 0 \\
\hline
\end{tabular}




\begin{tabular}{|c|c|c|c|}
\hline & 1000 & 0 & 0 \\
\hline & 1000 & 0 & 0 \\
\hline & 1000 & 0 & 0 \\
\hline & 1000 & 0 & 0 \\
\hline & 1000 & 0 & 0 \\
\hline & 1000 & 0 & 0 \\
\hline & 1000 & 0 & 0 \\
\hline & 1000 & 0 & 0 \\
\hline & 1000 & 0 & 0 \\
\hline \multirow{12}{*}{9} & 0 & 0 & 1000 \\
\hline & 1500 & 0 & 0 \\
\hline & 0 & 0 & 500 \\
\hline & 1000 & 0 & 0 \\
\hline & 500 & 0 & 0 \\
\hline & 500 & 0 & 0 \\
\hline & 500 & 0 & 0 \\
\hline & 0 & 0 & 500 \\
\hline & 0 & 0 & 1000 \\
\hline & 0 & 0 & 1500 \\
\hline & 0 & 0 & 2000 \\
\hline & 2500 & 0 & 0 \\
\hline \multirow{12}{*}{10} & 0 & 0 & 1000 \\
\hline & 0 & 0 & 2500 \\
\hline & 4000 & 0 & 0 \\
\hline & 1500 & 0 & 0 \\
\hline & 1500 & 0 & 0 \\
\hline & 1500 & 0 & 0 \\
\hline & 1500 & 0 & 0 \\
\hline & 0 & 0 & 1500 \\
\hline & 3000 & 0 & 0 \\
\hline & 1500 & 0 & 0 \\
\hline & 1500 & 0 & 0 \\
\hline & 0 & 0 & 1500 \\
\hline
\end{tabular}


Table 25: Profit values by period for Disassembly Facility

\begin{tabular}{|c|c|}
\hline Period & Profit \\
\hline 1 & -60088 \\
\hline 2 & -4849 \\
\hline 3 & 2431 \\
\hline 4 & 8985 \\
\hline 5 & 9008 \\
\hline 6 & 9000 \\
\hline 7 & -4512 \\
\hline 8 & 20959 \\
\hline 9 & 8998 \\
\hline 10 & -31495 \\
\hline 11 & 49514 \\
\hline 12 & 8957 \\
\hline
\end{tabular}




\section{R4 (Testing)}

Table 26: Subassembly transported and inventory for Testing Facility

\begin{tabular}{|c|c|c|c|c|}
\hline Subassembly & Transported $(4,5)$ & Transported $(4,3)$ & Transported $(4,6)$ & Inventory \\
\hline \multirow{12}{*}{1} & 0 & 0 & 0 & 1000 \\
\hline & 0 & 0 & 0 & 2000 \\
\hline & 0 & 0 & 0 & 2000 \\
\hline & 2500 & 0 & 0 & 2000 \\
\hline & 0 & 0 & 0 & 2000 \\
\hline & 500 & 0 & 0 & 2000 \\
\hline & 0 & 0 & 0 & 2000 \\
\hline & 0 & 0 & 0 & 2000 \\
\hline & 0 & 2000 & 0 & 2000 \\
\hline & 500 & 0 & 0 & 2000 \\
\hline & 500 & 0 & 0 & 2000 \\
\hline & 500 & 0 & 0 & 2000 \\
\hline \multirow{12}{*}{2} & 0 & 0 & 0 & 1000 \\
\hline & 0 & 0 & 0 & 2000 \\
\hline & 0 & 0 & 0 & 2000 \\
\hline & 1000 & 325 & 0 & 1500 \\
\hline & 0 & 116 & 0 & 1500 \\
\hline & 2058 & 0 & 0 & 1500 \\
\hline & 499 & 0 & 0 & 1500 \\
\hline & 0 & 0 & 0 & 1265 \\
\hline & 942 & 0 & 0 & 1500 \\
\hline & 0 & 558 & 0 & 1000 \\
\hline & 0 & 500 & 0 & 672 \\
\hline & 0 & 500 & 0 & 1500 \\
\hline \multirow{11}{*}{3} & 0 & 0 & 0 & 1000 \\
\hline & 0 & 0 & 0 & 2000 \\
\hline & 0 & 0 & 0 & 2000 \\
\hline & 1442 & 0 & 0 & 2000 \\
\hline & 0 & 0 & 0 & 2000 \\
\hline & 2057 & 0 & 0 & 2000 \\
\hline & 500 & 0 & 0 & 1500 \\
\hline & 0 & 0 & 0 & 1443 \\
\hline & 0 & 1000 & 0 & 943 \\
\hline & 0 & 0 & 0 & 443 \\
\hline & 0 & 1000 & 0 & 1443 \\
\hline
\end{tabular}




\begin{tabular}{|c|c|c|c|c|}
\hline & 500 & 0 & 0 & 943 \\
\hline \multirow{12}{*}{4} & 0 & 0 & 0 & 1000 \\
\hline & 0 & 0 & 0 & 1756 \\
\hline & 0 & 0 & 0 & 2000 \\
\hline & 2500 & 0 & 0 & 2000 \\
\hline & 0 & 0 & 0 & 2000 \\
\hline & 997 & 0 & 0 & 2000 \\
\hline & 0 & 0 & 0 & 2000 \\
\hline & 0 & 0 & 0 & 1500 \\
\hline & 1502 & 0 & 0 & 1000 \\
\hline & 0 & 0 & 0 & 2000 \\
\hline & 0 & 1000 & 0 & 1500 \\
\hline & 0 & 500 & 0 & 1000 \\
\hline \multirow{12}{*}{5} & 0 & 0 & 0 & 1000 \\
\hline & 0 & 0 & 0 & 500 \\
\hline & 1825 & 0 & 0 & 733 \\
\hline & 0 & 0 & 0 & 1218 \\
\hline & 0 & 0 & 0 & 1327 \\
\hline & 674 & 0 & 0 & 1615 \\
\hline & 0 & 0 & 0 & 2000 \\
\hline & 0 & 0 & 0 & 1500 \\
\hline & 2500 & 0 & 0 & 1000 \\
\hline & 0 & 500 & 0 & 739 \\
\hline & 0 & 500 & 0 & 239 \\
\hline & 0 & 500 & 0 & 1000 \\
\hline
\end{tabular}

Table 27: Part transported and inventory for Testing Facility

\begin{tabular}{|c|c|c|c|c|}
\hline Part & Transported (4,5) & Transported (4,3) & Transported (4,6) & Inventory \\
\hline \multirow{7}{*}{} & 0 & 0 & 0 & 1000 \\
\cline { 2 - 5 } & 500 & 36500 & 0 & 3000 \\
\cline { 2 - 5 } & 500 & 0 & 0 & 4000 \\
\cline { 2 - 5 } & 0 & 0 & 0 & 5000 \\
\cline { 2 - 5 } & 0 & 0 & 0 & 6000 \\
\cline { 2 - 5 } & 1000 & 0 & 0 & 6936 \\
\cline { 2 - 5 } & 0 & 0 & 0 & 6436 \\
\cline { 2 - 5 } & 1000 & 0 & 0 & 5936 \\
\hline
\end{tabular}




\begin{tabular}{|c|c|c|c|c|}
\hline & 500 & 0 & 0 & 4436 \\
\hline & 500 & 0 & 0 & 3936 \\
\hline \multirow{12}{*}{2} & 0 & 0 & 0 & 1000 \\
\hline & 500 & 0 & 0 & 1000 \\
\hline & 0 & 0 & 0 & 500 \\
\hline & 500 & 500 & 0 & 0 \\
\hline & 0 & 500 & 0 & 0 \\
\hline & 500 & 0 & 0 & 500 \\
\hline & 500 & 0 & 0 & 0 \\
\hline & 500 & 0 & 0 & 500 \\
\hline & 500 & 0 & 0 & 0 \\
\hline & 500 & 0 & 0 & 0 \\
\hline & 500 & 0 & 0 & 0 \\
\hline & 500 & 0 & 0 & 0 \\
\hline \multirow{12}{*}{3} & 0 & 0 & 0 & 1000 \\
\hline & 0 & 0 & 0 & 2500 \\
\hline & 2000 & 0 & 0 & 3000 \\
\hline & 0 & 0 & 0 & 3500 \\
\hline & 0 & 1000 & 0 & 4000 \\
\hline & 0 & 2228 & 0 & 4500 \\
\hline & 0 & 0 & 0 & 5000 \\
\hline & 2500 & 31771 & 0 & 4500 \\
\hline & 0 & 0 & 0 & 4000 \\
\hline & 0 & 1000 & 0 & 5000 \\
\hline & 0 & 500 & 0 & 4500 \\
\hline & 0 & 500 & 0 & 4000 \\
\hline \multirow{12}{*}{4} & 0 & 0 & 0 & 1000 \\
\hline & 0 & 0 & 0 & 2500 \\
\hline & 4074 & 0 & 0 & 3000 \\
\hline & 500 & 0 & 0 & 3500 \\
\hline & 0 & 0 & 0 & 4000 \\
\hline & 0 & 0 & 0 & 3500 \\
\hline & 0 & 0 & 0 & 5000 \\
\hline & 0 & 0 & 0 & 4500 \\
\hline & 0 & 0 & 0 & 4000 \\
\hline & 0 & 3000 & 0 & 3500 \\
\hline & 0 & 500 & 0 & 5500 \\
\hline & 0 & 500 & 0 & 5000 \\
\hline 5 & 0 & 0 & 0 & 1000 \\
\hline
\end{tabular}




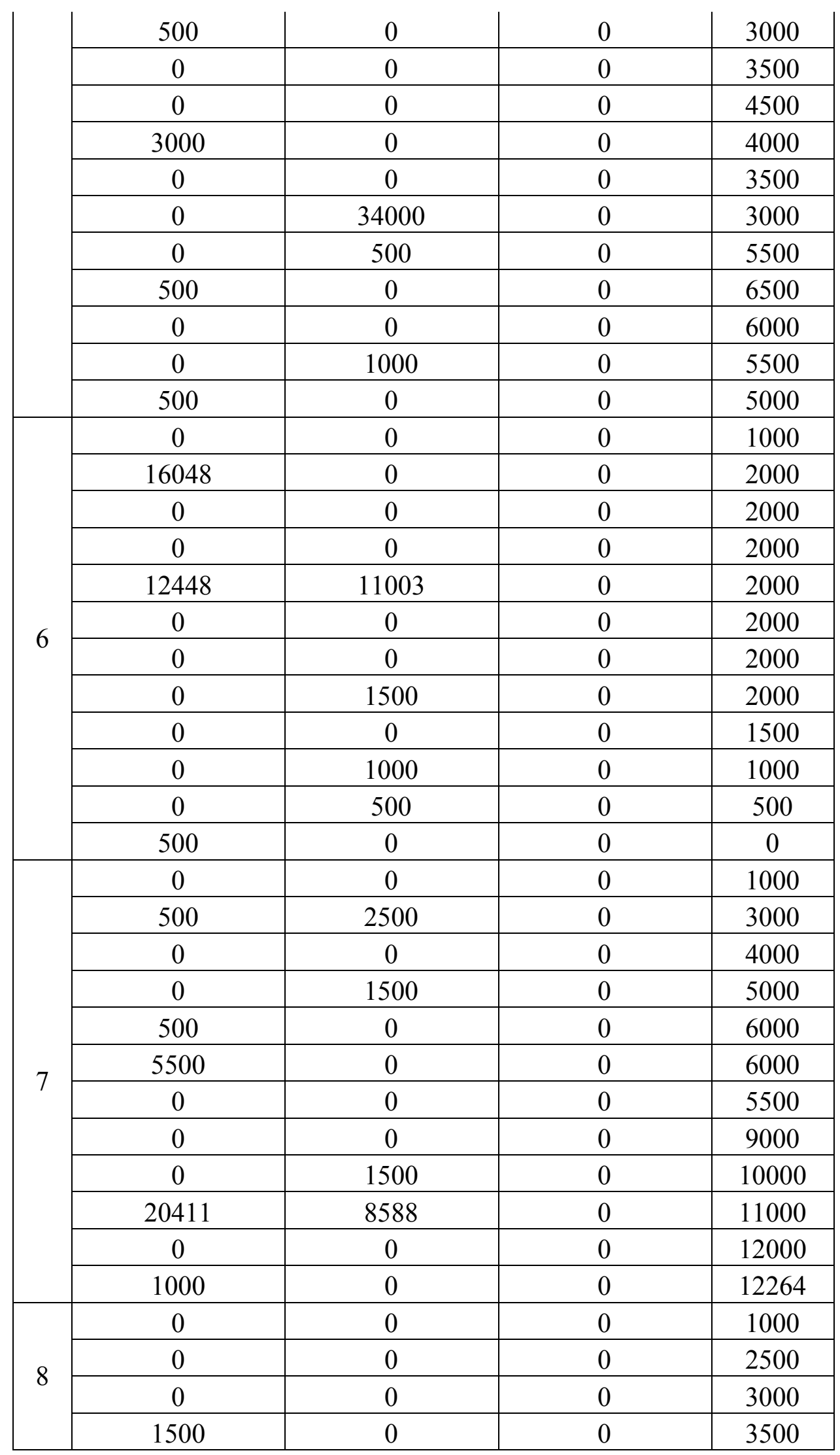




\begin{tabular}{|c|c|c|c|c|}
\hline & 0 & 0 & 0 & 4000 \\
\hline & 0 & 0 & 0 & 4500 \\
\hline & 17234 & 17765 & 0 & 5000 \\
\hline & 500 & 0 & 0 & 5500 \\
\hline & 0 & 0 & 0 & 6000 \\
\hline & 0 & 1000 & 0 & 6500 \\
\hline & 0 & 0 & 0 & 7000 \\
\hline & 1000 & 0 & 0 & 7500 \\
\hline \multirow{12}{*}{9} & 0 & 0 & 0 & 1000 \\
\hline & 0 & 0 & 0 & 2000 \\
\hline & 1500 & 0 & 0 & 1500 \\
\hline & 0 & 0 & 0 & 2000 \\
\hline & 3404 & 0 & 0 & 2000 \\
\hline & 0 & 0 & 0 & 2000 \\
\hline & 0 & 0 & 0 & 2000 \\
\hline & 15016 & 0 & 0 & 1500 \\
\hline & 0 & 0 & 0 & 1000 \\
\hline & 0 & 0 & 0 & 500 \\
\hline & 12551 & 0 & 0 & 0 \\
\hline & 10527 & 0 & 0 & 2000 \\
\hline \multirow{12}{*}{10} & 0 & 0 & 0 & 1000 \\
\hline & 0 & 4000 & 0 & 500 \\
\hline & 2500 & 500 & 0 & 4000 \\
\hline & 0 & 0 & 0 & 5000 \\
\hline & 0 & 3000 & 0 & 6000 \\
\hline & 0 & 0 & 0 & 7000 \\
\hline & 0 & 0 & 0 & 8000 \\
\hline & 0 & 3000 & 0 & 7500 \\
\hline & 3000 & 1500 & 0 & 10000 \\
\hline & 0 & 26000 & 0 & 11000 \\
\hline & 0 & 500 & 0 & 12000 \\
\hline & 0 & 500 & 0 & 11500 \\
\hline
\end{tabular}


Table 28: Profit values by period for Testing Facility

\begin{tabular}{|c|c|}
\hline Period & Profit \\
\hline 1 & -70000 \\
\hline 2 & 8992 \\
\hline 3 & 8995 \\
\hline 4 & 8992 \\
\hline 5 & 8991 \\
\hline 6 & 8923 \\
\hline 7 & 8981 \\
\hline 8 & 9009 \\
\hline 9 & 8998 \\
\hline 10 & 8999 \\
\hline 11 & 8999 \\
\hline 12 & 9001 \\
\hline
\end{tabular}




\section{R5 (Remanufacturing)}

Table 29: Material inventory for Remanufacturing Facility

\begin{tabular}{|c|c|}
\hline Material & Transported \\
\hline \multirow{12}{*}{1} & 0 \\
\hline & 6952 \\
\hline & 8026 \\
\hline & 1093 \\
\hline & 11676 \\
\hline & 13484 \\
\hline & 15951 \\
\hline & 18484 \\
\hline & 19112 \\
\hline & 2356 \\
\hline & 21574 \\
\hline & 23286 \\
\hline \multirow{12}{*}{2} & 0 \\
\hline & 0 \\
\hline & 0 \\
\hline & 8088 \\
\hline & 0 \\
\hline & 0 \\
\hline & 0 \\
\hline & 0 \\
\hline & 0 \\
\hline & 19911 \\
\hline & 2000 \\
\hline & 2000 \\
\hline
\end{tabular}

Table 30: Subassembly inventory for Remanufacturing Facility

\begin{tabular}{|c|c|}
\hline Subassembly & Inventory \\
\hline \multirow{5}{*}{1} & 1000 \\
\cline { 2 - 2 } & 500 \\
\cline { 2 - 2 } & 0 \\
\cline { 2 - 2 } & 2000 \\
\cline { 2 - 2 } & 1500 \\
\cline { 2 - 2 } & 1500 \\
\cline { 2 - 2 } & 1000 \\
\hline
\end{tabular}




\begin{tabular}{|c|c|}
\hline & 500 \\
\hline & 0 \\
\hline & 0 \\
\hline & 0 \\
\hline & 0 \\
\hline \multirow{12}{*}{2} & 1000 \\
\hline & 500 \\
\hline & 0 \\
\hline & 500 \\
\hline & 0 \\
\hline & 1558 \\
\hline & 1557 \\
\hline & 1057 \\
\hline & 1500 \\
\hline & 1000 \\
\hline & 500 \\
\hline & 0 \\
\hline \multirow{12}{*}{3} & 1000 \\
\hline & 500 \\
\hline & 0 \\
\hline & 942 \\
\hline & 442 \\
\hline & 2000 \\
\hline & 2000 \\
\hline & 1500 \\
\hline & 1000 \\
\hline & 500 \\
\hline & 0 \\
\hline & 0 \\
\hline \multirow{10}{*}{4} & 1000 \\
\hline & 500 \\
\hline & 0 \\
\hline & 2000 \\
\hline & 1500 \\
\hline & 1997 \\
\hline & 1497 \\
\hline & 997 \\
\hline & 2000 \\
\hline & 1500 \\
\hline
\end{tabular}




\begin{tabular}{|c|c|}
\hline \multirow{5}{*}{} & 1000 \\
\cline { 2 - 2 } & 500 \\
\hline \multirow{5}{*}{5} & 1000 \\
\hline \multirow{5}{*}{} & 500 \\
\hline & 1825 \\
\hline & 1325 \\
\cline { 2 - 2 } & 825 \\
\hline & 1000 \\
\hline & 500 \\
\hline & 0 \\
\hline & 2000 \\
\hline & 1500 \\
\hline & 1000 \\
\hline & 500 \\
\hline
\end{tabular}

Table 31: Part inventory for Remanufacturing Facility

\begin{tabular}{|c|c|}
\hline Part & Inventory \\
\hline \multirow{12}{*}{1} & 1000 \\
\hline & 1000 \\
\hline & 1000 \\
\hline & 500 \\
\hline & 0 \\
\hline & 500 \\
\hline & 0 \\
\hline & 500 \\
\hline & 0 \\
\hline & 0 \\
\hline & 0 \\
\hline & 0 \\
\hline \multirow{9}{*}{2} & 1000 \\
\hline & 1000 \\
\hline & 500 \\
\hline & 500 \\
\hline & 0 \\
\hline & 0 \\
\hline & 0 \\
\hline & 0 \\
\hline & 0 \\
\hline
\end{tabular}




\begin{tabular}{|c|c|}
\hline & 0 \\
\hline & 0 \\
\hline & 0 \\
\hline \multirow{12}{*}{3} & 1000 \\
\hline & 500 \\
\hline & 2000 \\
\hline & 1500 \\
\hline & 1000 \\
\hline & 500 \\
\hline & 0 \\
\hline & 2000 \\
\hline & 1500 \\
\hline & 1000 \\
\hline & 500 \\
\hline & 0 \\
\hline \multirow{12}{*}{4} & 1000 \\
\hline & 500 \\
\hline & 4074 \\
\hline & 4074 \\
\hline & 3574 \\
\hline & 3074 \\
\hline & 2574 \\
\hline & 2074 \\
\hline & 1574 \\
\hline & 1074 \\
\hline & 574 \\
\hline & 74 \\
\hline \multirow{12}{*}{5} & 1000 \\
\hline & 1000 \\
\hline & 500 \\
\hline & 0 \\
\hline & 2500 \\
\hline & 2000 \\
\hline & 1500 \\
\hline & 1000 \\
\hline & 1000 \\
\hline & 500 \\
\hline & 0 \\
\hline & 0 \\
\hline
\end{tabular}




\begin{tabular}{|c|c|}
\hline \multirow{12}{*}{6} & 1000 \\
\hline & 16548 \\
\hline & 16048 \\
\hline & 15548 \\
\hline & 27496 \\
\hline & 26996 \\
\hline & 26496 \\
\hline & 25996 \\
\hline & 25496 \\
\hline & 24996 \\
\hline & 24496 \\
\hline & 24496 \\
\hline \multirow{12}{*}{7} & 1000 \\
\hline & 1000 \\
\hline & 500 \\
\hline & 0 \\
\hline & 0 \\
\hline & 5000 \\
\hline & 4500 \\
\hline & 4000 \\
\hline & 3500 \\
\hline & 23411 \\
\hline & 22911 \\
\hline & 23411 \\
\hline \multirow{12}{*}{8} & 1000 \\
\hline & 500 \\
\hline & 0 \\
\hline & 1000 \\
\hline & 500 \\
\hline & 0 \\
\hline & 16734 \\
\hline & 16734 \\
\hline & 16234 \\
\hline & 15734 \\
\hline & 15234 \\
\hline & 15734 \\
\hline \multirow{3}{*}{9} & 1000 \\
\hline & 500 \\
\hline & 1500 \\
\hline
\end{tabular}




\begin{tabular}{|c|c|}
\hline \multirow{1}{*}{} & 1000 \\
\hline 3904 \\
\hline 3404 \\
\hline 2904 \\
\hline 17420 \\
\hline 16920 \\
\hline 16420 \\
\hline 28472 \\
\hline 38500 \\
\hline 1000 \\
\hline 500 \\
\hline 2500 \\
\hline 2000 \\
\hline 10 & 1500 \\
\hline 1000 \\
\hline 500 \\
\hline 0 \\
\hline 1000 \\
\hline 2500 \\
\hline 2000 \\
\hline 1500 \\
\hline 1000 \\
\hline
\end{tabular}

Table 32: Profit values by period for Remanufacturing Facility

\begin{tabular}{|c|c|}
\hline Period & Profit \\
\hline 1 & -70000 \\
\hline 2 & 10992 \\
\hline 3 & 11004 \\
\hline 4 & 10987 \\
\hline 5 & 10994 \\
\hline 6 & 11002 \\
\hline 7 & 11011 \\
\hline 8 & 11008 \\
\hline 9 & 11008 \\
\hline 10 & 10999 \\
\hline 11 & 11010 \\
\hline 12 & 11002 \\
\hline
\end{tabular}




\section{CURRICULUM VITAE}

NAME:

ADDRESS:
AMAN GUPTA

10733 Copper Ridge Dr. Louisville, KY 40241.

Ph. No. (502) 475-4426

DOB:

December 6, 1978

\section{EDUCATION}

Ph.D. Industrial Engineering (Operations Research)

University of Louisville, Louisville, KY

M.S. Industrial Engineering (Production Systems)

June'2003

State University of New York, Buffalo, NY

B.E. Mechanical Engineering

June'2000

Thapar Institute of Engineering and Technology, India

\section{INDUSTRY EXPERIENCE}

Industrial Engineer, IDS Engineering, Louisville KY

(September 2007 - Present)

Inventory Quality Project Manager, TMSi Logistics, 3PL for GE Appliances, Jeffersonville IN (July 2006 - Present)

Engineer, Swaraj Tractors, India

(July'00- June'01)

Industrial Engineering Intern, Swaraj Combine Division, India (Jan'99-June'99)

\section{ACADEMIC EXPERIENCE}

Research Assistant, Logistics and Distribution Institute (LODI) at University of Louisville, Louisville KY (Aug'05 - June’ 06)

Research Title: Optimization modeling for the operation of closed-loop supply chains.

Teaching and Research Assistant, Department of Industrial Engineering at University of Louisville, Louisville KY (Aug'04 - July'05)

Teaching and Research Assistant, Department of Industrial Engineering at North Carolina A\&T State University, Greensboro NC (Aug'03 - July'04)

Courses taught: Introduction to Industrial Engineering, AUTOCAD for facilities design. 


\section{CONFERENCE PAPERS AND PRESENTATIONS}

Gerald W. Evans, Gail W. DePuy, and Aman Gupta, Simulation and Optimization Methodologies to Determine Distribution System Inventory Policies, Proceedings of Industrial Engineering Research Conference, 2007.

Aman Gupta and Gerald W. Evans, Optimization Modeling for the Design and Operation of Closed-Loop Supply Chains, Proceedings of Industrial Engineering Research Conference, 2006.

Aman Gupta, Gerald W. Evans, and Suraj M. Alexander, Optimization Modeling for the Design and Operation of Closed-Loop Supply Chains, INFORMS Annual Conference, 2005.

Aman Gupta and Bala Ram, Integrating Human Performance into Discrete-Event Simulation Models for Manufacturing: A Survey, Proceedings of $14^{\text {th }}$ International Conference on Flexible Automation and Intelligent Manufacturing, \# FAIM04-109, 2004.

\section{HONORS}

Awarded the Research Fellowship for Doctoral Research by the Logistics and Distribution Institute (LODI) at University of Louisville.

\section{AFFILIATIONS}

- Institute of Industrial Engineers (IIE)

- Institute of Operations Research and the Management Sciences (INFORMS)

- American Statistical Association (ASA) 